\author{
Laureane $\mathcal{N}$ unes Masi
}

\title{
Efeitos dos ácidos graxos sobre a morte de células endoteliais
}

Dissertação apresentada ao Programa de Pós-Graduação em Fisiologia Humana do Instituto de Ciências Biomédicas da Universidade de São Paulo, para obtenção do Título de Mestre em Ciências.

Área de Concentração: Fisiologia Humana

Orientador: Prof. Dr. Rui Curi

São Paulo 


\section{DADOS DE CATALOGAÇÃO NA PUBLICAÇÃO (CIP) \\ Serviço de Biblioteca e Informação Biomédica do \\ Instituto de Ciências Biomédicas da Universidade de São Paulo \\ reprodução não autorizada pelo autor}

\section{Masi, Laureane Nunes.}

Efeitos dos ácidos graxos sobre a morte de células endoteliais / Laureane Nunes Masi.

- São Paulo, 2010.

Orientador: Rui Curi.

Dissertação (Mestrado) - Universidade de São Paulo. Instituto de Ciências Biomédicas. Programa de Pós-Graduação em Fisiologia Humana USP. Área de Concentração: Fisiologia Geral. Linha de Pesquisa: Fisiologia Celular.

Versão do título para o inglês: Effects of fatty acids on endothelial cell death.

Descritores: 1. Ácidos graxos 2. Morte celular 3. Óxido nítrico 4. Espécies reativas de oxigênio I. Curi, Rui II. Universidade de São Paulo. Instituto de Ciências Biomédicas. Programa de Pós-Graduação em Fisiologia Humana III. Título. 
Candidato(a):

Título da Dissertação:

Orientador(a):
Laureane Nunes Masi.

Efeito dos ácidos graxos sobre a morte de células endoteliais.

A Comissão Julgadora dos trabalhos de Defesa da Dissertação de Mestrado, em sessão pública realizada a ..................................., considerou
( ) Aprovado(a)
( ) Reprovado(a)

Examinador(a): Assinatura:

Nome:

Instituição:

Examinador(a): Assinatura:

Nome:

Instituição:

Presidente: Assinatura:

Nome:

Instituição: 


\section{Aos meus pais, familiares e amigos pela dedicação, incentivo e apoio constante para a minha formação.}




\section{AGRADECIMENTOS}

Ao meu orientador Prof.Dr.Rui Curi que acreditou no meu potencial dando oportunidade de aprender e crescer com suas orientações e discussões de resultados, sempre com paciência e entusiasmo. Obrigada pela paciência e compreensão professor!

À Érica que me orientou desde o início, com paciência e carinho, me auxiliou em todos os experimentos e ainda deu bons conselhos quando eu mais precisava.

À Thaís pela disposição às discussões e orientações, pelo exemplo de dedicação ao trabalho e pelo apoio na minha vida pessoal.

Aos amigos que estão sempre ao meu lado tornando meus dias mais felizes, em especial ao Renato, Marco, Jean, Hosana, Amanda, Tavane, Augusto, Sandro, Katherine, Alcione e Andressa. 
À todos os amigos do laboratório pelo profissionalismo e por terem tornado o ambiente de trabalho agradável e construtivo.

Aos técnicos Roberto e Tati pelo auxílio e atenção.

Ao José Maria pela boa vontade, esclarecimento e ajuda nos prazos e regras da pós-graduação.

Ao CSPQ, CAPES e FAPESP pelo apoio finaceiro. 
"A coragem nem sempre estrondeia. Às vezes, ela é a voz suave no fim do dia que diz: Tentarei novamente amanhã."

$$
\text { Mary Anne Radmacher }
$$




\section{RESUMO}

MASI, L. N. Efeitos dos ácidos graxos sobre a morte de células endoteliais. 2010. 107 f. Dissertação (Mestrado em Fisiologia Humana) - Instituto de Ciências Biomédicas, Universidade de São Paulo, São Paulo, 2010.

Em algumas patologias como diabetes e obesidade, as concentrações plasmáticas de ácidos graxos (AG) estão aumentadas causando resistência periférica à insulina, disfunção endotelial e risco aumentado de desenvolver doenças vasculares. Contudo, os efeitos diretos dos AG sobre o endotélio ainda precisam ser esclarecidos. No presente estudo, foram investigados os efeitos dos AG saturado (esteárico, muito tóxico), monoinsaturado (oléico, pouco tóxico) e a combinação desses com os AG poliinsaturados, $\omega-3$ e $\omega-6$, na morte de células endoteliais (linhagem celular ECV-304). Os parâmetros avaliados foram: viabilidade celular, fragmentação de DNA, conteúdo intracelular de óxido nítrico (NO) e produção de espécies reativas de oxigênio (ERO). Foram estudados os seguintes ácidos graxos: esteárico (SA) a $150 \mu \mathrm{M}$, oléico (OA) a $300 \mu \mathrm{M}$ e a combinação desses com os ácidos linoléico (LA), gamalinolênico $(\gamma \mathrm{A})$, eicosapentaenóico (EPA) e docosaexaenóico (DHA) a 50 e $100 \mu \mathrm{M}$. O SA induziu morte em 17,8 \% das células após tratamento por 24 horas, aumentou em 99,2 \% a produção de ERO após tratamento por 1 hora e não alterou o conteúdo de NO em relação ao veículo (etanol). A associação do SA com os AG $\omega-3$ não alterou a morte celular induzida pelo SA. O DHA a $50 \mu \mathrm{M}$ associado ao SA diminuiu em $58 \%$ o conteúdo de NO. O EPA a 50 e $100 \mu \mathrm{M}$ reduziu em 78,4 \% e $50 \%$, respectivamente, em relação ao SA somente. A combinação do SA com DHA ou EPA a $100 \mu \mathrm{M}$ diminuiu o conteúdo de ERO em aproximadamente $20 \%$ em relação ao SA. Os AG $\omega-6$ (LA e $\gamma$ A) aboliram a morte celular induzida pelo SA. O LA a $100 \mu \mathrm{M}$ aumentou o conteúdo de NO em 32,5\% e esse mesmo AG a 50 e $100 \mu \mathrm{M}$ reduziu em $50 \%$ e $67 \%$, respectivamente, a produção de ERO em relação ao SA. O OA não alterou a viabilidade celular e a produção de ERO, mas diminuiu o conteúdo de NO em $57 \%$ em relação ao veículo. A associação do OA com os AG $\omega-3$ e $\omega-6$ causou morte de aproximadamente $84 \%$ das células após tratamento por 24 horas, reduziu o conteúdo de NO em cerca de 60\% sem alterar a produção de ERO. Assim, os ácidos graxos poliinsaturados $\omega-6$ protegem contra a morte de células endoteliais induzida por ácido graxo saturado. O ácido oléico não é tóxico para as células endoteliais mesmo em altas 
concentrações (300 a $400 \mu \mathrm{M})$. Contudo, quando associado aos AG poliinsaturados $(\omega-3$ e $\omega$ 6) apresentou citotoxicidade.

Palavras-chave: Ácidos graxos. Morte celular. Óxido nítrico. Espécies reativas de oxigênio. 


\section{ABSTRACT}

MASI, L. N. Effects of fatty acids on endothelial cell death. $107 \mathrm{f}$. Master thesis (Human Physiology) - Instituto de Ciências Biomédicas da Universidade de São Paulo, São Paulo, 2010.

In some diseases such as type II diabetes and obesity plasma concentrations of fatty acids (FA) are increased causing insulin resistance, endothelial dysfunction and increased risk of developing vascular diseases. The direct effects of FA on endothelium however remain to be elucidated. In this study, the effects of saturated (stearic acid, high cytotoxicity), and monounsaturated (oleic acid, low cytotoxicity) and the combination of these fatty acids with polyunsaturated $\omega-3$ and $\omega-6$ PUFA, on endothelial cell (cell line ECV-304) death were investigated. The parameters examined were: cell death (cell viability and DNA fragmentation), intracellular content of nitric oxide (NO) and production of reactive oxygen species (ROS). The following fatty acids were studied: stearic (SA) at $150 \mu \mathrm{M}$, oleic (OA) at $300 \mu \mathrm{M}$, combined with linoleic (LA), gamma-linolenic $(\gamma \mathrm{A})$, eicosapentaenoic (EPA) and docosa-hexaenoic (DHA) fatty acids at 50 and $100 \mu \mathrm{M}$. SA led $17.8 \%$ of cells to death after 24 hour treatment, increased by $99.2 \%$ the release of ROS after treatment for 1 hour and did not alter the NO content as compared to vehicle (ethanol). The combination of SA with $\omega$-3 PUFA did not alter the proportion of dead cells induced by SA. DHA at $50 \mu \mathrm{M}$ plus SA decreased NO content by $58 \%$. EPA at 50 e 100 $\mu \mathrm{M}$ reduced by $78.4 \%$ and $50 \%$, respectively, as compared to SA only. The combination of SA with DHA or EPA at $100 \mu \mathrm{M}$ decreased the content of ROS at approximately $20 \%$ as compared to SA. $\omega-6$ PUFA, LA and $\gamma$ A, abolished cell death induced by SA. LA at $100 \mu \mathrm{M}$ increased NO content by $32.5 \%$ and this PUFA at 50 e $100 \mu \mathrm{M}$ decreased the production of ROS by $50 \%$ and $67 \%$, respectively. OA did not alter cell viability and production of ROS but decreased the NO content by $57 \%$ as compared to vehicle. The combination of OA with $\omega-3$ and $\omega-6$ PUFA increased the proportion of dead cells to approximately $84 \%$ after 24 hour treatment, decreased NO content by $60 \%$ and did not alter the production of ROS. Thus, $\omega-6$ PUFA protect against endothelial cell death induced by saturated FA. Oleic acid is not toxic to endothelial cells even at high concentrations. However, when associated with PUFA ( $\omega-3$ e $\omega-6)$ oleic acid causes cytotoxicity.

Key Words: Fatty acids. Cell death. Nitric oxide. Reactive oxygen species. 


\section{LISTA DE ILUSTRAÇÕES}

Quadro 1. Concentração tóxica dos ácidos graxos na viabilidade celular e fragmentação de DNA de células endoteliais ECV-304.

Quadro 2. Combinações dos ácidos graxos usados no tratamento de células endoteliais ECV304.

Figura 1. Viabilidade das células endoteliais ECV-304 incubadas por 6 horas com o ácido esteárico combinado com ácidos graxos $\omega-3$ e $\omega-6$.

Figura 2. Fragmentação de DNA em células endoteliais ECV-304 incubadas por 6 horas com ácido esteárico combinado com ácidos graxos $\omega-3$ e $\omega-6$

Figura 3. Viabilidade das células endoteliais ECV-304 incubadas por 24 horas com ácido esteárico combinado com ácidos graxos $\omega-3$ e $\omega-6$.

Figura 4. Fragmentação de DNA em células endoteliais ECV-304 incubadas por 24 horas com ácido esteárico combinado com os ácidos graxos $\omega-3$ e $\omega-6$.

Figura 5. Intensidade de fluorescência no conteúdo intracelular de óxido nítrico de células endoteliais ECV-304 incubadas por 1 hora com ácido esteárico combinado com os ácidos graxos $\omega-3$ e $\omega-6$.

Figura 6. Intensidade de fluorescência na produção de óxido nítrico intracelular de células endoteliais ECV-304 incubadas por 1 hora com ácido esteárico e o inibidor (L-NAME) da enzima óxido nítrico sintase (NOS). .46

Figura 7. Intensidade de fluorescência referente à produção de espécies reativas de oxigênio por células endoteliais ECV-304 incubadas por 1 hora com ácido esteárico combinado com ácidos graxos $\omega$-3 e $\omega-6$.

Figura 8. Viabilidade de células endoteliais ECV-304 incubadas por 6 horas com ácido oléico combinado com os ácidos graxos $\omega-3$ e $\omega-6$.

Figura 9. Fragmentação de DNA de células endoteliais ECV-304 incubadas por 6 horas com ácido oléico combinado com os ácidos graxos $\omega-3$ e $\omega-6$.

Figura 10. Viabilidade de células endoteliais ECV-304 incubadas por 24 horas com ácido oléico combinado com os ácidos graxos $\omega-3$ e $\omega-6$.

Figura 11. Fragmentação de DNA de células endoteliais ECV-304 incubadas por 24 horas com ácido oléico combinado com ácidos graxos $\omega-3$ e $\omega-6$.

Figura 12. Viabilidade de células endoteliais ECV-304 incubadas por 2 horas com ácido oléico combinado com os ácidos graxos $\omega-6$. 
Figura 13. Fragmentação de DNA de células endoteliais ECV-304 incubadas por 2 horas com ácido oléico combinado com ácidos graxos $\omega-6 \ldots \ldots$

Figura 14. Intensidade de fluorescência na produção de óxido nítrico intracelular de células endoteliais ECV-304 incubadas por 1 hora com ácido oléico combinado com os ácidos graxos $\omega-3$ e $\omega-6$

Figura 15. Intensidade de fluorescência referente à produção de espécies reativas de oxigênio por células endoteliais ECV-304 incubadas por 1 hora com ácido oléico combinado com ácidos graxos $\omega$-3 e $\omega-6$. 


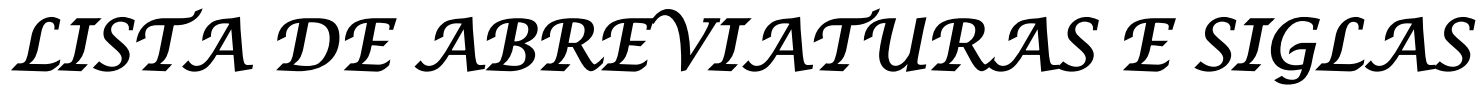

AG: Ácidos Graxos

AGL: Ácido Graxo Livre

AHA: American Heart Association

AP-1: Activator protein 1

ATP: Adenosina Trifosfato

BAEC: célula endotelial de aorta bovina

$\mathrm{BH}_{4}$ : tetrahidrobiopterina

CE: Célula endotelial

CMVL: Célula Muscular Vascular Lisa

$\mathrm{CO}_{2}$ : Dióxido de carbono

DAF-FM/DA: 4-amino-5-metilamino-2',7'-difluorofluoresceina diacetato

DCV: Doença Cardiovascular

DE: Disfunção Endotelial

DHA: Ácido docosa-hexaenóico

DNA: Ácido desoxirribonucléico

ECV-304: Célula endotelial de cordão humbilical humano - 304

EDCF: Fator constritor derivado do endotélio

EDHF: Fator hiperpolarizante derivado do endotélio

EDRF: Fator relaxante derivado do endotélio

eNOS, NOS III: Óxido nítrico sintase endotelial

EPA: Ácido eicosapentaenóico

EPC: Células endoteliais progenitoras

ERO: Espécies reativas de oxigênio

ERN: Espécies reativas de nitrogênio

$\mathrm{ET}_{1}$ : endotelina 1

EtOH: Etanol

$\mathrm{Fe}^{2+}:$ Ferro

$\mathrm{Fe}^{3+}:$ Ferroso

FITC: Fluorescein isothiocyanate

FL: Filtro

GPx: Glutationa Peroxidase 
h: Horas

HAC: célula de aorta humana

HAEC: célula endotelial de aorta humana

$\mathrm{HCl}$ : Ácido clorídrico

$\mathrm{HOCl}^{-}$: Ácido hipocloroso

$\mathrm{H}_{2} \mathrm{O}_{2}$ : Peróxido de hidrogênio

HREC: Célula endotelial de retina humana

HUVEC: Célula endotelial de cordão humbilical humano

ICAM-1: molécula de adesão intercelular 1

iNOS: Óxido nítrico sintase induzível

IP: Iodeto de propídio

JELIS: Japan EPA Lipid Intervention Study

JNK: Quinase amino-terminal Jun

$\mathrm{KCl}$ : Ácido hipocloroso

LA: Ácido linoléico

LDL: Lipoproteína de baixa densidade

LDL-ox: Lipoproteína de baixa densidade oxidada

L-NAME: NG-nitro-L-arginina metil éster

M: Molar

MAPK: Proteína quinase ativada por mitógeno

MCP-1: Proteína monócito quimioatraente-1

min: Minutos

mRNA: Ácido ribonucléico mensageiro

MUFAs: Ácidos graxos monoinsaturados

$\mathrm{N}_{2}$ : Nitrogênio líquido

$\mathrm{NaCl}$ : Cloreto de sódio

NADPH: Nicotinamida Adenina Dinucleotídio Fosfato reduzida

$\mathrm{NF \kappa B}$ : Fator de transcrição nuclear $\kappa \mathrm{B}$

NO: Óxido Nítrico

$\mathrm{NO}_{2}$ : Óxido Nitroso

$\mathrm{O}_{2:}$ Oxigênio

$\mathrm{O}^{-}{ }_{2}$ : Ânion superóxido

OA: Ácido oléico

$\mathrm{OH}$ : Radical hidroxila 
$\mathrm{ONOO}^{-}$: Peroxinitrito

PAEC: Célula endotelial de artéria pulmonar

PBS: Tampão fosfato salina

$\mathrm{PGI}_{2}$ : Prostaciclinas

PUFA: Ácidos graxos poliinsaturados

SA: Ácido esteárico

SFA: Ácido graxo saturado

SFB: Soro Fetal Bovino

SOD: Superóxido dismutase

TBARS: Substâncias reativas ao ácido tiobarbitúrico

TNF: Tumor Necrosis Factor

VCAM-1: molécula de adesão vascular 1 


\section{SUMÁRIO}

\section{INTRODVÇÃO}

1.10 endotélio.

1.2 Óxido nítrico

1.3 Estresse oxidativo

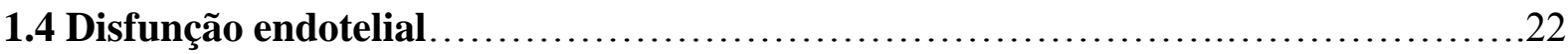



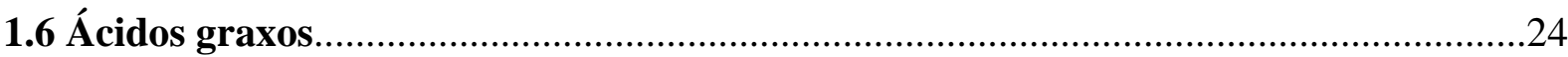

2 OBJETIVOS

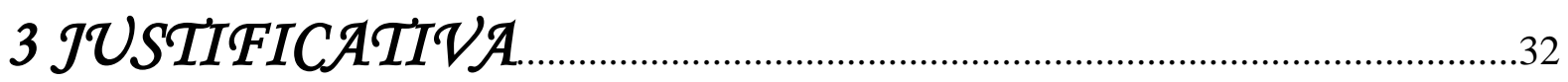

4 MATERIAIS E MÉTODOS.............................................................







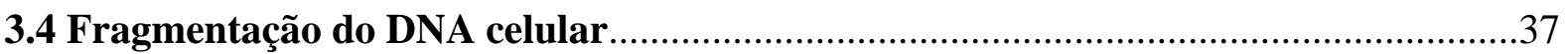

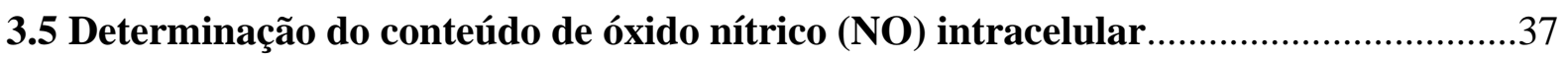

3.6 Determinação da produção de espécies reativas de oxigênio (ERO)...........................38

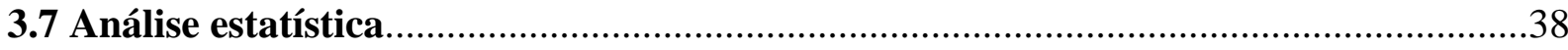


4.1 Combinação do ácido esteárico com os ácidos graxos $\omega$-3 e $\omega$-6 sobre as células endoteliais ECV-304

4.1.1 Morte celular.

4.1.2 Conteúdo intracelular de NO.

4.1.3 Produção de ERO.

4.2 Combinação do ácido oléico com os ácidos graxos $\omega$-3 e $\omega$-6 sobre as células endoteliais ECV-304

4.2.1 Morte celular. 49

4.2.2 Conteúdo intracelular de NO. .54

5.1 Efeito do ácido esteárico combinado com ácidos graxos $\omega-3$ e $\omega-6$ sobre a morte de células endoteliais ECV-304 59

5.2 Efeito do ácido oléico combinado com ácidos graxos $\omega$-3 e $\omega$-6 sobre a morte de células endoteliais ECV-304

7 CONCLUSÕES 


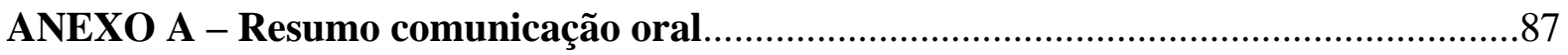

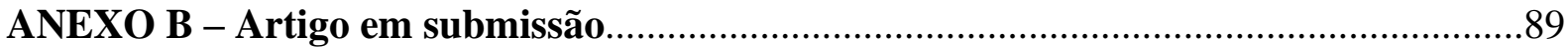




$$
1 \text { INTRODUÇÃO }
$$




\subsection{0 endotélio}

O endotélio é uma monocamada de células de origem embrionária mesodérmica que forma uma face contínua na parte íntima do sistema cardiovascular, incluindo artérias, veias e câmaras do coração (endocárdio), sendo que as paredes dos capilares são formadas unicamente por células endoteliais (LE BROCQ et al., 2008).

O endotélio era considerado um tecido inerte, descrito como um "extrato de nucleotídeos", cuja superfície possui substâncias com propriedades não reativas e não trombóticas para a circulação sanguínea e proteção contra substâncias pró-inflamatórias (GALLEY; WEBSTER, 2004). Nas últimas duas décadas, no entanto, tornou-se evidente que o endotélio atua na regulação do tônus vascular e em sua estrutura (LANDMESSER et al., 2004). Assim, uma série de descobertas iniciada na década de 70 mudou a percepção da comunidade científica em relação à função da célula endotelial (CE). Atualmente, o endotélio é considerado um "órgão" altamente complexo que responde a estímulos físicos e químicos produzindo diversas moléculas mensageiras, orgânicas e inorgânicas, que influenciam a função do tecido que o circunda, especialmente o fluxo sanguíneo. O endotélio sintetiza e libera fatores vasodilatadores, incluindo óxido nítrico (NO), fator hiperpolarizante derivado do endotélio (EDHF) e prostaciclinas $\left(\mathrm{PGI}_{2}\right)$, bem como fatores vasoconstritores (fatores vasoconstritores derivados do endotélio, EDCF) incluindo a endotelina 1 (ET1) (AIRD, 2007). A homeostase vascular é mantida pelo balanço entre esses fatores (MURAKAMI; SIMONS, 2009).

$\mathrm{O}$ endotélio é também responsivo à ativação inflamatória e expressa receptores (Pselectina, E-selectina, integrinas) e moléculas de adesão (molécula de adesão vascular 1 (VCAM-1) e intercelular 1 (ICAM-1)), com impacto na patofisiologia do tecido afetado (MESTAS; LEY, 2008). No sistema microvascular, o endotélio tem função crucial no controle da permeabilidade vascular a macromoléculas, controlando a difusão transcelular, intercelular e paracelular, em resposta a sinais moleculares (p.ex. histamina, partículas de carbono) e ambientais (p.ex. pressão hidrostática e osmótica) (VAN HINSBERG, 1997). Devido a essas propriedades é fundamental que o endotélio realize reparos rápidos ao sofrer danos e que as células apoptóticas sejam rapidamente substituídas por células endoteliais progenitoras circulantes (URBICH; DIMMELER, 2004). 


\section{2 Óxido nítrico}

No início de 1980, Robert Furchgott demonstrou a função parácrina das células endoteliais na parede do vaso. Ele observou que a aplicação de acetilcolina após préconstrição com norepinefrina resultava em outra vasoconstrição, enquanto que em anéis com o endotélio vascular intacto ocorria vasodilatação (FURCHGOTT; ZAWADZKI, 1980). Esse relaxamento das células musculares vasculares lisas induzido pela acetilcolina foi atribuído a uma substância denominada "fator relaxante derivado do endotélio" (EDRF). Em 1986, essa substância foi confirmada por Robert Furchgott, Louis Ignarro, Ferid Murad e Salvador Moncada como sendo o óxido nítrico (VANHOUTTE, 2009).

O NO tem como principal função proteger o endotélio contra doenças coronárias inibindo a inflamação, a proliferação de célula muscular vascular lisa, a adesão das plaquetas e a liberação de fator tecidual (GROVER-PÁEZ; ZAVALZA-GÓMES, 2009). Assim, a diminuição da sua atividade parece ser importante na disfunção endotelial. Este fato pode resultar de síntese reduzida (menor viabilidade da tetra-hidrobiopterina $\left(\mathrm{BH}_{4}\right)$ ou L-arginina um precursor do óxido nítrico), inibição de transdução de sinal ou inativação aumentada do óxido nítrico (radicais livres de oxigênio, dimetilarginina assimétrica) (NAPOLI; IGNARRO, 2009).

O óxido nítrico é uma molécula reativa que apresenta propriedades citotóxicas e citoprotetoras (GRISHAM, JOURD’HEUIL, WINK, 1999). O NO é citotóxico quando reage com o ânion superóxido formando peroxinitrito, um oxidante citotóxico (TRUJILLO, FERRER-SUETA, RADI, 2008), e protetor por seu efeito vasodilatador (DOBAROO et al., 2009).

O NO é produzido no endotélio pela isoforma constitutiva NO sintase dependente de $\mathrm{Ca}^{2+}$ (eNOS, NOS III) (MONCADA, 1997; LI et al., 2002; DUDZINSKI et al., 2006). O NO não previne somente a constrição anormal (vasoespasmo) de artérias coronárias, que favorecem a formação intraluminal de coágulos, mas também inibe a agregação de plaquetas, a expressão de moléculas de adesão na superfície de células endoteliais, a adesão e a penetração de monócitos na parede do vaso e a liberação e ação do peptídeo vasoconstritor e mitogênico endotelina-1 (LI; FORSTERMANN, 2009).

A liberação de NO como efeito protetor ocorre na presença de trombina e de substâncias liberadas após a agregação de plaquetas no endotélio. Quando essa função protetora do NO é interrompida, inicia-se uma resposta inflamatória que leva a aterosclerose (VALLANCE, 2003; COOKE, 2004; VOETSCH et al., 2004). 
Vários fatores podem alterar a capacidade do endotélio de liberar NO. Quando ocorre inibição na liberação de NO, a causa pode estar relacionada à alteração hormonal, idade, fumo (ativo ou passivo), hipercolesterolemia, obesidade e produção de radicais livres de oxigênio. Em contrapartida, fatores como tensão de cisalhamento, sexo, insulina, adiponectina, hormônios e arginina levam a um aumento na liberação de NO (HAYASHI et al., 2008).

\subsection{Estresse oxidativo}

O estresse oxidativo agudo e crônico no endotélio vascular é uma das causas de disfunção severa. O estresse oxidativo é um fator importante na patogênese e desenvolvimento de doenças cardiovasculares, incluindo hipertensão, dislipidemia, diabetes mellitus, aterosclerose, infarto do miocárdio, angina peitoral e parada cardíaca (SCHACHINGER; ZEIHER, 2000; NEUNTEUFL et al., 2000; HEITZER et al., 2001).

O estresse oxidativo induz proliferação celular, hipertrofia, apoptose e inflamação por ativação de cascatas de sinalização e fatores de transcrição. A produção em excesso de espécies reativas de oxigênio (ERO) e espécies reativas de nitrogênio (ERN) leva à oxidação de várias moléculas.

Várias enzimas oxidativas participam na produção dessas espécies reativas incluindo fosfato dinucleotídeo adenina-nicotinamida oxidase (NADPH), xantina oxidase, óxido nítrico sintase endotelial (eNOS), ciclooxigenase, glicose oxidase e lipooxigenase, e a cadeia de transporte de elétrons mitocondrial. ERO incluem ânion superóxido $\left(\mathrm{O}^{--}{ }_{2}\right)$, peróxido de hidrogênio $\left(\mathrm{H}_{2} \mathrm{O}_{2}\right)$, radical hidroxila $(\mathrm{OH})$, ácido hipocloroso $\left(\mathrm{HOCl}^{-}\right)$, e as ERN inclui $\mathrm{NO}$ e peroxinitrito $\left(\mathrm{ONOO}^{-}\right) . \mathrm{O}^{-}{ }_{2}, \mathrm{OH}$, e $\mathrm{NO}$ são classificados como radicais livres apresentando elétrons desemparelhados com forte potencial oxidativo. $\mathrm{H}_{2} \mathrm{O}_{2}, \mathrm{HOCl}^{-}$, e $\mathrm{ONOO}^{-}$são classificados como radicais não-livres que também possuem potencial oxidativo.

A partir da geração de $\mathrm{O}_{2}^{--}$, outro intermediário mais reativo é produzido pela dismutação espontânea ou catálise enzimática:

$$
2 \mathrm{O}^{-}{ }_{2}+2 \mathrm{H}+\longrightarrow \mathrm{H}_{2} \mathrm{O}_{2}+\mathrm{O}_{2}
$$

$\mathrm{Na}$ presença de metais de transição (p.ex. $\mathrm{Fe}^{3+}$ ), $\mathrm{O}_{2}^{--}$reduz $\mathrm{Fe}^{3+}$ para $\mathrm{Fe}^{2+}$ pela reação de Haber-Weiss ferro-catalisada (Eq. 2). A redução ferro-ferroso reage com $\mathrm{H}_{2} \mathrm{O}_{2}$ pela reação de Fenton (Eq. 3) e gera o radical hidroxila altamente reativo (LUM; ROEBUCK, 2001).

$$
\mathrm{O}_{2}^{--}+\mathrm{Fe}^{3+} \longrightarrow \mathrm{O}_{2}+\mathrm{Fe}^{2+}
$$




$$
\mathrm{H}_{2} \mathrm{O}_{2}+\mathrm{Fe}^{2+} \longrightarrow \mathrm{Fe}^{3+}+\mathrm{OH}^{-} \mathrm{OH}^{-}
$$

Além disso, ${\mathrm{o} \mathrm{O}^{-}}_{2}$ pode reagir com o NO para formar peroxinitrito, que se decompõe formando ${ }^{\circ} \mathrm{OH}$ e $\mathrm{NO}_{2}$ (BECKMAN et al., 1990).

Vários tipos celulares são fontes de ERO, incluindo célula muscular vascular lisa (CMVL) e célula endotelial. A enzima antioxidante superóxido dismutase (SOD) dismuta rapidamente $\mathrm{O}^{-}{ }_{2}$ para $\mathrm{H}_{2} \mathrm{O}_{2}$ que é eliminado pela glutationa peroxidase (GPx) e pela catalase como água. A SOD é classificada em três tipos: Cu/Zn SOD, Mn SOD e SOD extracelular.

A suscetibilidade de células vasculares ao estresse oxidativo depende do balanço entre o grau de estresse oxidativo e a capacidade de defesa antioxidante. Os mecanismos protetores antioxidantes são complexos e multifatoriais. SOD, GPx e catalase formam um sistema de defesa antioxidante que sequestra ERO na vasculatura inibindo a degradação de NO. A SOD converte rapidamente $\mathrm{O}^{--}{ }_{2}$ em $\mathrm{H}_{2} \mathrm{O}_{2}$. Este atua como segundo mensageiro intracelular participando no remodelamento vascular, inflamação, apoptose, e na proliferação de CMVL (FARACI; DIDION, 2004).

A peroxidação lipídica e a oxidação de proteínas induzem superexpressão de genes redox, aumenta o conteúdo de cálcio intracelular e causa fragmentação de DNA, resultando em danos às CMVL, endoteliais e miocárdicas (HIGASHI et al., 2009). Desta forma, o aumento na produção de ERO prejudica a função endotelial em humanos induzindo aterosclerose. Um mecanismo possível para se explicar a disfunção endotelial (DE) se refere ao aumento do estresse oxidativo que leva à inativação do NO. O conteúdo reduzido de NO além da produção aumentada de ERO pode explicar a vasodilatação endotélio-dependente deficiente que ocorre em pacientes com doenças cardiovasculares.

\subsection{Disfunção endotelial}

Disfunção endotelial (DE) é o termo usado para descrever qualquer atividade não fisiológica do endotélio, incluindo produção e expressão alterada de moléculas de adesão próinflamatórias. A DE é caracterizada pela ativação crônica do endotélio, que inclui a produção aumentada de citocinas pró-inflamatórias (SHAW et al., 2007) e a diminuição da capacidade de vasodilatação dependente de NO (BARTUS et al., 2005). Além disso, ocorrem alterações na produção de prostaciclinas $\left(\mathrm{PGI}_{2}\right)$ e fatores hiperpolarizantes derivados do endotélio 
(EDHF), bem como produção aumentada de ânion superóxido $\left(\mathrm{O}^{-{ }_{2}}\right)$, inativação de $\mathrm{NO}$, ativação pró-inflamatória e pró-trombótica do endotélio (BONETTI et al., 2003).

A disfunção endotelial é considerada o fator principal para o início e a progressão do processo aterosclerótico que ocorre na doença arterial coronariana, isquemia periférica, e em alguns tipos de infarto (KNOTTNERUS et al., 2009). A DE também tem sido associada à progressão de outras condições cardiovasculares, incluindo hipertensão (POLLOCK, 2006) e parada cardíaca (SANDOW; TARE, 2007).

A ativação do endotélio pode estar associada a danos ou a infecção no tecido, sendo essencial o recrutamento de plaquetas e leucócitos na indução da resposta inflamatória localizada. As citocinas e outros mediadores inflamatórios (p.ex., prostaglandinas e leucotrienos) além de induzir recrutamento de células inflamatórias têm efeito na liberação de alguns mediadores derivados do endotélio, incluindo ET-1 (KANSE et al., 1991), que age como um vasoconstritor potente e imediato (IHLING et al., 2001). Além disso, as citocinas também aumentam a expressão da enzima oxido nítrico sintase endotelial (eNOS) e conseqüentemente afetam a produção de $\mathrm{NO}$ e ERN (peroxinitrito, $\mathrm{ONOO}^{-}$).

A perda da função endotelial promove isquemia cardíaca em pacientes com angina estável (LIEBERMAN et al., 1996; BEHRENDT; GANZ, 2002), tendo impacto na ruptura da placa aterosclerótica resultando em infarto do miocárdio (DUPUIS et al., 1999). A disfunção endotelial está também associada à restenose após intervenções nas coronárias (LEVINE et al., 1995).

\subsection{Morte de células endoteliais}

O endotélio, devido a sua localização, fica continuamente exposto a células inflamatórias e fatores circulantes, os quais podem induzir ativação endotelial e danos teciduais. A indução de apoptose ocorre em células endoteliais após exposição a fatores circulantes pró-inflamatórios (XU, 2009). A morte das células endoteliais pode exacerbar a patogênese da aterosclerose por alterar a integridade da monocamada endotelial. Além disso, a indução de apoptose das células endoteliais pode também contribuir com a erosão da placa e aumentar a formação de trombos por induzir um estado pró-coagulante, fatores envolvidos no desenvolvimento da síndrome coronariana aguda (SIMA et al., 2009).

A principal evidência de que a apoptose das células endoteliais pode contribuir para o início da aterogênese é o fato de que os fatores de risco que causam disfunção endotelial e formação de lesão aterosclerótica induzem morte de célula endotelial in vitro. Esses fatores de 
risco incluem lipídios oxidados, tais como LDL oxidada ou lipoproteína (a) oxidada (PELLEGRINO et al., 2004; LU; DAUGHERTY, 2009) e a alta concentração de ERO (HULSMANS; HOLVOET, 2010). Além desses, o envelhecimento, fator importante na formação da lesão aterosclerótica, também induz apoptose de células endoteliais, como demonstrado em estudos in vitro e in vivo (VANNINI et al., 2008; FOREST et al., 2010). Em contrapartida, fatores protetores da função vascular, como fluxo sanguíneo laminar, protegem as células endoteliais contra a apoptose (BERARDI; TARBELL, 2009).

Sob condições normais, a homeostase do vaso e sua integridade funcional são mantidas por regeneração celular contínua e pela incorporação de células endoteliais progenitoras. No caso de injúria aguda, células endoteliais podem responder por apoptose e geração de micropartículas endoteliais, perda de trombomodulina e do inibidor do fator tecidual, levando a um estado pró-coagulante (CHIRONI et al., 2009).

Corpos residuais de células apoptóticas, as micropartículas, podem induzir diretamente disfunção endotelial (SABATIER et al., 2009). Micropartículas endoteliais circulantes ativam células endoteliais e, assim, induzem disfunção endotelial (BURNIER et al., 2009). Micropartículas são definidas como vesículas menores que $1 \mu \mathrm{m}$ de diâmetro e são derivadas da membrana plasmática de vários tipos celulares em resposta à ativação, injúria e/ou apoptose (HUGEL et al., 2005). O envolvimento de micropartículas em patologias foi demonstrado pela primeira vez em uma doença sanguínea adquirida denominada púrpura trombocitopênica idiopática (KAHN et al., 1975). Desde então, a relevância das micropartículas em diferentes condições patológicas tem sido estudada com enfoque em suas propriedades pró-coagulantes e sua participação na inflamação e disfunção vascular.

Bernal-Mizrachi et al. (2004) demonstraram que micropartículas derivadas de células apoptóticas estão aumentadas em pacientes com síndrome coronariana aguda. Cerca de um terço dessas micropartículas, detectadas nesses pacientes, expressam proteínas endoteliais. Outros grupos observaram aumento de células endoteliais circulantes no infarto do miocárdio e angina instável (MOREL et al., 2005).

\section{6 Ácidos graxos}

Os ácidos graxos (AG) são ácidos carboxílicos com uma cadeia carbônica longa, não ramificada, geralmente com número par de átomos de carbono. O grupo carboxila constitui a região polar e a cadeia de carbonos a região apolar da molécula. O tamanho da cadeia hidrocarbônica determina a classificação dos AG em cadeia curta (2 a 4 átomos de carbono), 
cadeia média (6 a 14 átomos de carbono) e cadeia longa (acima de 14 átomos de carbono). A presença de insaturações (duplas ligações) na cadeia carbônica classifica-os em saturados (não possuem insaturações), monoinsaturados (possuem 1 insaturação) e poliinsaturados (possuem mais de uma insaturação) (GUNSTONE, 1996).

Os ácidos graxos livres desempenham várias funções no organismo humano como reserva energética para produção de adenosina trifosfato (ATP) nas células, componente estrutural de membranas biológicas, isolamento e proteção de órgãos (McARTHUR et al., 1999).

Ácidos graxos essenciais são necessários para a sobrevivência e não podem ser sintetizados pelo organismo, sendo necessária sua ingestão pela dieta (DAS, 2006; LERMAN, 2006). Existem duas classes de ácidos graxos essenciais, os AG $\omega-6$ derivados do ácido linoléico (18:2) e os AG $\omega$-3 derivados do ácido $\alpha$-linolênico (18:3). Ambos AG, $\omega$-3 e $\omega-6$, são metabolizados pelas mesmas enzimas aos seus respectivos metabólitos de cadeia longa. Os AG essenciais são ativos e não requerem sua conversão para a maior parte de suas ações.

$\mathrm{O}$ atual conhecimento de que a dieta afeta diretamente a maioria dos fatores de riscos modificáveis de doenças cardiovasculares aumentou a importância da dieta na prevenção da aterosclerose (YUSUF et al., 2004), enfatizando a necessidade do consumo de AG específicos com propriedades antiinflamatórias, como os AG $\omega-3$ eicosapentaenóico (EPA 20:5) e o docosaexaenóico (DHA 22:6) (MASSARO et al., 2008). Desde os primeiros estudos com esquimós da Groenlândia, muitos outros confirmaram a associação entre AG $\omega$-3 e menor risco de doenças cardiovasculares (HE et al., 2009). Dois estudos de meta análise sugeriram que EPA e DHA reduzem significativamente o índice de morte súbita e cardíaca e possivelmente infarto, por consumo moderado de peixe (1-2 refeições/semana). Assim, os benefícios da ingestão de peixes superam os possíveis riscos por intoxicação com metilmercúrio, dioxinas, bifenóis policlorinado e outros possíveis contaminantes (WANG et al., 2006).

Os benefícios dos AG $\omega-3$ parecem resultar primeiramente do preenchimento dos fosfolípides de membrana com EPA e DHA (HARRIS, 2007), o que resulta em melhora da função arterial e endotelial (THIES et al., 2003), reduz agregação plaquetária (DIN et al., 2008), melhora o tônus autonômico (ABUISSA et al., 2005; O'KEEFE et al., 2006), melhora o limiar arrítmico (ANAND et al., 2008) e reduz a pressão sanguínea (UESHIMA et al., 2007). Ácidos graxos $\omega-3$ podem também reduzir a resistência à insulina (ITOH et al., 2007) e suprimir a produção de citocinas pró-inflamatórias (interleucina-6, interleucina-1 $\beta$ e fator de 
necrose tumoral- $\alpha$ ). Em pacientes com insuficiência cardíaca, doses de AG $\omega-3$ de 8 g por dia ou mais apresentam efeitos antiinflamatórios (MEHRA et al., 2006; LAVIE et al., 2009). Os AG $\omega$-3 têm também efeitos favoráveis no perfil lipídico do sangue. A American Heart Association (AHA) recomenda doses diárias de 2 a 4 g de DHA e EPA para pacientes com concentrações elevadas de triacilgliceróis no plasma (KRIS-ETHERTON et al., 2002).

Os AG $\omega$-3 ocorrem sempre juntos em fontes naturais - carne de peixe e óleo de peixe (KRIS-ETHERTON et al., 2003). De Caterina et al. (1994) demonstraram que os ácidos graxos $\omega$-3 adicionados à cultura de células endoteliais interferem na expressão de moléculas de adesão que estão envolvidas no processo de interação entre leucócitos e células endoteliais. Em estudos in vivo também ocorre inibição dessas moléculas em macrófagos de camundongos (MILLES et al., 2000). De Caterina e Massaro (2005) demonstraram que uma dieta rica em ácidos graxos da família $\omega$-3 (EPA e DHA) diminui a transcrição de genes (como moléculas de adesão e citocinas inflamatórias) ligados à ativação endotelial em resposta a estímulos inflamatórios e pró-aterogênicos.

Outra classe de ácidos graxos essenciais, os ácidos graxos $\omega-6$, está presente em alta quantidade nas dietas ocidentais, em especial o ácido linoléico. As principais fontes de ácidos graxos $\omega$-6 são os óleos vegetais como óleo de milho, girassol e soja. Uma vez consumidos, esses ácidos graxos são metabolizados. O ácido linoléico (18:2 $\omega$-6) é convertido em ácido $\gamma$ linolênico (18:3 $\omega$-6) e ácido dihomo- $\gamma$-linolênico $(20: 3 \omega-6)$ e formam intermediários da via de síntese do ácido araquidônico (20:4 $\omega$-6) por ação de elongases e dessaturases. O ácido araquidônico é então metabolizado para ácido docosapentaenóico (22:5 $\omega$-6) ou eicosanóides (SPRECHER et al., 1995).

A função dos AG $\omega-6$ na DCV é controverso. Alguns ácidos graxos dessa família, em especial o ácido linoléico, apresenta propriedades pró-inflamatórias e pró-aterogênicas aumentando a incidência de aterosclerose e hiperinsulinemia (YAM et al., 1996; HENNING et al., 2001). A presença do ácido linoléico na dieta contribui na ativação endotelial estimulando a expressão de moléculas de adesão como VCAM-1 pela ativação do fator de

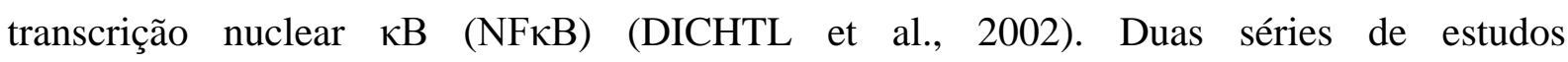
contemporâneos (1994 - 2000), realizados em cultura de células tratadas com ácidos graxos de cadeias carbônicas similares, diferindo somente no grau de saturação, demonstraram resultados divergentes. De Caterina (1998) e Libby (1999) observaram que AG poliinsaturados $\omega-6$ diminuem a ativação endotelial induzida por citocinas inflamatórias. Entretanto, Toborek (1998) e Henning (2001) demonstraram intensificação dos efeitos pró- 
inflamatórios e aterogênicos pelos AG $\omega-6$. De acordo com De Caterina (1998) e Massaro (1999), o ácido linoléico inibe a ativação endotelial independente da sua fonte (DE CATERINA et al., 1998; MASSARO et al., 1999). Essa observação contrapõe estudos anteriores que demonstraram efeito pró-ativador desse AG (HENNING et al., 2001; DICHTL et al., 2002). Por possuir fraca atividade de elongases e dessaturases, células endoteliais exibem síntese reduzida de ácido araquidônico a partir de ácido linoléico e, por essa razão, ocorre acúmulo intracelular desse AG (SPECTOR et al., 1981). Essa especificidade metabólica devido o conteúdo elevado de ácido linoléico em alimentos de consumo diário.

Os ácidos graxos saturados são considerados pró-inflamatórios, pró-trombóticos e próateroscleróticos. Em estudos epidemiológicos, como o "Seven Country Studies" foi mostrada alta correlação entre ingestão de gordura saturada e prevalência de DCV (KEYS, 1970). A dieta ocidental é rica em ácidos graxos saturados e sua principal fonte é a gordura do leite (5$15 \%$ ), o óleo de coco e a manteiga (10-15\%) (SAMPATH; NTAMBI, 2005). Entre os ácidos graxos saturados presentes na dieta, o ácido esteárico (ou estearato) é o segundo em predominância, sendo 25,8 \% do total de SFA ingerido e 2,9 \% do total da ingestão calórica diária (UNITED STATES DEPARTMENT OF AGRICULTURE - USDA, 2005).

O ácido esteárico foi descrito pela primeira vez por Michel Eugene Chevreul em 1823. É também denominado ácido n-octadecanóico (18:0) por ser composto por 18 átomos de carbonos sem dupla ligação. Além das fontes dietéticas, o ácido esteárico pode ser sintetizado endogenamente a partir de moléculas de acetil-CoA. O ácido esteárico é um candidato na substituição dos AG trans utilizados na fabricação de alimentos industrializadas, por ter as propriedades físicas necessárias de uma gordura sólida (KRIS-ETHERTON et al., 2005). Existem evidências de que os efeitos do ácido esteárico são consideravelmente diferentes daqueles dos AG saturados de cadeias mais curtas como ácido láurico (C12:0), mirístico (C14:0) e palmítico (C16:0) (KRIS-ETHERTON et al., 1993; PAI; YEH, 1996, 1997). O ácido mirístico é responsável pelo aumento nas concentrações de colesterol sanguíneo em animais e humanos (HAYES, 1995), seguido pelos ácidos láurico e palmítico. Keys et al. (1965) e Hegsted et al. (1965) mostraram que, ao contrário dos ácidos láurico, mirístico e palmítico, o ácido esteárico não aumenta as concentrações plasmáticas de colesterol em indivíduos saudáveis. Woollett et al. (1992) observaram em hamsters que, embora dietas ricas em ácidos láurico, mirístico ou palmítico aumentem a concentração de colesterol plasmático por redução da atividade do receptor LDL e aumentem a taxa de produção de LDL, o ácido esteárico não mostra esse efeito sendo associado a uma resposta hipocolesterolêmica. 
Artwohl et al. (2008) demonstraram que o ácido esteárico causa apoptose de células endoteliais humanas em cultura e em várias linhagens (HUVEC, HAEC, HREC, EPC) e parece ser absorvido de forma menos eficiente devido a sua cadeia longa e saturação (SAMPATH; NTAMBI, 2005).

Ao contrário da dieta ocidental rica em ácidos graxos saturados, a dieta mediterrânea é rica em frutas, vegetais e óleo de oliva. Este óleo é rico em ácido oléico (C18:1), que apresenta, conforme o "Seven Country Studies", relação inversa com DCV (KEYS, 1970). Em alguns países mediterrâneos, o ácido oléico chega a atingir aproximadamente 29 \% da ingestão calórica diária. Em um estudo americano com profissionais de saúde e enfermeiras foi mostrada redução de $19 \%$ no risco de DCV quando a ingestão de ácido graxo monoinsaturado foi aumentada em $5 \%$ (do total de energia diária ingerida) (HU et al., 1997). A ingestão de ácido oléico parece contribuir na redução de vários fatores de risco para doenças coronarianas como hipertensão (TERÉS et al., 2008), diabetes (GARG et al., 1992; HANNAH; HOWARD, 1994; GRIFFIN et al., 1996) e obesidade (BOSELLO et al., 1990).

Em estudos in vitro com célula endotelial foi mostrado que os principais AG poliinsaturados presentes na dieta e o ácido oléico podem prevenir a ativação endotelial inibindo a expressão de moléculas de adesão ou aumentando a produção de NO (CHRISTON, 2003). O tratamento da célula endotelial com ácido oléico in vitro reduz a sensibilidade desta a oxidantes, tornando o ambiente menos oxidativo com consequente redução da produção intracelular de ERO (BAEUERLE; HENKEL, 1994; SPOLARICS, 1996). Nesse ambiente, o

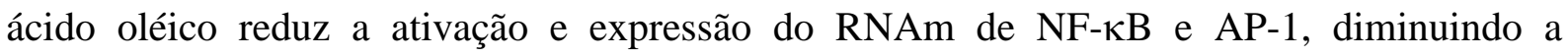
expressão endotelial de moléculas de adesão para monócitos circulantes e contribuindo com efeito ateroprotetor vascular direto (MASSARO et al., 1999; MASSARO et al., 2002; TOBOREK et al., 2002). Além disso, o tratamento com ácido oléico protege a CE da superexpressão de VCAM-1, ICAM-1 e E-selectina induzida por citocinas (CARLUCCIO et al., 1999).

Em contrapartida a esses estudos, alguns autores sugerem efeitos negativos dos ácidos graxos livres (AGL) circulantes, tais como o ácido oléico, em pacientes diabéticos (KUSUNOKI et al., 2007). Em cultura de células musculares de aorta de ratos mantidas em meio contendo ácido oléico em concentração similar a aquela encontrada em pacientes diabéticos, observou-se aumento significativo no número de receptores de endotelina-1 (KWOK et al., 2000; ORAM et al., 2004).

Uma dieta rica em gordura (cerca de $50 \%$ ) promove inflamação em indivíduos saudáveis, bem como em diabéticos tipo 2. Ácidos graxos saturados na dieta modulam ações 
pró-inflamatórias (BASU et al., 2006) e elevam o risco de desenvolver DCV (HU et al., 1997; SINGH et al., 2002; OH et al., 2005). Os ácidos graxos da família $\omega$-3 modulam a resposta inflamatória e diminuem os fatores ateroscleróticos (HE et al., 2009) e o ácido oléico melhora a função endotelial (CHRISTON, 2003). A função dos AGs $\omega-6$ na DCV é ainda controverso (CHRISTON, 2003). Observam-se assim modulações específicas dos diferentes ácidos graxos sobre fatores envolvidos no processo aterosclerótico. O excesso de lipídios no plasma, resultante de situações patológicas como diabetes e obesidade ou dietas ricas em gordura, acarreta lipotoxicidade vascular causando aterosclerose (MATTERN; HARDIN, 2007).

Alta concentração de AGL, principalmente ácidos graxos poliinsaturados e ácidos graxos voláteis, pode aumentar a morte de células in vitro por apoptose ou, quando em concentrações elevadas, por necrose (HATANAKA et al., 2006; CURY-BOAVENTURA et al., 2006a, 2006b; FELIPPE et al., 1997). A morte celular por apoptose ocorre em doses próximas às concentrações de AGL no plasma, como avaliada pela indução de perda internucleossomal de DNA, condensação de cromatina e perda de núcleo (HATANAKA et al., 2006; CURY-BOAVENTURA et al., 2006a, 2006b; LOPES et al., 1999; FELIPPE et al., 1997). Altas doses de AGL levam à necrose, com perda rápida da integridade de membrana e expansão celular. Esses efeitos são associados ao estresse oxidativo por serem parcialmente reduzidos por agentes antioxidantes como o tocoferol (HATANAKA et al., 2006; CURYBOAVENTURA et al., 2006a, 2006b; LOPES et al., 1999; FELIPPE et al., 1997). Devido ao acúmulo de triacilgliceróis e colesterol nas células lisas da musculatura vascular (MARTINET et al., 2002), pode ocorrer apoptose dessas por aumento na produção de ERO (TANIYAMA; GRIENDLING, 2003). Desta forma, é importante investigar como os ácidos graxos atuam sobre a morte de células endoteliais e as alterações no balanço oxidativo entre NO e ERO. 


\section{OBJETIVOS}


O objetivo desse trabalho foi investigar os efeitos dos ácidos graxos poliinsaturados $\omega$ 3 (DHA e EPA) e $\omega-6$ (ácido linoléico e $\gamma$-linolênico) sobre a morte celular induzida pelo ácido esteárico (saturado) e a participação do NO e ERO nesse processo. Também avaliou-se os efeitos dos ácidos graxos poliinsaturados $\omega$-3 (DHA e EPA) e $\omega$-6 (ácido linoléico e $\gamma$ linolênico) associados ao ácido oléico que apresenta baixa citotoxicidade. Os parâmetros avaliados foram: morte celular (perda de integridade de membrana e fragmentação de DNA), conteúdo intracelular de óxido nítrico e produção de espécies reativas de oxigênio (ânion superóxido). 


\section{JUSTIFICATIVA}


Nos óleos administrados a pacientes e utilizados na dieta, há sempre uma composição variada de ácidos graxos. Nesse estudo investigou-se o efeito da combinação de ácidos graxos poliinsaturados $\omega$-3 e $\omega$-6 com os ácidos esteárico (muito tóxico) e o oléico (pouco tóxico) sobre a morte de células endoteliais. A morte das células endoteliais exacerba a patogênese da aterosclerose por contribuir com a erosão da placa e aumentar a formação de trombos induzindo um estado pró-coagulante. 


$$
\begin{array}{r}
4 \text { MATERIAIS E } \\
\text { MÉTODOS }
\end{array}
$$




\subsection{Cultura de células}

Foram utilizadas células ECV-304. Esta é uma linhagem de células endoteliais do cordão umbilical de humanos, doadas pela Dra. Sonia Jancar (Instituto de Ciências Biomédicas, Universidade de São Paulo, Brasil). As células foram mantidas em meio RPMI1640, enriquecido com glutamina ( $2 \mathrm{mM})$, tamponado com bicarbonato de sódio ( $24 \mathrm{mM})$ e Hepes (20 mM), contendo soro fetal bovino (SFB) (10\%) e antibióticos (penicilina e estreptomicina, $10000 \mathrm{U} / \mathrm{mL}$ ). A cultura celular foi mantida a $37{ }^{\circ} \mathrm{C}$ em atmosfera com $5 \%$ de $\mathrm{CO}_{2}$ e $95 \%$ de ar em ambiente úmido. O repique das células foi efetuado quando as garrafas apresentavam confluência ao redor de $90 \%$. Inicialmente avaliou-se a toxicidade dos AG para as células endoteliais (Quadro 1). Podemos observar que o ácido esteárico é muito tóxico para essas células.

Quadro 1. Concentração máxima tolerável dos ácidos graxos na viabilidade de células endoteliais ECV-304.

\begin{tabular}{|c|c|}
\hline Ácidos Graxos & Viabilidade celular [ ] $\boldsymbol{\mu M}$ \\
\hline Esteárico (SA) & 100 \\
\hline Oléico (OA) & Sem efeito até $500 \mu \mathrm{M}$ \\
\hline Docosaexaenóico (DHA) & 350 \\
\hline Eicosapentaenóico (EPA) & 300 \\
\hline Linoléico (LA) & Sem efeito até $500 \mu \mathrm{M}$ \\
\hline$\gamma-$ Linolênico $(\gamma \mathrm{A})$ & 300 \\
\hline
\end{tabular}

$\mathrm{n}=9$ amostras após tratamento com AG por 24 horas. Todos os valores foram significativos $(\mathrm{p}<0,05)$ em relação ao controle. Dados obtidos por Érica Paula Portioli Sanches.

\subsection{Tratamento das células ECV-304 com AG}

As células foram tratadas com os ácidos graxos: esteárico (18:0) ou oléico (18:1), combinados com linoléico (18:2), $\gamma$-linolênico (18:3), eicosapentaenóico (EPA) (20:5) ou docosa-hexaenóico (DHA) (22:6), dissolvidos em etanol de acordo com o Quadro 2: 
Quadro 2 - Combinações dos ácidos graxos usadas no tratamento de células endoteliais ECV-304.

\begin{tabular}{|c|c|c|c|c|}
\hline & $\omega-3$ & $\omega-3$ & $\omega-6$ & $\omega-6$ \\
\hline $\begin{array}{l}\text { Ácido graxo saturado: esteárico } \\
\qquad(150 \mu \mathrm{M})\end{array}$ & $\begin{array}{c}\text { DHA } \\
(50 \text { e } 100 \mu \mathrm{M})\end{array}$ & $\begin{array}{c}\mathrm{EPA} \\
(50 \text { e } 100 \mu \mathrm{M})\end{array}$ & $\begin{array}{c}\text { linoléico } \\
(50 \text { e } 100 \mu \mathrm{M})\end{array}$ & $\begin{array}{l}\gamma \text {-linolênico } \\
(50 \text { e } 100 \mu \mathrm{M})\end{array}$ \\
\hline $\begin{array}{l}\text { Ácido graxo monoinsaturado } \\
\qquad \text { cis - oléico }(300 \mu \mathrm{M})\end{array}$ & $\begin{array}{c}\text { DHA } \\
(50 \text { e } 100 \mu \mathrm{M})\end{array}$ & $\begin{array}{c}\mathrm{EPA} \\
(50 \text { e } 100 \mu \mathrm{M})\end{array}$ & $\begin{array}{c}\text { linoléico } \\
(50 \text { e } 100 \mu \mathrm{M})\end{array}$ & $\begin{array}{l}\gamma \text {-linolênico } \\
(50 \text { e } 100 \mu \mathrm{M})\end{array}$ \\
\hline
\end{tabular}

As concentrações foram determinadas com base no estudo de citotoxicidade previamente realizado (Quadro 1). Utilizamos uma concentração alta dos ácidos graxos esteárico $(150 \mu \mathrm{M})$ e oléico $(300 \mu \mathrm{M})$ e concentrações baixas dos ácidos graxos $\omega$-3 e $\omega$-6 (50 e $100 \mu \mathrm{M})$. Avaliamos também os ácidos esteárico e oléico nas concentrações de 200 e 250 $\mu \mathrm{M}, 350$ e $400 \mu \mathrm{M}$, respectivamente.

Os ácidos graxos foram diluídos em etanol devido a sua baixa solubilidade em solução aquosa. O mesmo procedimento é utilizado por vários grupos de pesquisa nesta área (MANICKAM; SINCLAIR; CAMERON-SMITH, 2010; COETZEE et al., 2010; KATAKURA et al., 2010). Não foi adicionado albumina, pois isso dificultaria especificar a quantidade de ácidos graxos livres. Cada molécula de albumina pode se ligar a até seis moléculas de ácido graxo, porém, com afinidades diferentes. Os valores obtidos nesse estudo foram sempre comparados aos do veículo.

\subsection{Viabilidade celular}

As células foram cultivadas em placas de 6 poços por 24 horas com as diferentes combinações de AG $(150-400 \mu \mathrm{M})$. Após centrifugação a $500 \mathrm{x} g$ por 5 minutos, a $4{ }^{\circ} \mathrm{C}$, o sobrenadante foi desprezado e o precipitado ressuspenso em $400 \mu \mathrm{L}$ de PBS (pH 7,4). Foram adicionados $40 \mu \mathrm{L}$ de solução de iodeto de propídio (IP) (20 $\mu \mathrm{g}$ por mL em PBS) e as células foram analisadas em citômetro de fluxo FACSCalibur (Becton Dickinson System, San Juan, CA, EUA). O IP é um composto fluorescente altamente solúvel em água que não atravessa membranas intactas. Assim, permite detectar as células com perda de integridade de membrana. O IP se liga ao DNA intercalando-se entre as bases, portanto, célula com membrana íntegra não permite a entrada do fluorocromo, apresentando assim baixa 
fluorescência. Já a célula cuja membrana apresenta-se rompida permite a entrada do iodeto de propídio que se liga ao DNA e emite alta fluorescência quando excitada pelo laser. A fluorescência foi detectada no canal FL2 (fluorescência laranja-avermelhada - 585/42 nm). Foram consideradas viáveis as células endoteliais que emitiam baixa intensidade de fluorescência. Dez mil eventos foram adquiridos por amostra em histograma. Os histogramas foram analisados utilizando o programa "Cell Quest" (Becton Dickinson, San Juan, CA, EUA).

\subsection{Fragmentação do DNA celular}

A fragmentação de DNA foi avaliada por citometria de fluxo de acordo com o método descrito por Nicoletti et al. (1991). As células foram cultivadas conforme descrito no item 3.4. Uma alíquota de $400 \mu \mathrm{L}$ de células em PBS (pH 7,4) foi colocada em tubo cônico de 1000

$\mu \mathrm{L}$. Posteriormente, estas células foram centrifugadas à $400 \mathrm{~g}$ e o precipitado de células obtido foi ressuspenso em $300 \mu \mathrm{L}$ de uma solução hipotônica contendo IP $2 \mu \mathrm{g} / \mathrm{mL}, 0,1 \%$ de citrato de sódio e $0,1 \%$ de Triton X-100. Nessas condições, as células foram incubadas por 30 minutos a temperatura ambiente e na ausência de luz. Nesse ensaio, a membrana celular é rompida pelo Triton X-100, permitindo a entrada de iodeto de propídeo na célula. Este se liga ao DNA e as células que o apresentam íntegro emitem alta fluorescência. No entanto, as que apresentam DNA fragmentado pelas endonucleases emitem baixa fluorescência. A fluorescência foi determinada no canal FL2 (fluorescência laranja-avermelhada - 585/42 nm). Foram consideradas em processo de morte as células que emitiram baixa intensidade de fluorescência. Os eventos foram avaliados como descritos no item 3.3.

\subsection{Determinação do conteúdo de óxido nítrico intracelular}

O conteúdo intracelular de NO foi determinado utilizando o corante fluorescente 4amino-5-metilamino-2',7'-difluorofluoresceina diacetato (DAF-FM/DA) (Molecular Probes, Invitrogen, Carlsbad, CA, EUA). Esse composto passa facilmente pela membrana celular por difusão e ao reagir com o NO forma o composto fluorescente benzoatrizol.

As células ( $1 \times 10^{5}$ por poço) foram cultivadas em placas de 24 poços, no dia anterior ao tratamento, contendo lamínulas previamente limpas. No dia do experimento, as células foram tratadas com DAF-DA $(10 \mu \mathrm{M})$ em meio RPMI-1640 por 30 minutos a $37{ }^{\circ} \mathrm{C}$. Após 
esse período, as células foram lavadas com PBS e foi usado como controle negativo um inibidor não seletivo da NOS, o NG-nitro-L-arginina metil éster (L-NAME) a $300 \mu \mathrm{M}$ por 30 minutos. Em seguida, foram adicionados os AG combinados (vide Quadro 1) por 1 hora. Esse período de tratamento foi determinado com base em experimentos anteriores de curva tempodependente realizados pelo nosso grupo de pesquisa (Érica Paula Portioli Sanches). As células foram visualizadas em microscópio de fluorescência (Carl Zeiss Vision, MunchenHallbergmoos, Alemanha), no filtro 520/450 nm. As células foram analisadas através da intensidade de fluorescência usando o software KS 300 (Herestraat, Leuven, Bélgica).

\subsection{Determinação da produção de espécies reativas de oxigênio (ERO)}

A produção de espécies reativas de oxigênio foi avaliada por imunofluorescência utilizando o fluoróforo hidroetidina. A hidroetidina atravessa as membranas celulares sendo clivada por ERO, formando brometo de etídeo, que se intercala nas bases nitrogenadas da molécula de DNA. As células foram tratadas por 30 minutos com os ácidos graxos combinados (vide Quadro 1). Esse período de tratamento foi determinado com base em experimentos anteriores de curva tempo-dependente realizados pelo nosso grupo de pesquisa (Érica Paula Portioli Sanches). Após o tratamento, as células foram incubadas com hidroetidina $(1 \mu \mathrm{M})$ por 30 minutos à temperatura ambiente no escuro. As células foram visualizadas em microscópio de fluorescência (Carl Zeiss Vision, Munchen-Hallbergmoos, Alemanha), no filtro 590/46 nm, e analisadas pela intensidade de fluorescência usando o software KS 300 (Herestraat, Leuven, Bélgica).

\subsection{Análise estatística}

Os resultados foram analisados através do programa Graph Pad Prism (Graph Pad Software Inc., San Diego, CA, USA) versão 5.0. Os dados estão apresentados como média \pm erro padrão da média e foram analisados por one-way ANOVA, seguido do pós-teste de Tukey, considerando como nível de significância $\mathrm{p}<0,05$. 


$$
5 \text { RESULTADOS }
$$


4.1 Efeito da combinação do ácido esteárico com os ácidos graxos $\omega$-3 e $\omega$-6 sobre as células endoteliais ECV-304

\subsubsection{Morte celular}

O tratamento com ácido esteárico (SA) e os AG $\omega$-3 e $\omega-6$ por 6 horas não alterou a viabilidade celular (Figura 1). Apenas a associação ao ácido eicosapentaenóico (EPA) a 50 $\mu \mathrm{M}$ aumentou em 20 \% a fragmentação do DNA quando comparado ao SA (Figura 2).

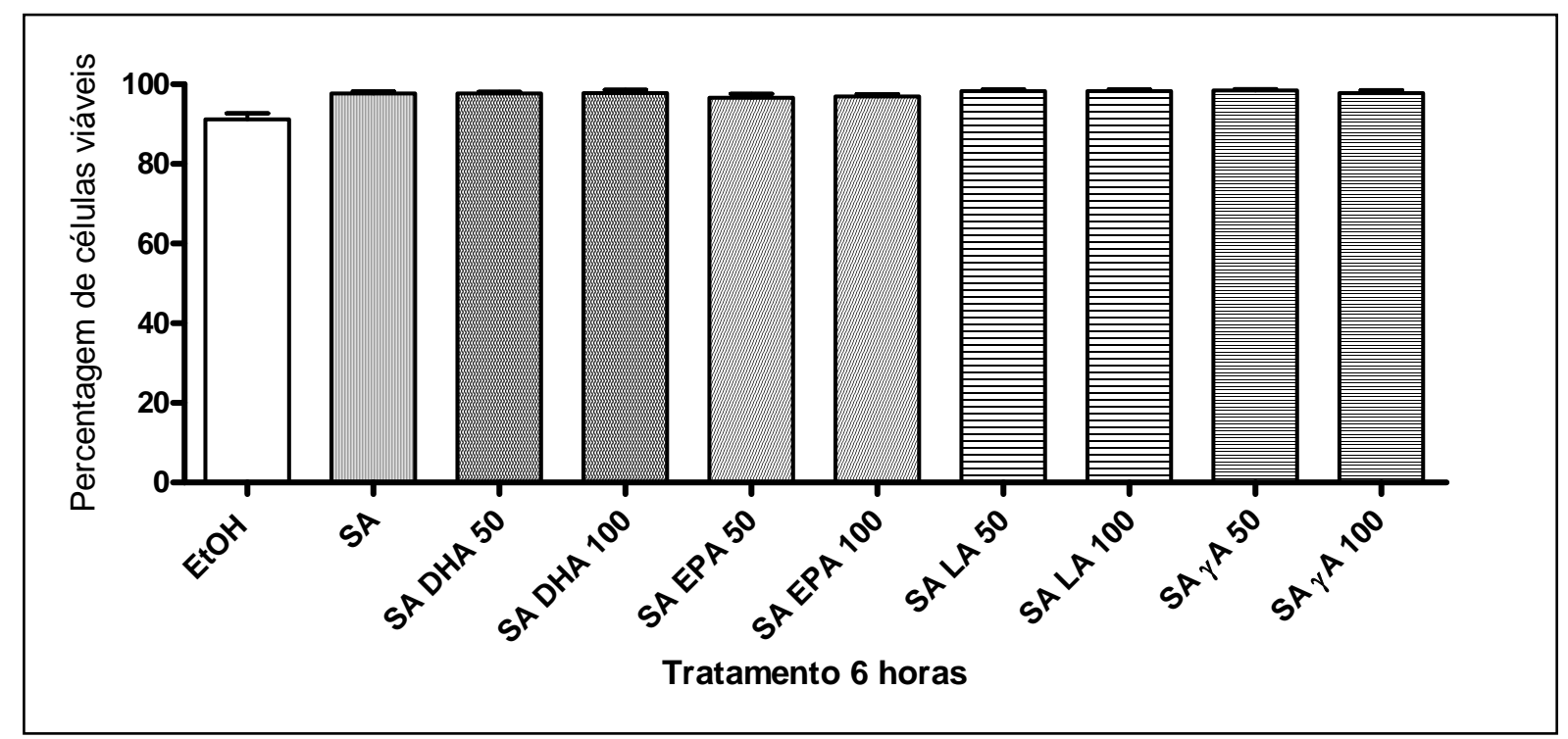

Figura 1. Viabilidade das células endoteliais ECV-304 incubadas por 6 horas com o ácido esteárico combinado com ácidos graxos $\omega$-3 e $\omega$-6. Células endoteliais da linhagem ECV304 foram cultivadas com os AG por 6 horas e analisadas por citometria de fluxo. A fluorescência foi mensurada em filtro FL2 $(585 / 42 \mathrm{~nm})$. Os valores estão apresentados como média $\pm \mathrm{EPM}(\mathrm{n}=9)$. EtOH = etanol; $\mathrm{SA}=$ ácido esteárico sempre a $150 \mu \mathrm{M} ; \mathrm{DHA}=$ ácido docosaexaenóico; EPA = ácido eicosapentaenóico; LA = ácido linoléico; $\gamma \mathrm{A}=$ ácido $\gamma$-linolênico; todos a 50 ou $100 \mu \mathrm{M}$ como indicado. 


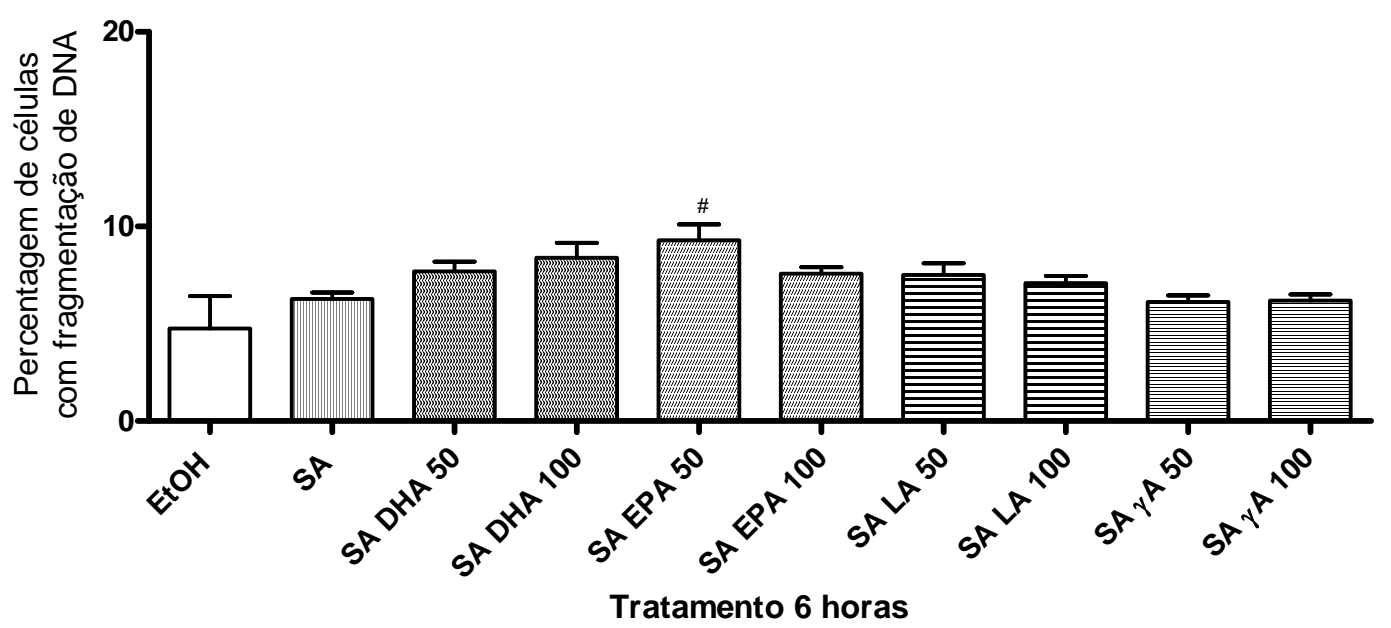

Figura 2. Fragmentação de DNA em células endoteliais ECV-304 incubadas por 6 horas com ácido esteárico combinado com ácidos graxos $\omega-3$ e $\omega$-6. Células endoteliais da linhagem ECV-304 foram cultivadas com os AG por 6 horas e analisadas por citometria de fluxo. A fluorescência foi mensurada em filtro FL2 $(585 / 42 \mathrm{~nm})$. Os valores estão apresentados como média \pm EPM (n=9). \# p<0,05 em relação ao ácido esteárico. EtOH = etanol; $\mathrm{SA}=$ ácido esteárico sempre a $150 \mu \mathrm{M} ; \mathrm{DHA}=$ ácido docosaexaenóico; EPA = ácido eicosapentaenóico; $\mathrm{LA}=$ ácido linoléico; $\gamma \mathrm{A}$ = ácido $\gamma$-linolênico; todos a 50 ou $100 \mu \mathrm{M}$ como indicado. 
No tratamento por 24 horas, o SA a $150 \mu \mathrm{M}$ diminuiu a viabilidade celular em $17,8 \%$ em relação ao etanol. A combinação SA com o ácido docosaexaenóico (DHA) a $100 \mu \mathrm{M}$ diminuiu em 18,6 \% a viabilidade celular comparada ao SA. A associação do SA com EPA a 50 e $100 \mu \mathrm{M}$ aumentou a viabilidade celular em 12,3\% e 8,9\%, respectivamente, comparado ao SA. O SA associado aos AG $\omega-6$ (LA e $\gamma \mathrm{A}$, a 50 e $100 \mu \mathrm{M})$ aumentou o número de células viáveis em $20 \%$ comparado ao SA (Figura 3). A viabilidade celular foi reduzida em 24 horas pelo AG esteárico em $8,9 \%$ a $200 \mu \mathrm{M}$ e $11,4 \%$ a $250 \mu \mathrm{M}$, em relação ao veículo (etanol) (Inserto da Figura 3).

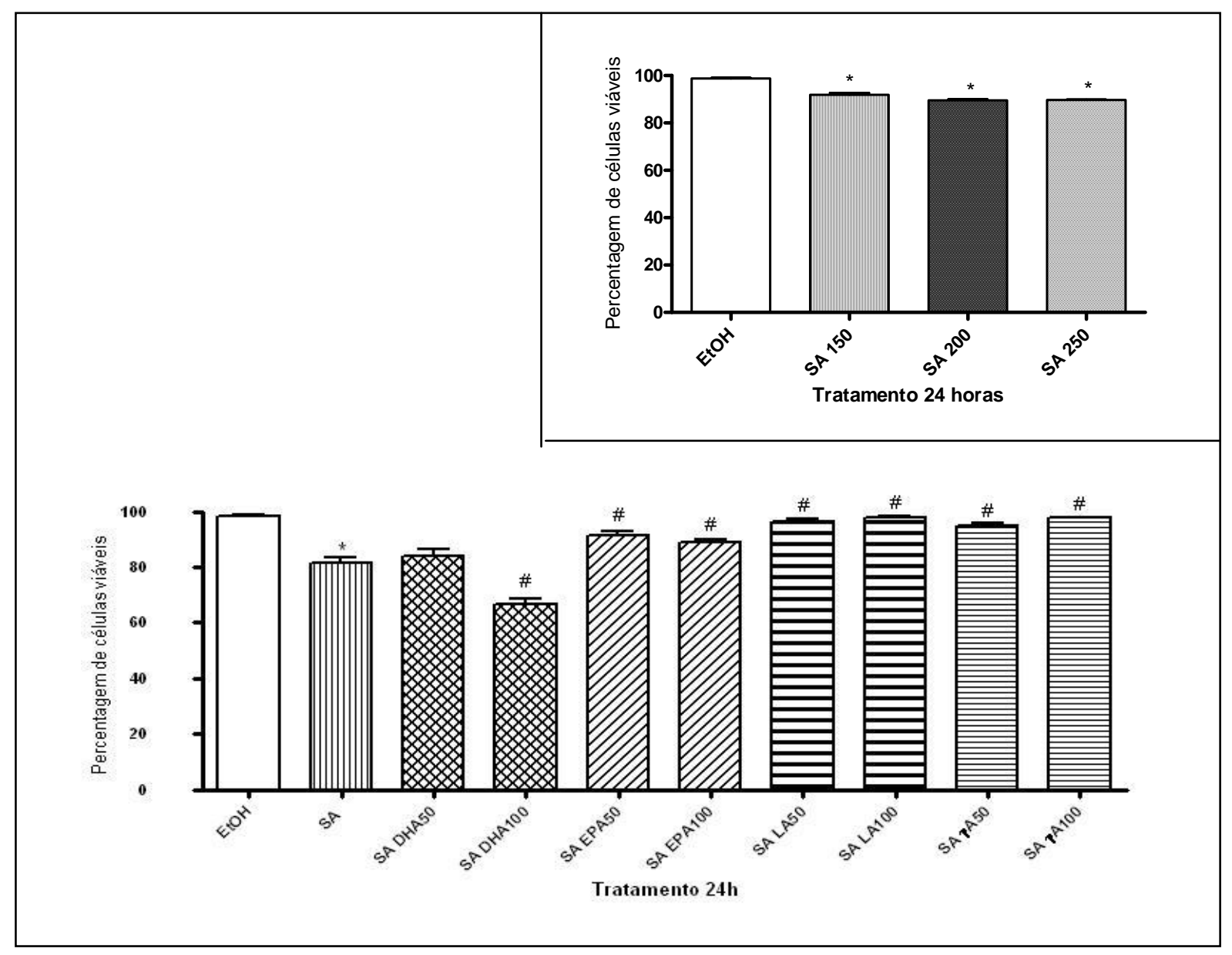

Figura 3. Viabilidade das células endoteliais ECV-304 incubadas por 24 horas com ácido esteárico combinado com ácidos graxos $\omega-3$ e $\omega$-6. Células endoteliais da linhagem ECV304 foram cultivadas com os AG por 24 horas e analisadas por citometria de fluxo. A fluorescência foi mensurada em filtro FL2 (585/42 nm). Estão em inserto os dados do efeito do ácido esteárico nas concentrações de 150, 200 e $250 \mu \mathrm{M}$. Os valores estão apresentados como média $\pm \operatorname{EPM}(n=9)$. * $\mathrm{p}<0,05$ em relação ao etanol; \# $\mathrm{p}<0,05$ em relação ao esteárico. $\mathrm{EtOH}=$ etanol; $\mathrm{SA}=$ ácido esteárico sempre a $150 \mu \mathrm{M} ; \mathrm{DHA}=$ ácido docosaexaenóico; $\mathrm{EPA}=$ ácido eicosapentaenóico; $\mathrm{LA}=$ ácido linoléico; $\gamma \mathrm{A}=$ ácido $\gamma$ linolênico; todos a 50 ou $100 \mu \mathrm{M}$ como indicado. 
O tratamento com SA a $150 \mu \mathrm{M}$ por 24 horas aumentou a fragmentação de DNA das células ECV-304 em 17,9 vezes comparado ao veículo (etanol). Os AG poliinsaturados $\omega-3$ (DHA e EPA) não alteraram o efeito do SA. Entretanto, os AG poliinsaturados $\omega-6$ (LA e $\gamma \mathrm{A}$ ) reduziram significativamente o número de células com fragmentação de DNA induzido pelo tratamento com SA. A redução de células com fragmentação de DNA pelos AG $\omega-6$ foi de 35,7 $\%$ e $79 \%$ para o LA a 50 e $100 \mu \mathrm{M}$, respectivamente, e de $35 \%$ e $46,5 \%$ para o $\gamma \mathrm{A}$ a 50 e 100 $\mu \mathrm{M}$, respectivamente (Figura 4). O ácido esteárico aumentou a fragmentação de DNA em 24 horas em 3,5 vezes a $200 \mu \mathrm{M}$ e em 4 vezes a $250 \mu \mathrm{M}$, em relação ao veículo (Inserto da Figura 4).

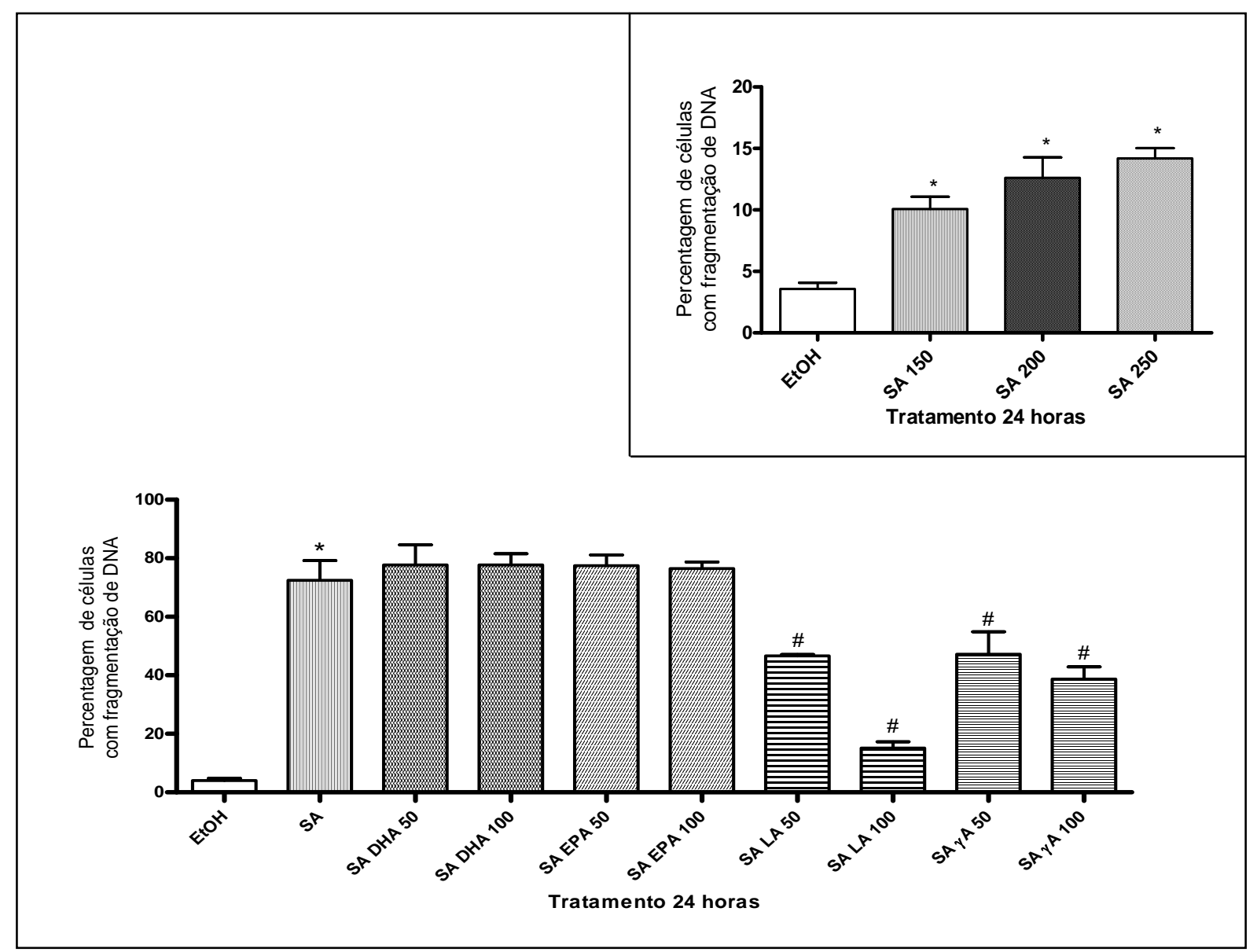

Figura 4. Fragmentação de DNA em células endoteliais ECV-304 incubadas por 24 horas com ácido esteárico combinado com os ácidos graxos $\omega-3$ e $\omega$-6. Células endoteliais da linhagem ECV-304 foram cultivadas com os AG por 24 horas e analisadas por citometria de fluxo. A fluorescência foi mensurada em filtro FL2 (585/42 nm). Estão em inserto os dados do efeito do ácido esteárico nas concentrações de 150, 200 e $250 \mu \mathrm{M}$. Os valores estão apresentados como média $\pm \operatorname{EPM}(\mathrm{n}=9)$. $* \mathrm{p}<0,05$ em relação ao etanol; \# $\mathrm{p}<0,05$ em relação ao esteárico. $\mathrm{EtOH}=$ etanol; $\mathrm{SA}=$ ácido esteárico sempre a $150 \mu \mathrm{M} ; \mathrm{DHA}=$ ácido docosaexaenóico; $\mathrm{EPA}=$ ácido eicosapentaenóico; $\mathrm{LA}=$ ácido linoléico; $\gamma \mathrm{A}=$ ácido $\gamma$ linolênico; todos a 50 ou $100 \mu \mathrm{M}$ como indicado. 
O SA não alterou o conteúdo de óxido nítrico em 1 hora de tratamento comparado ao veículo. A combinação com DHA a $50 \mu \mathrm{M}$ diminuiu em $58 \%$ e com EPA a 50 e $100 \mu \mathrm{M}$ diminuiu em $78,4 \%$ e $50 \%$, respectivamente, o conteúdo de NO comparado ao SA. O SA a $150 \mu \mathrm{M}$ associado ao $\omega-6 \mathrm{LA}$ a $50 \mu \mathrm{M}$ diminuiu em $27 \%$ e com o $\gamma \mathrm{A}$ a 50 e $100 \mu \mathrm{M}$ diminuiu em 25,5 \% e 60,5\%, respectivamente, o conteúdo de NO em relação ao SA. Somente a combinação do SA com LA a $100 \mu \mathrm{M}$ levou a um aumento de $40 \%$ em relação ao SA (Figura 5). O ácido esteárico a $150 \mu \mathrm{M}$ e $200 \mu \mathrm{M}$ não reduziu o conteúdo intracelular de óxido nítrico em 24 horas, mas a $250 \mu \mathrm{M}$ aumentou em $60 \%$ em relação ao etanol (Inserto da Figura 5). 


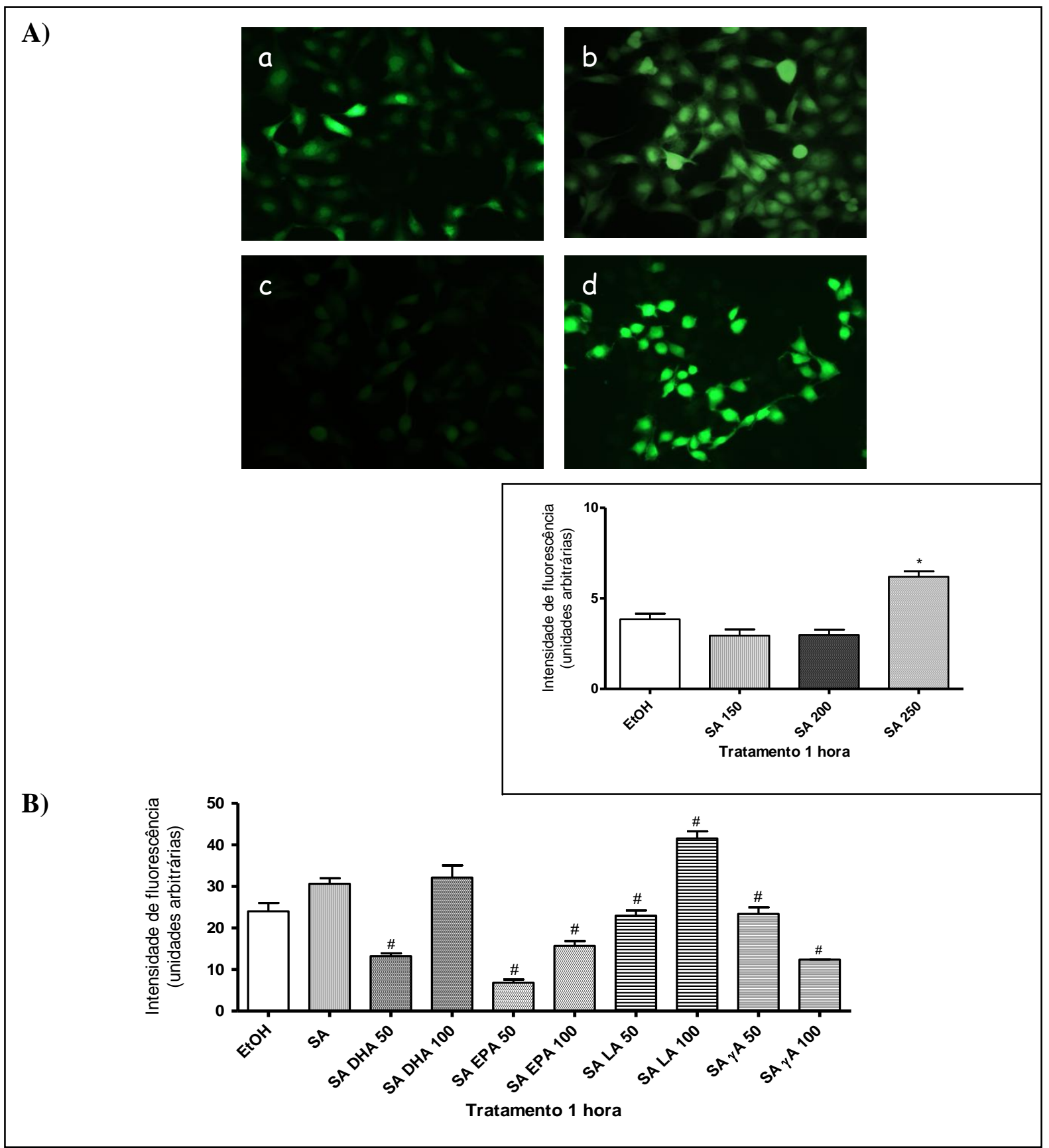

Figura 5. Intensidade de fluorescência referente ao conteúdo intracelular de óxido nítrico de células endoteliais ECV-304 incubadas por 1 hora com ácido esteárico combinado com os ácidos graxos $\boldsymbol{\omega}-\mathbf{3}$ e $\boldsymbol{\omega}$-6. Células endoteliais da linhagem ECV-304 foram cultivadas com uma sonda fluorescente (DAF-FM/DA) por 30 minutos e em seguida tratadas com os AG por 1 hora e analisadas por microscopia de fluorescência para determinação do conteúdo intracelular de NO utilizando o filtro $520 / 450 \mathrm{~nm}$. (A) As fotos ilustram os resultados mais significativos; a. Etanol; b. ácido esteárico $150 \mu \mathrm{M}$; c. ácido esteárico $150 \mu \mathrm{M}+$ ácido eicosapentaenóico $50 \mu \mathrm{M}$; d. ácido esteárico $150 \mu \mathrm{M}+$ ácido linoléico 100 $\mu \mathrm{M}$. Estão em inserto os dados do efeito do ácido esteárico nas concentrações de 150, $200 \mathrm{e}$ $250 \mu \mathrm{M}$. (B) $\mathrm{O}$ gráfico mostra os resultados expressos em média \pm EPM de 3 experimentos realizados em duplicata. * $\mathrm{p}<0,05$ em relação ao etanol; \# $\mathrm{p}<0,05 \mathrm{em}$ relação ao esteárico. EtOH = etanol; SA = ácido esteárico sempre a $150 \mu \mathrm{M}$; DHA = ácido docosaexaenóico; $\mathrm{EPA}=$ ácido eicosapentaenóico; $\mathrm{LA}=$ ácido linoléico; $\gamma \mathrm{A}=$ ácido $\gamma$ linolênico; todos a 50 ou $100 \mu \mathrm{M}$ como indicado. 
Utilizou-se como controle negativo um inibidor não seletivo da enzima óxido nítrico sintase (NOS), o L-Nitro-Arginina-Metil-Ester (L-NAME), e não foi obtida fluorescência, confirmando assim a especificidade da determinação do NO (Figura 6).


Figura 6. Intensidade de fluorescência referente ao conteúdo de óxido nítrico intracelular em células endoteliais ECV-304 incubadas por 1 hora com ácido esteárico e com o inibidor (L-NAME) da enzima óxido nítrico sintase (NOS). Células endoteliais da linhagem ECV-304 foram cultivadas com uma sonda fluorescente (DAF-FM/DA) por 30 minutos e em seguida foi adicionado um inibidor não seletivo da NOS (L-NAME) a 300 $\mu \mathrm{M}$ por 30 minutos. Posteriormente, as células foram tratadas com o ácido esteárico e com L-NAME por 1 hora e analisadas por microscopia de fluorescência para determinação do conteúdo intracelular de NO utilizando o filtro $520 / 450 \mathrm{~nm}$. As fotos ilustram os resultados mais significativos; a. ácido esteárico $150 \mu \mathrm{M}$; b. ácido esteárico $150 \mu \mathrm{M}+$ L-NAME. 


\subsubsection{Produção de ERO}

Os valores do conteúdo de ERO nos tratamentos com AG mostrados na Figura 7B foram subtraídos dos valores obtidos com etanol usado como veículo. A produção de espécies reativas de oxigênio foi aumentada em 2,2 vezes pelo tratamento com SA em relação ao etanol. A associação do SA com DHA, EPA e ácido $\gamma$-linolênico $(\gamma \mathrm{A})$ a $50 \mu \mathrm{M}$ não alterou a produção de ERO em relação ao SA. Entretanto, o SA associado ao DHA, EPA e $\gamma$ A a 100 $\mu \mathrm{M}$ diminuiu em aproximadamente $20 \%$ a produção de ERO em relação ao SA. O SA associado ao LA a 50 e $100 \mu \mathrm{M}$ diminuiu em $50 \%$ e $67 \%$, respectivamente, a produção de ERO em relação ao SA (Figura 7). O ácido esteárico a 150, 200 e $250 \mu \mathrm{M}$ aumentou a produção de ERO em células endoteliais em cerca de 2 vezes em relação ao veículo (etanol), sem diferença significativa entre as concentrações (Inserto da Figura 7). 
A)

B)


Figura 7. Intensidade de fluorescência referente à produção de espécies reativas de oxigênio por células endoteliais ECV-304 incubadas por 1 hora com ácido esteárico combinado com ácidos graxos $\omega$-3 e $\boldsymbol{\omega}$-6. Células endoteliais da linhagem ECV-304 foram cultivadas com os AG por 30 minutos e em seguida com o fluoróforo hidroetidina por mais 30 minutos. Posteriormente, as células foram analisadas em microscopia de fluorescência para determinação da produção de ânion superóxido com o filtro 590/46 nm. O gráfico mostra o valor da produção de ERO induzida por AG subtraído dos valores obrtidos com etanol. (A) As fotos ilustram os resultados mais significativos; a. Etanol; b. ácido esteárico; c. ácido esteárico + EPA $100 \mu \mathrm{M}$; d. ácido esteárico + ácido linoléico $100 \mu \mathrm{M}$. Estão em inserto os dados do efeito do ácido esteárico nas concentrações de 150, 200 e $250 \mu \mathrm{M}$. (B) Os resultados estão expressos em média \pm EPM de 3 experimentos realizados em duplicata. $* \mathrm{p}<0,05$ em relação ao etanol; \# $\mathrm{p}<0,05$ em relação ao ácido esteárico. $\mathrm{EtOH}=$ etanol; $\mathrm{SA}=$ ácido esteárico sempre a $150 \mu \mathrm{M}$; DHA = ácido docosaexaenóico; EPA = ácido eicosapentaenóico; LA = ácido linoléico; $\gamma \mathrm{A}=$ ácido $\gamma$-linolênico; todos a 50 ou $100 \mu \mathrm{M}$ como indicado. 


\subsection{Efeito da combinação do ácido oléico com os ácidos graxos $\omega$-3 e $\omega$-6 sobre as células endoteliais ECV-304}

\subsubsection{Morte celular}

No tratamento por 6 horas, o ácido oléico $(\mathrm{OA})$ a $300 \mu \mathrm{M}$ e sua associação aos $\mathrm{AG} \omega$ 3 não alteraram a viabilidade celular. No entanto, a combinação do OA com os AG $\omega-6$ reduziu a porcentagem de células viáveis em relação ao OA em 49,3 \% e 57,4 \% para o LA a 50 e $100 \mu \mathrm{M}$, respectivamente, e em 51,58\% para o $\gamma \mathrm{A}$ a $100 \mu \mathrm{M}$ (Figura 8).

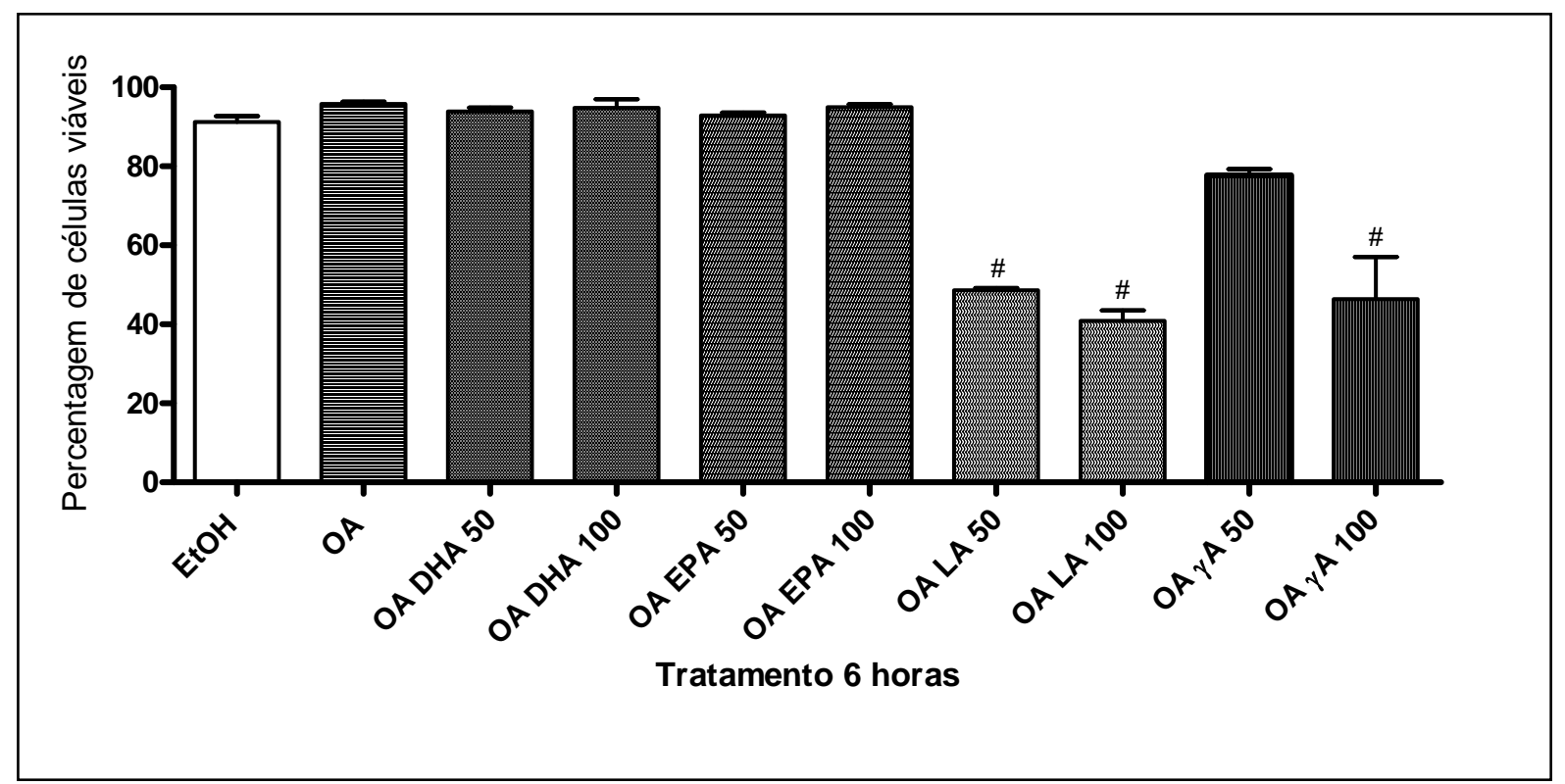

Figura 8. Viabilidade das células endoteliais ECV-304 incubadas por 6 horas com o ácido oléico combinado com os ácidos graxos $\omega$-3 e $\omega$-6. Células endoteliais da linhagem ECV-304 foram cultivadas com os AG por 6 horas e analisados por citometria de fluxo. A fluorescência foi mensurada em filtro FL2 $(585 / 42 \mathrm{~nm})$. Os valores estão apresentados como média $\pm \operatorname{EPM}(n=9)$. \# p $<0,05$ em relação ao ácido oléico. EtOH = etanol; $\mathrm{OA}=$ ácido oléico sempre a $300 \mu \mathrm{M}$; DHA = ácido docosaexaenóico; $\mathrm{EPA}=$ ácido eicosapentaenóico; LA = ácido linoléico; $\gamma \mathrm{A}=$ ácido $\gamma$-linolênico; todos a 50 ou $100 \mu \mathrm{M}$ como indicado. 
O OA a $300 \mu \mathrm{M}$ e sua associação aos AG $\omega$-3 não causaram fragmentação de DNA nas células endoteliais ECV-304. Em contrapartida, a combinação do OA com os AG $\omega-6$ aumentou a fragmentação de DNA em relação ao OA em 7,7 e 16,3 vezes para o LA a 50 e $100 \mu \mathrm{M}$, respectivamente; e em 5 e 15,6 vezes para o $\gamma \mathrm{A}$ a 50 e $100 \mu \mathrm{M}$, respectivamente (Figura 9).

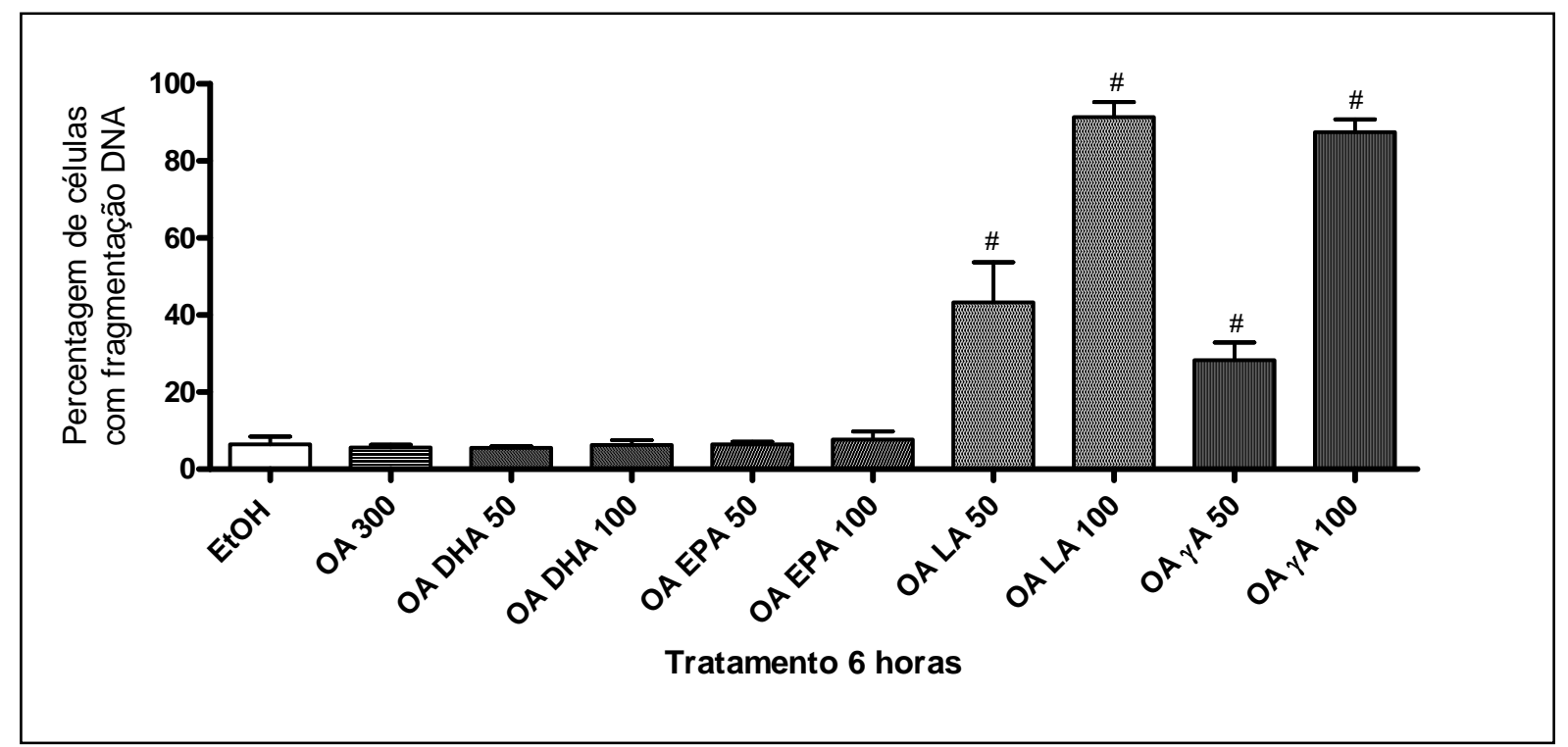

Figura 9. Fragmentação de DNA nas células endoteliais ECV-304 incubadas por 6 horas com o ácido oléico combinado com os ácidos graxos $\omega$-3 e $\omega$-6. Células endoteliais da linhagem ECV-304 foram cultivadas com os AG por 6 horas e analisadas por citometria de fluxo. A fluorescência foi mensurada em filtro FL2 $(585 / 42 \mathrm{~nm})$. Os valores estão apresentados como média $\pm \mathrm{EPM}(\mathrm{N}=9)$. \# $\mathrm{p}<0,05$ em relação ao ácido oléico. $\mathrm{EtOH}=$ etanol; $\mathrm{OA}=$ ácido oléico sempre a $300 \mu \mathrm{M}$; DHA = ácido docosaexaenóico; EPA = ácido eicosapentaenóico; LA = ácido linoléico; $\gamma \mathrm{A}=$ ácido $\gamma$-linolênico; todos a $50 \mathrm{ou}$ $100 \mu \mathrm{M}$ como indicado. 
No tratamento por 24 horas, o OA a $300 \mu \mathrm{M}$ não causou perda de integridade de membrana. A associação do OA com os AG $\omega-3$ e $\omega-6$ diminuiu a viabilidade das células endoteliais ECV-304 em relação ao OA em: 87,2 \% e 91,32 \% para o DHA; 81,3 \% e 86,5 \% para o EPA; 76,8 \% e 77,11\% para o LA; 75,2 \% e 82,52 \% para o $\gamma \mathrm{A}$, todos a 50 e $100 \mu \mathrm{M}$, respectivamente (Figura 10). O ácido oléico a 350 e $400 \mu \mathrm{M}$ não alterou a integridade da membrana de células endoteliais ECV-304 em 24 horas de tratamento (Inserto da Figura 10).

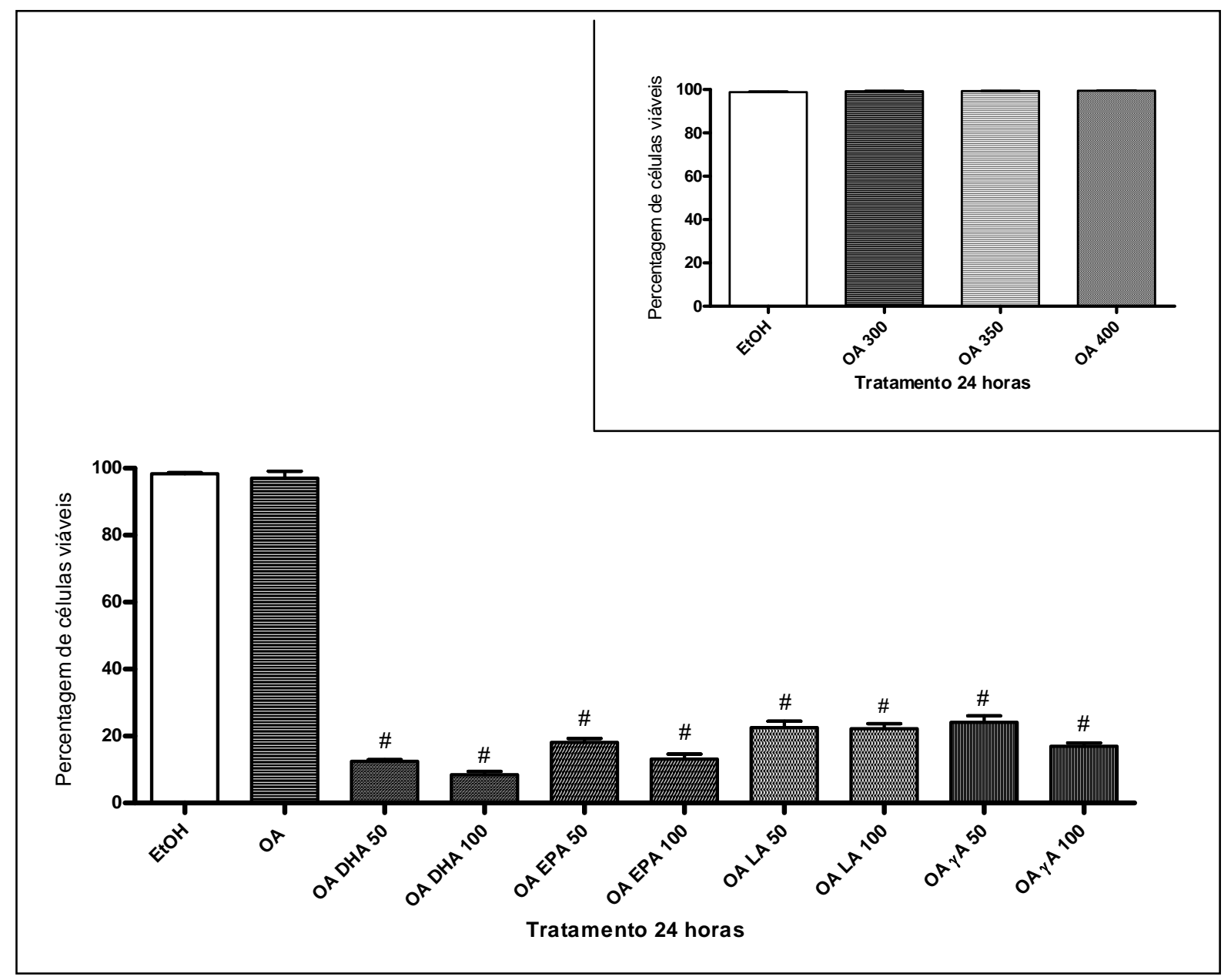

Figura 10. Viabilidade das células endoteliais ECV-304 incubadas por 24 horas com o ácido oléico combinado com os ácidos graxos $\omega$-3 e $\omega$-6. Células endoteliais da linhagem ECV-304 foram cultivadas com os AG por 24 horas e analisadas por citometria de fluxo. A fluorescência foi mensurada em filtro FL2 (585/42 nm). Estão em inserto os dados do efeito do ácido oléico nas concentrações de 300, 350 e $400 \mu \mathrm{M}$. Os valores estão apresentados como média $\pm \mathrm{EPM}(\mathrm{N}=9)$. \# $\mathrm{p}<0,05$ em relação ao ácido oléico. $\mathrm{EtOH}=$ etanol; $\mathrm{OA}=$ ácido oléico sempre a $300 \mu \mathrm{M}$; DHA = ácido docosaexaenóico; EPA = ácido eicosapentaenóico; $\mathrm{LA}=$ ácido linoléico; $\gamma \mathrm{A}=$ ácido $\gamma$-linolênico; todos a $50 \mathrm{ou}$ $100 \mu \mathrm{M}$ como indicado. 
O tratamento por 24 horas com o OA a $300 \mu \mathrm{M}$ aumentou a fragmentação de DNA das células endoteliais ECV-304 em 5 vezes em relação ao veículo (etanol). A combinação com os AG $\omega$-3 e $\omega$-6 aumentou a fragmentação de DNA em relação ao OA em: 2,4 e 2,5 vezes para o DHA; 3,7 e 3,3 vezes para o LA e o $\gamma \mathrm{A}$, todos a 50 e $100 \mu \mathrm{M}$, respectivamente, e 3,2 vezes para o EPA a $50 \mu \mathrm{M}$ (Figura 11). Em contrapartida, o ácido oléico aumentou a fragmentação de DNA em 5 vezes a $300 \mu \mathrm{M}, 7,8$ vezes a $350 \mu \mathrm{M}$ e em 9,5 vezes a $350 \mu \mathrm{M}$, em relação ao veículo (etanol) (Inserto da Figura 11).



Figura 11. Fragmentação de DNA nas células endoteliais ECV-304 incubadas por 24 horas com o ácido oléico combinado com ácidos graxos $\omega-3$ e $\omega$-6. Células endoteliais da linhagem ECV-304 foram cultivadas com os AG por 24 horas e analisadas por citometria de fluxo. A fluorescência foi mensurada em filtro FL2 $(585 / 42 \mathrm{~nm})$. Estão em inserto os dados do efeito do ácido oléico nas concentrações de 300, 350 e $400 \mu \mathrm{M}$. Os valores estão apresentados como média \pm EPM $(\mathrm{N}=9) . * \mathrm{p}<0,05$ em relação ao etanol; \# $\mathrm{p}<0,05$ em relação ao ácido oléico. EtOH = etanol; $\mathrm{OA}=$ ácido oléico sempre a $300 \mu \mathrm{M}$; DHA = ácido docosaexaenóico; $\mathrm{EPA}=$ ácido eicosapentaenóico; $\mathrm{LA}=$ ácido linoléico; $\gamma \mathrm{A}=$ ácido $\gamma$-linolênico; todos a 50 ou $100 \mu \mathrm{M}$ como indicado. 
O período de incubação foi reduzido para duas horas com o objetivo de avaliar a viabilidade das células nas combinações de ácidos graxos que causaram morte celular com 6 e 24 horas de tratamento. Não houve diferença significativa na viabilidade celular e fragmentação de DNA entre os tratamentos no período de duas horas (Figuras 12 e 13).

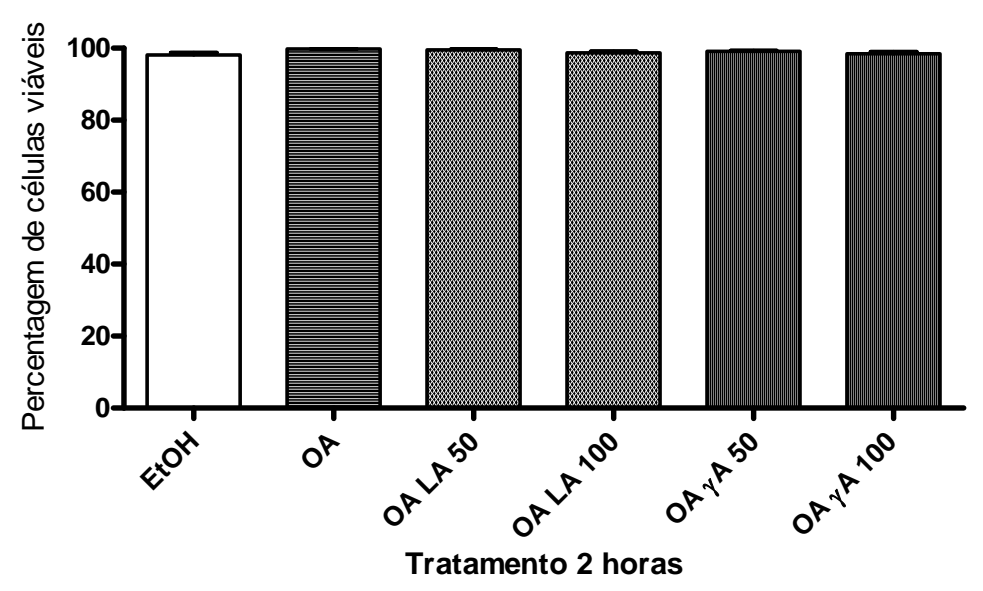

Figura 12. Viabilidade das células endoteliais ECV-304 incubadas por 2 horas com o ácido oléico combinado com os ácidos graxos $\boldsymbol{\omega}-\mathbf{6}$. Células endoteliais da linhagem ECV-304 foram cultivadas com os AG por 2 horas e analisadas por citometria de fluxo. A fluorescência foi mensurada em filtro FL2 $(585 / 42 \mathrm{~nm})$. Os valores estão apresentados como média \pm $\mathrm{EPM}(\mathrm{N}=6) . \mathrm{EtOH}=$ etanol; $\mathrm{OA}=$ ácido oléico sempre a $300 \mu \mathrm{M} ; \mathrm{LA}=$ ácido linoléico; $\gamma \mathrm{A}$ = ácido $\gamma$-linolênico; todos a 50 ou $100 \mu \mathrm{M}$ como indicado.

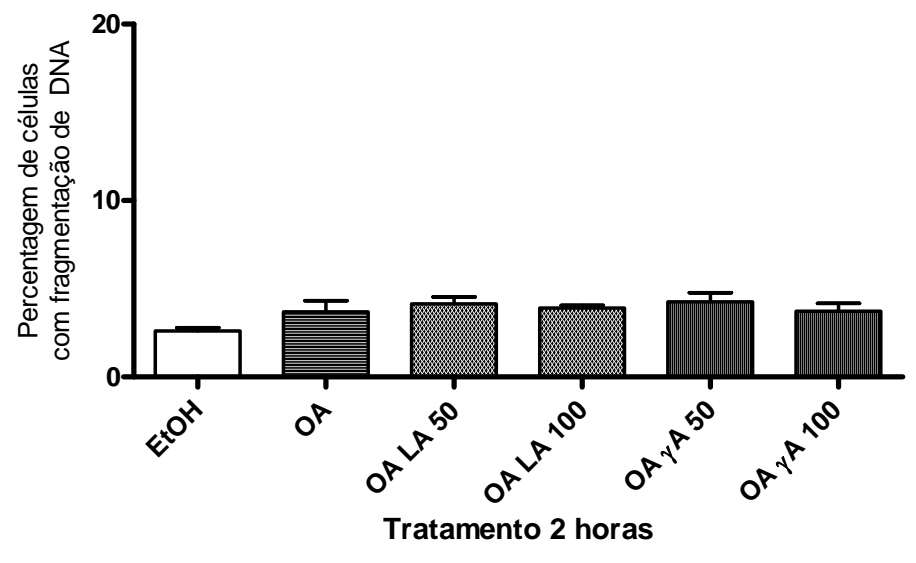

Figura 13. Fragmentação de DNA em células endoteliais ECV-304 incubadas por 2 horas com o ácido oléico combinado com ácidos graxos $\boldsymbol{\omega}$-6. Células endoteliais da linhagem ECV304 foram cultivadas com os AG por 2 horas e analisadas por citometria de fluxo. A fluorescência foi mensurada em filtro FL2 $(585 / 42 \mathrm{~nm})$. Os valores estão apresentados como média $\pm \mathrm{EPM}(\mathrm{N}=6) . \mathrm{EtOH}=$ etanol; $\mathrm{OA}=$ ácido oléico sempre a $300 \mu \mathrm{M} ; \mathrm{LA}=$ ácido linoléico; $\gamma \mathrm{A}=$ ácido $\gamma$-linolênico; todos a 50 ou $100 \mu \mathrm{M}$ como indicado. 
O OA a $300 \mu \mathrm{M}$ diminuiu o conteúdo intracelular de óxido nítrico nas células endoteliais ECV-304 em 57,2 \% em relação ao veículo (etanol). A associação do OA aos AG $\omega-3$ e $\omega-6$ não alterou o efeito do OA no conteúdo de NO (Figura 14). Na concentração de $350 \mu \mathrm{M}$, o ácido oléico não alterou o conteúdo intracelular de NO em relação ao veículo, mas a $400 \mu \mathrm{M}$ aumentou em 2 vezes (Inserto da Figura 14). 
A)
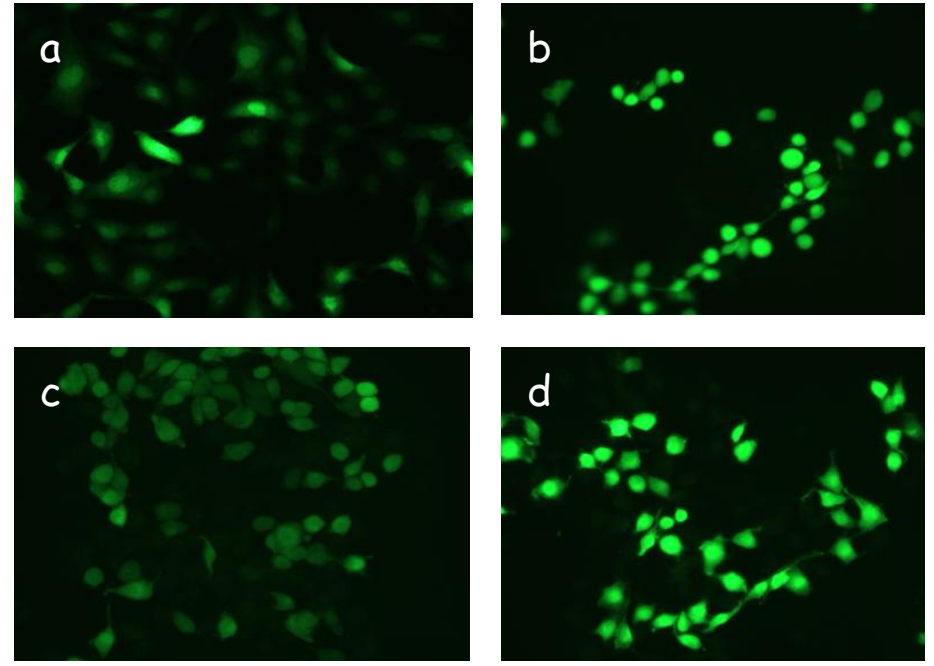

B)
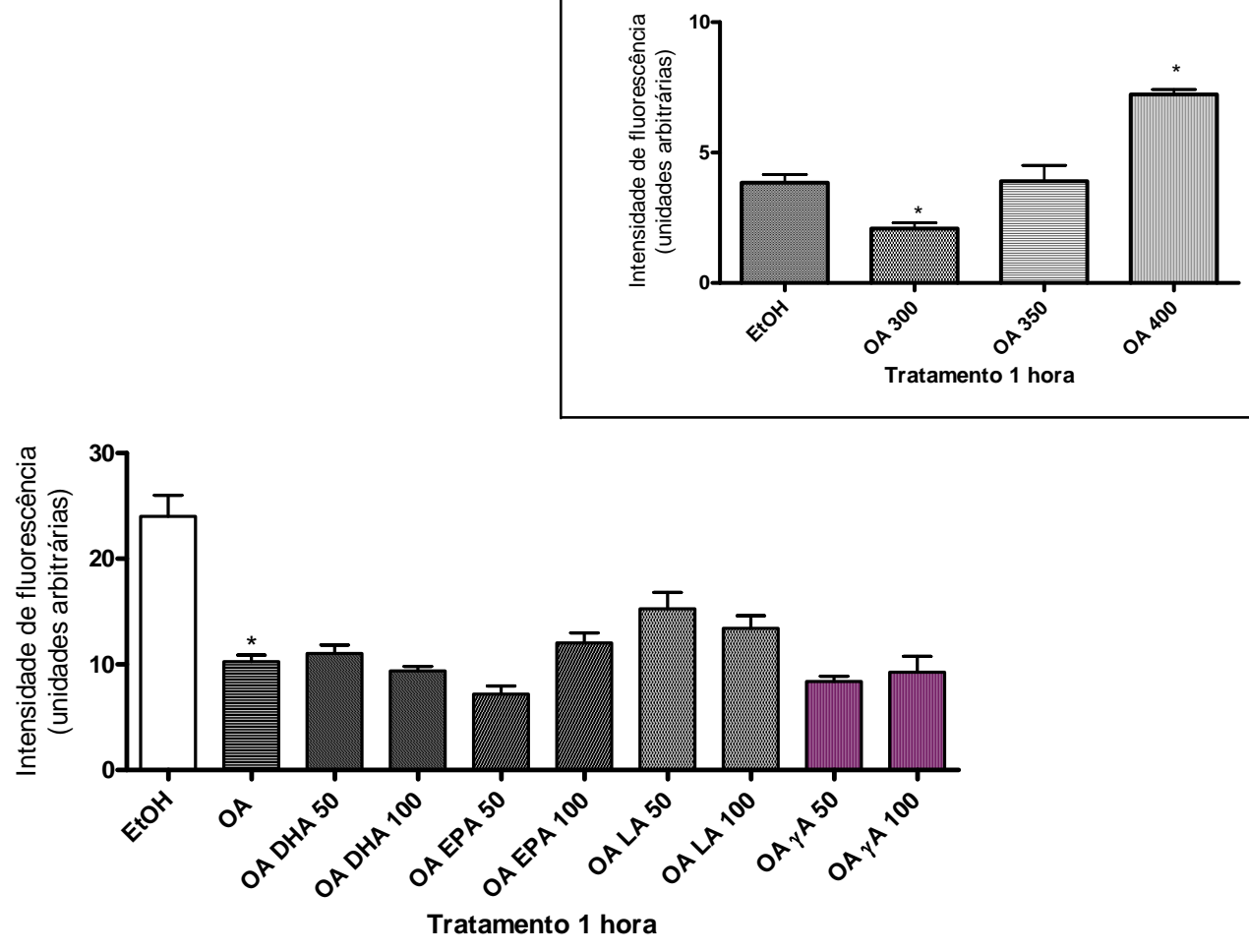

Figura 14. Intensidade de fluorescência referente ao conteúdo intracelular de óxido nítrico nas células endoteliais ECV-304 incubadas por 1 hora com o ácido oléico combinado com os ácidos graxos $\boldsymbol{\omega}-\mathbf{3}$ e $\boldsymbol{\omega}$-6. Células endoteliais da linhagem ECV-304 foram incubadas com uma sonda fluorescente (DAF-FM/DA) por 30 minutos e em seguida tratadas com os AG por 1 hora e analisadas por microscopia de fluorescência utilizando o filtro 520/450 nm. (A) As fotos ilustram os resultados mais significativos; a. Etanol; b. Oléico $300 \mu \mathrm{M}$; c. Oléico $300 \mu \mathrm{M}+$ EPA $50 \mu \mathrm{M}$; d. Oléico $300 \mu \mathrm{M}+$ Linoléico $50 \mu \mathrm{M}$. Estão em inserto os dados do efeito do ácido oléico nas concentrações de 300, 350 e $400 \mu \mathrm{M}$. (B) Os resultados estão expressos em média \pm EPM de 3 experimentos realizados em duplicata; * $\mathrm{p}<0,05 \mathrm{em}$ relação ao etanol. $\mathrm{EtOH}=$ etanol; $\mathrm{OA}=$ ácido oléico sempre a $300 \mu \mathrm{M}$; DHA = ácido docosaexaenóico; $\mathrm{EPA}=$ ácido eicosapentaenóico; $\mathrm{LA}=$ ácido linoléico; $\gamma \mathrm{A}=$ ácido $\gamma$ linolênico; todos a 50 ou $100 \mu \mathrm{M}$ como indicado. 
Os valores do conteúdo de ERO nos tratamentos com AG mostrados na Figura 15B foram subtraídos dos valores obtidos pelo veículo. A produção de ERO não foi alterada pelo OA e suas combinações (Figura 15). O ácido oléico a $350 \mu \mathrm{M}$ não alterou a produção de ERO, mas a $400 \mu \mathrm{M}$ aumentou em $50 \%$ em relação ao veículo (etanol) (Inserto da Figura 15). 




Figura 15. Intensidade de fluorescência referente à produção de espécies reativas de oxigênio por células endoteliais ECV-304 incubadas por 1 hora com o ácido oléico combinado com ácidos graxos $\omega-3$ e $\boldsymbol{\omega}$-6. Células endoteliais da linhagem ECV-304 foram cultivadas com os AG por 30 minutos e em seguida com o fluoróforo hidroetidina por mais 30 minutos. Posteriormente, as células foram analisadas em microscopia de fluorescência para determinação da produção de ânion superóxido utilizando o filtro $590 / 46 \mathrm{~nm}$. O gráfico mostra o valor da produção de ERO induzida por AG subtraído dos valores obrtidos com etanol. (A) As fotos ilustram os resultados mais significativos; a. Etanol; b. Oléico $300 \mu \mathrm{M}$; c. Oléico $300 \mu \mathrm{M}+$ EPA $100 \mu \mathrm{M}$; d. Oléico $300 \mu \mathrm{M}+$ Linoléico $100 \mu \mathrm{M}$. Estão em inserto os dados do efeito do ácido oléico nas concentrações de 300, 350 e $400 \mu \mathrm{M}$. (B) Os resultados estão expressos como média \pm EPM de 3 experimentos realizados em duplicata; * $\mathrm{p}<0,05$ em relação ao etanol. EtOH $=$ etanol; OA = ácido oléico sempre a $300 \mu \mathrm{M} ;$ DHA = ácido docosaexaenóico; EPA = ácido eicosapentaenóico; LA = ácido linoléico; $\gamma \mathrm{A}$ = ácido $\gamma$-linolênico; todos a 50 ou $100 \mu \mathrm{M}$ como indicado. 


\section{DISCUSSÃO}




\subsection{Efeitos do ácido esteárico combinado com ácidos graxos $\omega$-3 e $\omega$-6 sobre a morte de células endoteliais ECV-304}

Disfunção endotelial, aterosclerose e doenças cardiovasculares são mediadas por fatores como angiotensina II, citocinas pró-inflamatórias e ácidos graxos livres. Ácidos graxos apresentam efeitos diferentes e algumas vezes opostos no endotélio vascular. Nesse estudo, o ácido esteárico aumentou a morte de células endoteliais ECV-304 e a produção de ERO sem alterar o conteúdo intracelular de NO. Ácidos graxos poliinsaturados $\omega-3$ (DHA e EPA) não protegeram as células endoteliais da morte induzida pelo ácido esteárico, diminuíram a produção de ERO e o conteúdo de NO. Em contrapartida, os ácidos graxos $\omega-6$ (LA e $\gamma \mathrm{A})$ reduziram a morte celular induzida pelo ácido esteárico, diminuíram a produção de ERO e o ácido linoléico levou a um aumento no conteúdo intracelular de NO.

A morte celular induzida pelo ácido esteárico foi também observada em outros estudos (ARTWOHL et al., 2004; RIOUX; LEGRAND, 2007; HARVEY et al., 2009). Artwohl et al. (2008) mostraram que o ácido esteárico causa apoptose em várias linhagens de células endoteliais (HUVEC, HAEC, EPC e HREC). A apoptose de células endoteliais pode afetar diretamente a trombogenicidade pela liberação de micropartículas apoptóticas na corrente sanguínea (BLANN et al., 2009). Concentrações elevadas de células endoteliais apoptóticas são observadas em pacientes com infarto do miocárdio e angina instável (CHIRONI et al., 2009). Assim, a morte de células endoteliais induzida por ácidos graxos é um processo importante na disfunção do endotélio.

Os ácidos graxos $\omega$-3 (DHA e EPA) possuem propriedades anti-inflamatórias e antiapoptóticas (MASSARO et al., 2008; SUPHIOGLU et al., 2010). Artwohl et al. (2008) avaliaram os efeitos de diferentes ácidos graxos na apoptose de células endoteliais de tecidos envolvidos em complicações vasculares diabéticas e observaram que o EPA, em baixas concentrações, inibe a apoptose induzida pelo ácido esteárico em HUVEC, HAEC, EPC e HREC, e reduz também a rigidez de membrana induzida pelo ácido esteárico em células HUVEC. Além disso, AG $\omega-3$ podem modular a transcrição de genes pró-inflamatórios e fatores de crescimento (PRICE et al., 2000). Em nosso estudo, não houve redução da morte de células endoteliais ECV-304 induzida pelo ácido esteárico nos tratamentos com os AG $\omega$-3 EPA e DHA. O ácido esteárico aumentou a morte de celular de forma dose-dependente. A morte celular observada na combinação do ácido esteárico com o DHA poderia ser atribuída a alta sobrecarga de ácidos graxos $(200$ e $250 \mu \mathrm{M})$, mas a associação ao EPA reduziu o efeito 
do SA. Assim, a combinação de ácidos graxos foi mais importante que a concentração final no processo de morte celular. Os AG $\omega-3$ EPA e DHA promovem efeitos benéficos de maneira diferenciada (MORI et al., 2000; MORI et al., 2003; GORJÃO et al., 2009). Em cultura de células endoteliais pré-incubadas por 24 horas com esses AG (WEBER et al., 1995), DHA (20 $\mu \mathrm{M})$, mas não EPA, inibiu a expressão de VCAM-1 reduzindo o conteúdo de RNAm dessa molécula de adesão.

Dietas ricas em AG $\omega-6$ aceleram os processos aterogênicos e diabetogênicos (SCHMITZ; ECKER, 2008). Entretanto, em alguns estudos foi demonstrado que os AG $\omega-6$ reduzem o risco de doenças cardiovasculares (DCV) (HARRIS et al., 2007). Nesse estudo, observamos que os AG $\omega$-6 linoléico e gama-linolênico protegem as células endoteliais da morte induzida pelo ácido esteárico. Esrey et al. (1996) e Pietinen et al. (1997) não encontraram associação significativa entre a ingestão (ou conteúdos teciduais) de LA (ou AG $\omega$-6) e o risco de doenças cardiovasculares. Também, não foi relatada diferença entre ingestão de LA e infarto do miocárdio (SAUVAGET et al., 2004).

O óxido nítrico é um agente vasodilatador e inibe a síntese de citocinas próinflamatórias, quimiocinas e expressão de moléculas de adesão leucocitária, reduz ativação e agregação de plaquetas e a proliferação da célula muscular vascular lisa (WHITELEY et al., 2009). Wu (2002) e Milkowski et al. (2010) revisaram extensivamente a regulação da produção de óxido nítrico pela dieta. Fatores dietéticos podem ser benéficos para a saúde ou contribuir para a patogênese de doenças crônicas devido a modulação da produção de NO pela iNOS ou eNOS (WU, 2002). Alteração na produção e transporte de óxido nítrico vascular resulta em disfunção endotelial que pode evoluir para doenças cardiovasculares como hipertensão e aterosclerose (CHEN et al., 2008). A proteção contra uma diminuição na produção de NO pela vasculatura pode prevenir o desenvolvimento de doenças vasculares. Por sua vez, danos às células endoteliais podem reduzir ou até mesmo abolir as funções do NO (SIMIONESCU, 2007). Alguns AG (ácido oléico, linoléico e gama-linolênico) diminuem a produção de NO em células endoteliais da artéria pulmonar (PAEC) de maneira dose e tempo dependente (KARMAN et al., 1997). Nesse estudo, o tratamento com SA a $150 \mu \mathrm{M}$ e $200 \mu \mathrm{M}$ não alterou o conteúdo de NO em células endoteliais ECV-304, mas a $250 \mu \mathrm{M}$ ocorreu aumento significativo. Song et al. (2006) mostraram que o ácido esteárico a $600 \mu \mathrm{M}$ não altera a produção de NO em células endoteliais do cordão umbilical humano (HUVEC) em 24 horas. Kuroda et al. (2001) também observaram que o ácido palmítico a $100 \mu \mathrm{M}$ em 1 hora de 
tratamento, outro ácido graxo saturado presente em alta concentração na circulação sanguínea, não afeta a produção de NO em células endoteliais de aorta bovina.

Nós observamos que os AG $\omega-3$, DHA e EPA, a $50 \mu \mathrm{M}$, na presença do SA, reduzem o conteúdo intracelular de NO. Esse resultado pode estar associado com o aumento da morte celular observada nesses tratamentos. Entretanto, AG $\omega-6$ associados ao SA levaram a um aumento no conteúdo intracelular de NO em relação ao tratamento com SA. O aumento ocorreu no tratamento com o ácido linoléico a $50 \mu \mathrm{M}$. Este efeito foi devido à associação dos ácidos graxos, pois a mesma sobrecarga de ácido esteárico (nessa concentração) não alterou o conteúdo intracelular de NO. Esse aumento no conteúdo de NO pode estar associado ao efeito protetor do ácido linoléico na morte de células endoteliais induzida pelo ácido esteárico. Esses dados corroboram com os de Saraswathi et al. (2004). Esses autores mostraram que o ácido linoléico a $90 \mu \mathrm{M}$, por 3 horas de tratamento, aumenta a produção de NO em células endoteliais de pulmão de porco.

Vários tipos de doenças vasculares são associados ao aumento do estresse oxidativo e inativação do NO (LI; FORSTERMANN, 2009). A produção elevada de ERO causa inativação de NO e esse parece ser um processo efetivo na diminuição do conteúdo de NO e aceleração da disfunção endotelial (HIGASHI et al., 2009). A suplementação com antioxidantes enzimáticos ou químicos protege o NO contra o superóxido endógeno e exógeno e melhora a função endotelial (LAURSEN et al., 1997). O aumento da produção de ERO por AG tem sido demonstrado em diferentes tipos celulares como célula muscular vascular lisa (LU et al., 1998), célula muscular esquelética (RACHEK et al., 2006; LAMBERTUCCI et al., 2008), cardiomiócitos (FAUCONNIER et al., 2007), célula tubular proximal (ISHOLA et al., 2006), hepatócitos (SRIVASTAVA et al., 2000), neutrófilos (LEVADA-PIRES et al., 2010), linfócitos (CURY-BOAVENTURA et al., 2005) e adipócitos (GUO et al., 2006). O ácido esteárico causou aumento na produção de ERO nas células endoteliais ECV304 após tratamento por 30 minutos, sem diferença entre as concentrações de 150, 200 e $250 \mu \mathrm{M}$.

A combinação do SA com DHA ou EPA levou a uma redução na produção de ERO. Esse efeito não foi suficiente para impedir as alterações na morte celular e no conteúdo intracelular de NO induzidas pelo ácido esteárico. Nossos resultados corroboram com os observados por Richard et al. (2008). Esses autores observaram menor produção de ERO em células endoteliais de aorta humana tratadas com AG $\omega$-3 em comparação aos tratamentos com ácidos graxos saturado, monoinsaturado e poliinsaturado $\omega-6$, todos a $10 \mu \mathrm{M}$.

Em condições fisiológicas, a produção controlada de ERO contribui na homeostasia vascular. ERO modulam a atividade de moléculas tais como proteínas quinases e canais iônicos, expressão de mediadores pro-inflamatórios, migração celular e apoptose. Maziere et 
al. (1998) compararam os efeitos dos AG $\omega-3$ e $\omega-6$ em células endoteliais. Esses autores observaram que os AG $\omega$-3 diminuem o conteúdo de ácido tiobarbitúrico (TBARs), indicando menor peroxidação lipídica, e produção de ânion superóxido quando comparados aos AG $\omega-6$. Em nosso estudo, os AG $\omega$-6, ácido linoléico e $\gamma$-linolênico a $100 \mu \mathrm{M}$, causaram diminuição na produção de ERO induzida pelo ácido esteárico. Esses resultados não confirmam estudos que indicam que AG poliinsaturados $\omega$-6 tem maior efeito na produção de ânion superóxido que ácidos graxos saturados (SCHONFELD, REISER, 2006, 2007).

Em resumo, AG $\omega$-3 diminuíram o conteúdo intracelular de NO, a produção de ERO e não protegeram células endoteliais ECV-304 da morte induzida pelo ácido esteárico. Em contrapartida, AG $\omega-6$ inibiram a morte celular induzida pelo ácido esteárico, aumentaram o conteúdo intracelular de NO e diminuíram a produção de ERO. Esses resultados são sugestivos de que os AG $\omega-6$ apresentam efeito protetor mais potente que os AG $\omega-3$ nos efeitos causados pelo ácido esteárico em células endoteliais ECV-304. 


\subsection{Efeito do ácido oléico combinado com ácidos graxos $\omega$-3 e $\omega$-6 sobre a morte de células endoteliais ECV-304}

Os efeitos benéficos da dieta Mediterrânea rica em ácido oléico referem-se à diminuição efetiva no risco de DCV (CARLUCCIO et al., 2007). O ácido oléico a 300, 350 e $400 \mu \mathrm{M}$ não causa perda de integridade de membrana em células endoteliais ECV-304 em 24 horas de tratamento. Em contrapartida, ocorre aumento dose-dependente na fragmentação de DNA. Artwohl et al. (2008) mostraram que o ácido oléico não causa apoptose de células endoteliais (HUVEC, HAEC, HREC, EPC) até $300 \mu \mathrm{mol} / \mathrm{L}$. Henning et al. (2001) demonstraram que o ácido oléico não ativa células endoteliais in vitro, confirmando assim os benefícios desse nos primeiros eventos da aterosclerose quando comparado aos outros ácidos graxos.

A associação do OA a $300 \mu \mathrm{M}$ com os AG $\omega-3$ e $\omega-6$ por 24 horas de tratamento aumentou a perda de viabilidade celular e a fragmentação de DNA. O aumento na morte celular observada nos tratamentos com o ácido oléico associados aos AG $\omega$-3 e $\omega$-6 não pode ser atribuído a alta concentração $(200$ e $250 \mu \mathrm{M})$, mas sim à combinação de ácidos graxos, pois o ácido oléico não causou morte celular mesmo em $400 \mu \mathrm{M}$.

Os efeitos benéficos do ácido oléico são controversos. O ácido oléico tem papel importante na prevenção do câncer, mas ainda não é certo se esse é um efeito direto ou secundário do ácido graxo na estabilidade do óleo (prevenindo o estresse oxidativo) (VISIOLI et al., 2002). Embora o ácido oléico esteja presente em alta concentração no óleo de oliva (MENENDEZ et al., 2005), ele é também encontrado em grande quantidade em alimentos fast-food da dieta ocidental em países não-Mediterrâneos (VISIOLI et al., 2004). Esses países tem alta incidência de doenças cardiovasculares e pode ser atribuído a ingestão concomitante de ácido oléico com outros ácidos graxos.

O OA a $300 \mu \mathrm{M}$ reduziu o conteúdo intracelular de NO nas células endoteliais ECV304 após 1 hora de tratamento, a $350 \mu \mathrm{M}$ não alterou e a $400 \mu \mathrm{M}$ levou à um aumento significativo. Carluccio et al. (1999) mostraram, em experimentos in vitro, que o ácido oléico pode prevenir a ativação endotelial em células HUVEC aumentando a produção de $\mathrm{NO}$ e inibindo a expressão de moléculas de adesão. O conteúdo intracelular de NO em células endoteliais ECV-304 tratadas por 1 hora com OA combinado com os AG $\omega$-3 e $\omega$-6 também foi reduzido e não foi diferente do tratamento com o ácido oléico a $300 \mu \mathrm{M}$. 
O ácido oléico a 300 e $350 \mu \mathrm{M}$ não aumentou a produção de $\mathrm{O}^{-{ }_{2}}$ em células endoteliais ECV-304 com 30 minutos de tratamento, apenas a $400 \mu \mathrm{M}$ causou aumento significativo. A associação do OA com os AG $\omega-3$ e $\omega-6$ não alterou a produção de ERO, o que confirma a importância da combinação dos ácidos graxos e não da concentração final. A oxidação de ácidos graxos causa seqüestro de ERO, reduzindo o seu conteúdo e a ativação do NFkB (THANOS; MANIATIS, 1995; MARUI et al., 1993). Uma dieta rica em óleo de oliva reduz o estresse oxidativo celular, modificando lipoproteínas, reduzindo mediadores inflamatórios e controlando a ativação de genes envolvidos na inflamação, provavelmente via NFאB ou outros fatores de transcrição nuclear (PÉREZ-JIMÉNEZ et al., 2007).

Em resumo, o OA não causou morte celular mesmo em altas concentrações, mas diminuiu o conteúdo de NO sem alterar a produção de ERO. Os AG poliinsaturados $\omega-6$ associados ao OA causaram morte celular sem alterar o efeito do OA no conteúdo de NO e na produção de ERO. Assim, o ácido oléico que apresenta baixo efeito citotóxico, quando associado aos AG poliinsaturados, apresenta citotoxicidade. 


$$
7 \text { CONCLUSÕES }
$$


- Os ácidos graxos poliinsaturados $\omega-6$ protegeram contra a morte de células endoteliais induzida pelo ácido esteárico. Os ácidos graxos $\omega$-3 não apresentaram o mesmo efeito.

- O ácido oléico não é tóxico para as células endoteliais mesmo em altas concentrações. Contudo, quando associado aos AG poliinsaturados (em particular os $\omega-6$ ) apresenta citotoxicidade.

- O efeito dos ácidos graxos poliinsaturados $\omega$-3 sobre o endotélio depende da combinação com outros ácidos graxos; com saturado não parece apresentar efeito citoprotetor.

- O mesmo vale para os ácidos graxos poliinsaturados $\omega-6$, não apresentando citoproteção na associação com monoinsaturado. 


\section{REFERÊTNCIAS}


ABUISSA, H.; O'KEEFE, J. H. JR.; HARRIS, W.; LAVIE, C. J. Autonomic function, omega-3, and cardiovascular risk. Chest, v. 127, n. 4, p. 1088-91, 2005.

AGRICULTURAL RESEARCH SERVICE DATA TABLES - USDA. Intakes of 19 Individual Fatty Acids: Results from the 1994-1996 Continuing Servey of Food Intakes by Individuals, USDA, Beltsville, MD. Disponível em:

http://www.barc.usda.gov/bhnrc/foodsurvey/home.htm. Acesso em: 15 jul. 2009.

AIRD, W. C. Phenotypic heterogeneity of the endothelium: I. Structure, function, and mechanisms. Circ. Res., v. 100, n. 2, p. 158-73, 2007.

ANAND, R. G.; ALKADRI, M.; LAVIE, C. J.; MILANI, R. V. The role of fish oil in arrhythmia prevention. J. Cardiopulm. Rehabil. Prev., v. 28, n. 2, p. 92-8, 2008.

ARTWOHL, M.; LINDENMAIR, A.; SEXL, V.; MAIER, C.; RAINER, G.; FREUDENTHALER, A.; HUTTARY, N. ; WOLZT, M.; NOWOTNY, P.; LUGER, A.; BAUMGARTNER-PARZER, S. M. Different mechanisms of saturated versus polyunsaturated FFA-induced apoptosis in human endothelial cells. J. Lipid. Res., v. 49, n. 12, p. 2627-40, 2008.

ARTWOHL, M.; RODEN, M.; WALDHAUSL, W.; FREUDENTHALER, A.; BAUMGARTNER-PARZER, S. M. Free fatty acids trigger apoptosis and inhibit cell cycle progression in human vascular endothelial cell. FASEB J., v. 18, n. 1, p. 146-8, 2004.

BAEUERLE, P. A.; HENKEL, T. Function and activation of NF-kappa B in the immune system. Annu. Rev. Immunol., v. 12, p. 141-79, 1994.

BARTUS, M.; LOMNICKA, M.; LORKOWSKA, B.; FRANCZYK, M.; KOSTOGRYS, R. B.; PISULEWSKI, P. M.; CHLOPICKI, S. Hypertriglyceridemia but not hypercholesterolemia induces endothelial dysfunction in the rat. Pharmacol. Rep., v. 57, p. 127-37, 2005.

BASU, A.; DEVARAJ, S.; JIALAL, I. Dietary factors that promote or retard inflammation. Arterioscler. Thromb. Vasc. Biol., v. 26, n. 5, p. 995-1001, 2006.

BECKMAN, J. S.; BECKMAN, T. W.; CHEN, J.; MARSHALL, P. A.; FREEMAN, B. A. Apparent hydroxyl radical production by peroxynitrite: implications for endothelial injury from nitric oxide and superoxide. Proc. Nati. Acad. Sci. U.S.A., v. 87, n. 4, p. 1620-4, 1990.

*De acordo com: ASSOCIAÇÃO BRASILEIRA DE NORMAS TÉCNICAS. NBR 6023: Informação e documentação: referências: elaboração. Rio de Janeiro, 2002. 
BEHRENDT, D.; GANZ, P. Endothelial function: from vascular biology to clinical applications. Am. J. Cardiol., supl. 90, p. 40L-48L, 2002.

BERARDI, D. E.; TARBELL, J. M. Stretch and shear interactions affect intercellular junction protein expression and turnover in endothelial cells. Cell. Mol. Bioeng., v. 2, n. 3, p. 320-31, 2009.

BERNAL-MIZRACHI, L.; JY, W.; FIERRO, C.; MACDONOUGH, R.; VELAZQUES, H. A.; PUROW, J.; JIMENEZ, J. J.; HORSTMAN, L. L.; FERREIRA, A.; DE MARCHENA, E.; AHN, Y. S. Endothelial microparticles correlate with high-risk angiographic lesions in acute coronary syndromes. Int. J. Cardiol., v. 97, n. 3, p. 439-46, 2004.

BLANN, A.; SHANTSILA, E.; SHANTSILA, A. Microparticles and arterial disease. Semin. Thromb. Hemost., v. 35, n. 5, p. 488-96, 2009.

BONETTI, P. O.; LERMAN, L. O.; LERMAN, A. Endothelial dysfunction: a marker of atherosclerotic risk. Arterioscler. Thromb. Vasc. Biol., v. 23, p. 168-75, 2003.

BOSELLO, O.; ZAMBONI, M.; ARMELLINI, F.; ZOCCA, I.; BERGAMO ANDREIS, I. A.; SMACCHIA, C.; MILANI, M. P.; COMINACINI, L. Modifications of abdominal fat and hepatic insulin clearance during severe caloric restriction. Ann. Nutr. Metab., v. 34, n. 6, p. 359-65, 1990.

BURNIER, L.; FONTANA, P.; KWAK, B. R.; ANGELILLO-SCHERRER, A. Cell-derived microparticles in haemostasis and vascular medicine. Thromb. Haemost., v. 101, n. 3, p. 439-51, 2009.

CARLUCCIO, M. A.; MASSARO, M.; BONFRATE, C.; SICULELLA, L.; MAFFIA, M.; NICOLARDI, G.; DISTANTE, A.; STORELLI, C.; DE CATERINA, R. Oleic acid inhibits endothelial activation: A direct vascular antiatherogenic mechanism of nutritional component in the mediterranean diet. Arterioscler. Thromb. Vasc. Biol., v. 19, n. 2, p. 220-8, 1999.

CARLUCCIO, M. A.; MASSARO, M.; SCODITTI, E.; DE CATERINA, R. Vasculoprotective potential of olive oil components. Mol. Nutr. Food Res., v. 51, n. 10, p. 1225-34, 2007.

CHEN, C.; CHAI, H.; WANG, X.; JIANG, J.; JAMALUDDIN, M. S.; LIAO, D.; ZHANG, Y.; WANG, H.; BHARADWAJ, U.; ZHANG, S.; LI, M.; LIN, P.; YAO, Q. Soluble CD40 ligand induces endothelial dysfunction in human and porcine coronary artery endothelial cells. Blood, v. 112, p. 3205-16, 2008. 
CHIRONI, G. N.; BOULANGER, C. M.; SIMON, A.; DIGNAT-GEORGE, F.; FREYSSINET, J. M.; TEDGUI, A. Endothelial microparticles in diseases. Cell. Tissue. Res., v. 335, n. 1, p. 143-51, 2009.

CHRISTON, R. A. Mechanisms of action of dietary fatty acids in regulating the activation of vascular endothelial cells during atherogenesis. Nutr. Rev., v. 61, n. 8, p. 272-9, 2003.

COETZEE, M.; BOEYENS, J. C. A.; STANDER, B. A.; FRAY, L. M.; HIESS, J.; CHUA, W. H.; KRUGER, M.C. The effects of arachidonic acid and docosahexaenoic acid on proliferation of and osteoclast formation from raw 264.7 murine monocytes. ISSFAL, p. 65, 2010 .

COOKE, J. P. The pivotal role of nitric oxide for vascular health. Can. J. Cardiol., v. 20, p. 7-15, 2004.

CURY-BOAVENTURA, M. F.; GORJÃO, R.; DE LIMA, T. M.; NEWSHOLME, P.; CURI, R. Comparative toxicity of oleic and linoleic acido on human lymphocytes. Life Sci., v. 78, n. 13, p. 1448-56, 2006a.

CURY-BOAVENTURA, M. F.; GORJÃO, R.; DE LIMA, T. M.; PIVA, T. M.; PERES, C. M.; SORIANO, F. G., CURI, R. Toxicity of a soybean oil emulsion on human lymphocytes and neutrophils. JPEN J. Parenter. Enteral. Nutr., v. 30, n. 2, p. 115-23, 2006b.

CURY-BOAVENTURA, M. F.; POMPEIA, C.; CURI, R. Comparative toxicity of oleic acid and linoleic acid on Raji cells. Nutrition, v. 21, p. 395-405, 2005.

DAS, U. N. Essential fatty acids - a review. Curr. Pharm. Biotechnol., v. 7, n. 6, p. 467-82, 2006.

DE CATERINA, R.; BERNINI, W.; CARLUCCIO, M. A.; LIAO, J. K.; LIBBY, P. Structural requirements for inhibition of cytokine-induced endothelial activation by unsaturated fatty acids. Lipid Res., v. 39, n. 5, p. 1062-70, 1998.

DE CATERINA, R.; CYBULSKY, M. I.; CLINTON, S. K.; GIMBRONE, M. A. JR.; LIBBY, P. The Omega-3 fatty acid docosahexaenoate reduces cytokine-induced expression of proatherogenic and proinflammatory proteins in human endothelial cells. Arterioscler. Thromb., v. 14, p. 1829-36, 1994. 
DE CATERINA, R.; MASSARO, M. Omega-3 fatty acids and the regulation of expression of endothelial pro-atherogenic and pro-inflammatory genes. J. Membrane Biol., v. 206, p. 203$16,2005$.

DICHTL, W.; ARES, M. P.; JONSON, A. N.; JOVINGE, S.; PACHINGER, O.; GIACHELLI, C. M.; HAMSTEN, A.; ERIKSSON, P.; NILSSON, J. Linoleic acid-stimulated vascular adhesion molecule-1 expression in endothelial cells depends on nuclear factorkappaB activation. Metabolism, v. 51, n. 3, p. 327-33, 2002.

DIN, J. N.; HARDING, S. A.; VALERIO, C. J.; SARMA, J.; LYALL, K.; RIEMERSMA, R. A.; NEWBY, D. E.; FLAPAN, A. D. Dietary intervention with oil rich fish reduces plateletmonocyte aggregation in man. Atherosclerosis, v. 197, n. 1, p. 290-6, 2008.

DOBARRO, D.; GÓMEZ-RUBÍN, M. C.; SANCHEZ-RECALDE, A.; MORENO, R.; GALEOTE, G.; JIMENEZ-VALERO, S.; CALVO, L.; LÓPEZ DE SÁ, E.; LÓPEZSENDÓN, J. L. Current pharmacological approach to restore endothelial dysfunction. Cardiovasc. Hematol. Agents Med. Chem., v.7, n.3, p.212-22, 2009.

DUDZINSKI, D. M.; IGARASHI, J.; GREIF, D.; MICHEL, T. The regulation and pharmacology of endothelial nitric oxide sinthase. Annu. Rev. Pharmacol. Toxicol., v. 46, p. 235-76, 2006.

DUPUIS, J.; TARDIF, J. C.; CEMACEK, P.; THÉROUX, P. Cholesterol reduction rapidly improves endothelial function after acute coronary syndromes. The RECIFE (reduction of cholesterol in ischemia and function of the endothelium) trial. Circulation, v. 99, n. 25, p. 3227-33, 1999.

DUVALL, W. L. Endothelial dysfunction and antioxidants. Mt. Sinai. J. Med., v. 72, n. 2, p. 71-80, 2005.

ESREY, K. L.; JOSEPH, L.; GROVER, S. A. Relationship between dietary intake and coronary heart disease mortality: lipid research clinics prevalence follow-up study. J. Clin. Epidemiol., v. 49, n. 2, p. 211-6, 1996.

FARACI, F. M.; DIDION, S. P. Vascular protection : superoxide dismutase isoforms in the vessel wall. Arterioscler. Thromb. Vasc. Biol., v. 24, n. 8, p. 1367-73, 2004.

FAUCONNIER, J.; ANDERSSON, D. C.; ZHANG, S. J.; LANNER, J. T.; WIBOM, R.; KATZ, A.; BRUTON, J. D.; WESTERBLAD, H. Effects of palmitate on $\mathrm{Ca}(2+)$ handling in adult control and ob/ob cardiomyocytes: impact of mitochondrial reactive oxygen species.

Diabetes, v. 56, n. 4, p. 1136-42, 2007. 
FELIPPE, C. R.; CALDER, P. C.; VECCHIA, M. G.; CAMPOS, M. R.; MANCINI-FILHO, J.; NEWSHOLME, E. A.; CURI, R. Fatty acid composition of lymphocytes and macrophages from rats fed fiber-rich diets: a comparison between oat bran- and wheat bran-enriched diets. Lipids, v. 32, n. 6, p. 587-91, 1997.

FOREST, A.; PAUTAS, E.; RAY, P.; BONNET, D.; VERNY, M.; AMABILE, N.; BOULANGER, C.; RIOU, B.; TEDGUI, A.; MALLAT, Z.; BODDAERT, J. Circulating microparticles and procoagulant activity in elderly patients. J. Gerontol. A. Biol. Sci. Med. Sci., v. 65, n. 4, p. 414-20, 2010.

FURCHGOTT, R. F.; ZAWADZKI, J. V. The obligatory role of endothelial cells in the relaxation of arterial smooth muscle by acetylcholine. Nature, v. 288, n. 5789, p. 373-6, 1980.

GALLEY, H. F.; WEBSTER, N. R. Physiology of the endothelium. Br. J. Anaesth., v. 93, n. 1, p. 105-13, 2004.

GARG, A.; GRUNDY, S. M.; KOFFLER, M. Effect of high carbohydrate intake on hyperglycemia, islet function, and plasma lipoproteins in NIDDM. Diabetes Care, v. 15, n. 11, p. $1572-80,1992$.

GORJÃO, R.; AZEVEDO-MARTINS, A. K.; RODRIGUES, H. G.; ABDULKADER, F.; ARCISIO-MIRANDA, M.; PROCOPIO, J.; CURI, R. Comparative effects of DHA and EPA on cell function. Pharmacol. Ther., v. 122, p. 56-64, 2009

GRIFFIN, M. E.; DIMITRIADIS, E.; LENEHAN, K.; OWENS, D.; COLLINS, P.; JOHNSON, A.; TOMKIN, G. H. Non-insulin-dependent diabetes mellitus: dietary monounsaturated fatty acids and low-density lipoprotein composition and function. Q. J. M., v. 89, n. 3, p. 211-6, 1996.

GRISHAM, M. B.; JOURD'HEUIL, D.; WINK, D. A. Nitric oxde.I.Physiological chemistry of nitric oxide and its metabolites: implications in inflammation. Am. J. Physiol., v. 276, n. 2, p. 315-21, 1999.

GROVER-PÁEZ, F.; ZAVALZA-GÓMES, A. B. Endothelial dysfunction and cardiovascular risk factors. Diabetes Res. Clin. Pract., v. 84, n. 1, p. 1-10, 2009.

GUNSTONE, F. Fatty acids - nomenclature, structure, isolation and structure determination, biosynthesis and chemical synthesis. In. Fatty acid and lipids chemistry. Blackie Academic \& Profesional, Glasgow, p. 1-33, 1996. 
GUO, W.; XIE, W.; HAN, J. Modulation od adipocyte lipogenesis by octanoate: involvement of reactive oxygen species. Nutr. Metab., v. 27, p. 3-30, 2006.

HANNAH, J. S.; HOWARD, B. V. Dietary fats, insulin resistance, and diabetes. J. Cardiovasc. Risk, v. 1, n. 1, p. 31-7, 1994.

HARRIS, W. S. International recommendations for consumption of long-chain omega-3 fatty acids. J. Cardiovasc. Med., v. 8, n. 1, p. 50-2, 2007.

HARRIS, W. S.; POSTON, W. C.; HADDOCK, C. K. Tissue n-3 and n-6 fatty acids and risk for coronary heart disease events. Atherosclerosis, v. 193, n. 1, p. 1-10, 2007.

HARVEY, K. A.; WALKER, C. L.; PAVLINA, T. M.; XU, Z.; ZALOGA, G. P.; SIDDIQUI, R. A. Long-chain saturated fatty acids induce pro-inflammatory responses and impact endothelial cell growth. Clin. Nutr., p. 1-9, 2009. (In press)

HATANAKA, E.; LEVADA-PIRES, A. C.; PITHON-CURI, T. C.; CURI, R. Systematic study on ROS production induced by oleic, linoleic, and gamma-linolenic acids in human and rat neutrophils. Free Radic. Biol. Med., v. 41, n. 7, p. 1124-32, 2006.

HAYASHI, T; YANO, K.; MATSUI-HIRAI, H.; YOKOO, H.; HATTORI, Y.; IGUCHI, A. Nitric oxide and endothelial cellular senescence. Pharmacol. Ther., v. 120, n. 3, p. 333-9, 2008.

HAYES, K. C. Saturated fats and blood lipids: new slant on an old story. Can. J. Cardiol., v. 11, p. 39-46, 1995.

HE, K.; LIU, K.; DAVIGLUS, M. L.; JENNY, N. S.; MAYER-DAVIS, E.; JIANG, R.; STEFFEN, L.; SISCOVICK, D.; TSAI, M.; HERRINGTON, D. Associations of dietary longchain n-3 polyunsaturated fatty acids and fish with biomarkers of inflammation and endothelial activation (from the Multi-Ethnic Study of Atherosclerosis [MESA]). Am. J. Cardiol., v. 103, n. 9, p. 1238-43, 2009.

HEGSTED, D. M.; MCGANDY, R. B.; MYERS, M. L.; STARE, F. J. Quantitative effects of dietary fat on serum cholesterol in man. Am. J. Clin. Nutr., v. 17, n. 5, p. 281-95, 1965.

HEITZER, T.; SCHLINZIG, T.; KROHN, K.; MEINERTZ, T.; MUNZEL, T. Endothelial dysfunction, oxidative stress, and risk of cardiovascular events in patients with coronary artery disease. Circulation, v. 104, n. 22, p. 2673-8, 2001. 
HENNIG, B.; LEI, W.; ARZUAGA, X.; GHOSH, D. D.; SARASWATHI, V.; TOBOREK, M. Linoleic acid induces proinflammatory events in vascular endothelial cells via activation of PI3K/Akt and ERK 1/2 signaling. J. Nutr. Biochem., v. 17, n. 11, p. 766-72, 2006.

HENNING, B.; TOBOREK, M.; MCCLAIN, C. J. High-energy diets, fatty acids and endothelial cell function: implications for atherosclerosis. J. Am. Coll. Cardiol., v. 20, p. 97 $105,2001$.

HIGASHI, Y.; NOMA, K.; YOSHIZUMI, M.; KIHARA, Y. Endothelial function and oxidative stress in cardiovascular diseases. Circ. J., v. 73, n. 3, p. 411-8, 2009.

HUGEL, B.; MARTINEZ, M. C.; KUNZELMANN, C.; FREYSSINET, J. M. Membrane microparticles: two sides of the coin. Physiology (Bethesda), v. 20, p. 22-7, 2005.

HULSMANS, M.; HOLVOET, P. The vicious circle between oxidative stress and inflammation in atherosclerosis. J. Cell. Mol. Med., v. 14, n. 1-2, p. 70-8, 2010.

ISHOLA, D. A. JR.; POST, J. A.; VAN TIMMEREN, M. M.; BAKKER, S. J.; GOLDSCHMEDING, R.; KOOMANS, H. A.; BRAAM, B.; JOLES, J. A. Albumin-bound fatty acids induce mitochondrial oxidant stress and impair antioxidant responses in proximal tubular cells. Kidney Int., v. 70, n. 4, p. 724-31, 2006.

KNOWLES, R. G.; MONCADA, S. Nitric oxide synthases in mammals. Biochem. J., v. 298, n. 2, p. 249-58, 1994.

HU, F. B; STAMPFER, M. J.; MANSON, J. E. Dietary fat intake and the risk of coronary heart disease in women. N. Engl. J. Med., v. 337, p. 1491-9, 1997.

IHLING, C.; SZOMBATHY, T.; BOHRMANN, B.; BROCKHAUS, M.; SCHAEFER, H. E.; LOEFFLER, B. M. Coexpression of endothelin-converting enzyme-1 and endothelin-1 in different stages of human atherosclerosis. Circulation, v. 104, n. 8, p. 864-9, 2001.

ITOH, M.; SUGANAMI, T.; SATOH, N.; TANIMOTO-KOYAMA, K.; YUAN, X.; TANAKA, M.; KAWANO, H.; YANO, T.; AOE, S.; TAKEYA, M.; SHIMATSU, A.; KUZUYA, H.; KAMEI, Y.; OGAWA, Y. Increased adiponectin secretion by highly purified eicosapentaenoic acid in rodent models of obesity and human obese subjects. Arterioscler. Thromb. Vasc. Biol., v. 27, n. 9, p. 1918-25, 2007.

KAHN, A.; MARIE, J.; GALAND, C.; BOIVIN, P. Molecular mechanism of erythrocyte pyruvate kinase deficiency. Humagenetik, v. 29, n. 4, p. 271-80, 1975. 
KANSE, S. M.; TAKAHASHI, K.; LAM, H. C.; REES, A.; WARREN, J. B.; PORTA, M.; MOLINATTI, P.; GATHEI, M.; BLOOM, S. R. Cytokine stimulated endothelin release from endothelial cells. Life Sci., v. 48, n. 14, p. 1379-84, 1991.

KARMAN, R. J.; GUPTA, M. P.; GARCIA, J. G.; HART, C. M. Exogenous fatty acids modulate the functional and cytotoxic responses of cultured pulmonary artery endothelial cells to oxidant stress. J. Lab. Clin. Med., v. 129, n. 5, p. 548-56, 1997.

KATAKURA, K.; HASHIMOTO, M.; OKUI, T.; SHIDO, O. Effects of polyunsaturated fatty acids on the cell cycle and the expression of bHLH transcription factors in neural stem cells. ISSFAL, p. 87, 2010.

KEYS, A. Effects of different dietary fats on plasma-lipid levels. Lancet, v. 1, n. 7380, p. 318-9, 1965.

KEYS, A. A practical, palatable and prudent way of eating. J. Med. Assoc. Ga., v. 59, n. 9, p. 355-9, 1970.

KNOTTNERUS, I. L.; TEN CATE, H.; LODDER, J.; KESSELS, F.; VAN OOSTENBRUGGE, R. J. Endothelial dysfunction in lacunar stroke: a systematic review. Cerebrovasc. Dis., v. 27, n. 5, p. 519-26, 2009.

KRIS-ETHERTON, P. M.; DERR, J.; MITCHELL, D. C.; MUSTAD, V. A.; RUSSELL, M. E.; MCDONNELL, E. T.; SALABSKY, D.; PEARSON, T. A. The role of fatty acid saturation on plasma lipids, lipoproteins, and apolipoproteins: I. effects of whole food diets high in cocoa butter, olive oil, soybean oil, dairy butter, and milk chocolate on the plasma lipids of young men. Metabolism, v. 42, n. 1, p. 121-9, 1993.

KRIS-ETHERTON, P. M.; GRIEL, A. E.; PSOTA, T. L.; GEBAUER, S. K.; ZHANG, J.; ETHERTON, T. D. Dietary stearic acid and risk of cardiovascular disease: intake, sources, digestion, and absorption. Lipids, v. 40, n. 12, p. 1193-200, 2005.

KRIS-ETHERTON, P. M.; HARRIS, W. S.; APPEL, L. J. Fish consumption, fish oil, omega3 fatty acids, and cardiovascular disease. Circulation, v. 106, n. 21, p. 2747-57, 2002.

KRIS-ETHERTON, P. M.; HARRIS, W. S.; APPEL, L. J. Fish consumption, fish oil, omega3 fatty acids, and cardiovascular disease. Arterioscler. Thromb. Vasc. Biol., v. 23, n. 2, p. 20-30, 2003. 
KURODA, R.; HIRATA, K.; KAWASHIMA, S.; YOKOYAMA, M. Unsaturated free fatty acids inhibit $\mathrm{Ca} 2+$ mobilization and NO release in endotelial cells. Kobe J. Med. Sci., v. 47, n. 5, p. 211-9, 2001.

KUSUNOKI, M.; TSUTSUMI, K.; NAKAYAMA, M.; KUROKAWA, T.; NAKAMURA, T.; OGAWA, H.; FUKUZAWA, Y.; MORISHITA, M.; KOIDE, T.; MIYATA, T. Relationshipi between serum concentrations of saturated fatty acids and unsaturated fatty acids and the homeostasis model insulin resistance index in Japanese patients with type 2 diabetes mellitus. J. Med. Invest., v. 54, n. 3-4, p. 243-7.

KWOK, C. F.; SHIH, K. C.; HWU, C. M.; HO, L. T. Linoleic acid and oleic acid increase the endothelin-1 binding and action in cultured rat aortic smooth muscle cells. Metabolism, v. 49, n. 11, p. 1386-9, 2000.

LANDMESSER, U.; HORNING, B.; DREXLER, H. Endothelial function: a critical determinant in atherosclerosis? Circulation, v. 109, n. 1, p. II27-33, 2004.

LAVIE, C. J.; MILANI, R. V.; MEHRA, M. R.; VENTURA, H. O. Omega-3 polyunsaturated fatty acids and cardiovascular diseases. J. Am. Coll. Cardiol., v. 54, n. 7, p. 585-94, 2009.

LE BROCQ, M.; LESLIE, S. J.; MILIKEN, P.; MEGSON, I. L. Endothelial dysfunction: from molecular mecanisms to measurement, clinical implications, and therapeutic opportunities. Antioxid. Redox. Sign., v. 10, n. 9, p. 1631-74, 2008.

LERMAN, R. H. Essential fatty acids. Altern. Ther. Health Med., v. 12, n. 3, p. 20-9, 2006.

LEVADA-PIRES, A. C.; FONSECA, C. E.; HATANAKA, E.; ALBA-LOUREIRO, T.; D'ANGElO, A.; VELHOTE, F. B.; CURI, R.; PITHON-CURI, T. C. The effect of an adventure race on lymphocyte and neutrophil death. Eur. J. Appl. Physiol., v. 109, n. 3, p. 447-53, 2010.

LEVINE, G.; CHODOS, A. P.; LOSCALZO, J. Restenosis following coronary angioplasty: clinical presentations and therapeutic options. Clin. Cardiol., v. 18, n. 12, p. 693-703, 1995.

LI, H.; FORSTERMANN, U. Prevention of atherosclerosis by interference with the vascular nitric oxide system. Curr. Pharm. Des., v. 15, n. 27, p. 3133-45, 2009.

LI, H.; WALLERATH, T.; FORSTERMANN, U. Physiological mechanisms regulatin the expression of endothelial-type NO sinthase. Nitric oxide, v. 7, n. 2, p. 132-47, 2002. 
LIBBY, P.; RIDKER, P. M. Novel inflammatory markers of coronary risk: theory versus practice. Circulation, v. 100, n. 11, p. 1148-50, 1999.

LIEBERMAN, E. H.; GERHARD, M. D.; UEHATA, A.; SELWYN, A. P.; GANZ, P.; YEUNG, A. C.; CREAGER, M. A. Flow-induced vasodilation of the human brachial artery is impaired in patients <40 years of age with coronary artery disease. Am. J. Cardiol., v. 78, n. 11, p. 1210-4, 1996.

LOPES, L. R.; LAURINDO, F. R.; MANCINI-FILHO, J.; CURI, R.; SANNOMIYA, P. NADPH-oxidase activity and lipid peroxidation in neutrophils from rats fed fat-rich diets.

Cell Biochem. Funct., v. 17, n. 1, p. 57-64, 1999.

LU, H.; DAUGHERTY, A. Atherosclerosis: cell biology and lipoproteins. Curr. Opin. Lipidol., v. 20, n. 6, p. 528-9, 2009.

LU, G.; GREENE, E. L.; NAGAI, T.; EGAN, B. M. Reactive oxygen species are critical in the oleic acid-mediated mitogenic signaling pathway in vascular smooth muscle cells. Hypertension, v. 32, n. 6, p. 1003-10, 1998.

LUM, H.; ROEBUCK, K. A. Oxidant stress and endothelial cell dysfunction. Am. J. Physiol. Cell Physiol., v. 280, n. 4, p. 719-41, 2001.

MANICKAM, E.; SINCLAIR, A. J.; CAMERON-SMITH, D. Supressive action os eicosapentaenoic acid on lipid droplet formation in 3T3-L1 adipocytes. Lipids Health Dis.; v. 9, n. 1, p. 57, 2010.

MARTINET, W.; SCHRIJVERS, D. M.; De MEYER, G. R.; THIELEMANS, J.; KNAAPEN, M. W. ; HERMAN, A. G.; KOCKX, M. M. Gene expression profiling of apoptosis-related genes in human atherosclerosis: upregulation of death-associated protein kinase. Arterioscler. Thromb. Vasc. Biol., v. 22, p. 2023-29, 2002.

MARUI, N.; OFFERMANN, M. K.; SWERLICK, R.; KUNSCH, C.; ROSEN, C. A.; AHMAD, M.; ALEXANDER, R. W.; MEDFORD, R. M. Vascular cell adhesion molecule-1 (VCAM-1) gene transcription and expression are regulated through an antioxidant-sensitive mechanism in human vascular endothelial cells. J. Clin. Invest., v. 92, n. 4, p. 1866-74, 1993.

MASSARO, M.; CARLUCCIO, M. A.; BONFRATE, C.; SICULELLA, L.; LAZZERINI, G.; BERNINI, W.; BASTA, G.; DE CATERINA, R. The Double Bond in unsaturated fatty acids is the necessary and sufficient requirement for the inhibition of expression of endothelial leucocyte adhesion molecules through interference with nuclear factor-kappaB activation. Lipids, v. 34, p. 213-4, 1999. 
MASSARO, M.; CARLUCCIO, M. A.; DE CATERINA, R. Direct vascular antiatherogenic effects of oleic acid: a clue to the cardioprotective effects of the Mediterranean diet. Cardiologia, v. 44, n. 6, p. 507-13, 1999.

MASSARO, M.; CARLUCCIO, M. A.; PAOLICCHI, A.; BOSETTI, F.; SOLAINI, G.; DE CATERINA, R. Mechanisms for reduction of endothelial activation by oleate: inhibition of nuclear factor-kappaB through antioxidant effects. Prostaglandins Leukot. Essent. Fatty Acids, v. 67, p. 175-81, 2002.

MASSARO, M.; SCODITTI, E.; CARLUCCIO, M. A., DE CATERINA, R. Basic mechanisms behind the effects of n-3 fatty acids on cardiovascular disease. Prostaglandins Leukot. Essent. Fatty Acids, v. 79, p. 109-15, 2008.

MATTERN, H. M.; HARDIN, C. D. Vascular metabolic dysfunction and lipotoxicity. Physiol. Res., v. 56, p. 149-158, 2007.

MAZIÈRE, C.; DANTIN, F.; CONTE, M. A.; DEGONVILLE, J.; ALI, D.; DUBOIS, F.; MAZIÈRE, J. C. Polyunsaturated fatty acid enrichment enhances endothelial cell-induced low-density-lipoprotein peroxidation. Biochem. J., v. 336, p. 57-62, 1998.

MCARTHUR, M. J.; ATSHAVES, B. P.; FROLOV, A.; FOXWORTH, W. D.; KIER, A. B.; SCHROEDER, F. Cellular uptake and intracellular trafficking of long chain fatty acids. J. Lipid Res., v. 40, n. 8, p. 1371-83, 1999.

MEHRA, M. R.; LAVIE, C. J.; VENTURA, H. O.; MILANI, R. V. Fish oils produce antiinflammatory effects and improve body weight in severe heart failure. J. Heart Lung Transplant., v. 25, n. 7, p. 834-8, 2006.

MENENDEZ, J. A.; VELLON, L.; COLOMER, R.; LUPU, R. Oleic acid the main monounsaturated fatty acido f olive oil, supresses Her-2/neu (erbB-2) expresión and synergistically enhances the growth inhibitory effects of trastuzumab (Herceptin) in breast cancer cells with Her-2/neu oncogene amplification. Ann. Oncol., v. 16, p. 359-371, 2005.

MESTAS, J.; LEY, K. Monocyte-endothelial cell interactions in the development of atherosclerosis. Trends Cardiovasc. Med., v. 18, n. 6, p. 228-32, 2008.

MILKOWSKI, A.; GARG, H. K.; COUGHLIN, J. R.; BRYAN, N. S. Nutritional epidemiology in the context of nitric oxide biology: a risk-benefit evaluation for dietary nitrite and nitrate. Nitric Oxide, v. 22, p. 110-119, 2010. 
MILlES, E. A.; WALLACE, F. A.; CALDER, P. C. Dietary fish oil reduces intercellular adhesion molecule 1 and scavenger receptor expression on murine macrophages. Atherosclerosis, v. 152, p. 43-50, 2000.

MONCADA, S. Nitric oxide in the vasculature: physiology and pathophysiology. Ann. N. Y. Acad. Sci., v. 811, p. 60-9, 1997.

MORI, T. A.; WATTS, G. F.; BURKE, V.; HILME, E.; PUDDEY, I. B.; BEILIN, L. J. Differential effects of eicosapentaenoic acid and docosahexaenoic acid on vascular reactivity of the forearm microcirculation in hyperlipidemic overweight men. Circulation, v. 102, n. 11, p. 1264-9, 2000.

MORI, T. A.; WOODMAN, R. J.; BURKE, V.; PUDDEY, I. B.; CROFT, K. D.; BEILIN, L. J. Effect of eicosapentaenoic acid and docosahexaenoic acid on oxidative stress and inflammatory markers in treated-hypertensive type 2 diabetic subjects. Free Radic. Biol. Med., v. 35, n. 7, p. 772-81, 2003.

MURAKAMI, M.; SIMONS, M. Regulation of vascular integrity. J. Mol. Med., v. 87, n. 6, p. 571-82, 2009.

NAPOLI, C.; IGNARRO, L. J. Nitric oxide and pathogenic mechanisms involved in the development of vascular diseases. Arch. Pharm. Res., v. 32, n. 8, p. 1103-8, 2009.

NEUNTEUFL, T.; PRIGLINGER, U.; HEHER, S.; ZEHETGRUBER, M.; SOREGI, G.; LEHR, S.; HUBER, K.; MAURER, G.; WEIDINGER, F.; KOSTNER, K. Effects of vitamin E on chronic and acute endothelial dysfunction in smokers. J. Am. Coll. Cardiol., v. 35, n. 2, p. 277-83, 2000 .

NICOLETTI, I.; MIGLIORATI, G.; PAGLIACCI, M. C.; GRIGNANI, F.; RICCARDI, C. A rapid and simple method for measuring thymocyte apoptosis by propidium iodide staining and flow cytometry. J. Immunol. Methods, v. 139, n. 2, p. 271-9, 1991.

OH, K.; HU, F. B.; MANSON. J. E.; STAMPFER, M. J.; WILLETT, W. C. Dietary fat intake and risk of coronary heart disease in women: 20 years of follow-up of the nurses' health study. Am. J. Epidemiol., v. 161, p. 672-9, 2005.

O'KEEFE, J. H. JR.; ABUISSA, H.; SASTRE, A.; STEINHAUS, D. M.; HARRIS, W. S. Effects of omega-3 fatty acids on resting heart rate, heart rate recovery after exercise, and heart rate variability in men with healed myocardial infarctions and depressed ejection fractions. Am. J. Cardiol., v. 97, n. 8, p. 1127-30, 2006. 
ORAM, J. F.; BORNFELDT, K. E. Direct effects of long-chain non-esterified fatty acids on vascular cells and their relevance to macrovascular complications of diabetes. Front Biosci., v. 9, p. 1240-53, 2004.

PAI, T.; YEH, Y. Y. Stearic acid unlike shorter-chain saturated fatty acids is poorly utilized for triacylglycerol synthesis and beta-oxidation in cultured rat hepatocytes. Lipids, v. 31, n. 2, p. 159-64, 1996.

PAI, T.; YEH, Y. Y. Desaturation of stearate is insufficient to increase the concentrations of oleate in cultured rat hepatocytess. J. Nutr., v. 127, n. 5, p. 753-7, 1997.

PELLEGRINO, M.; FURMANJAK-KAZMIERCZAK, E.; LEBLANC, J. C.; CHO, T.; CAO, K.; MARCOVINA, S. M.; BOFFA, M. B.; CÔTÉ, G. P.; KOSCHINSKY, M. L. The apolipoprotein(a) component of lipoprotein(a) stimulates actin stress fiber formation and loss of cell-cell contact in cultured endothelial cells. J. Biol. Chem., v. 279, n. 8, p. 6526-33, 2004.

PÉREZ-JIMÉNEZ, F.; RUANO, J.; PEREZ-MARTINEZ, P.; LOPEZ-SEGURA, F.; LOPEZMIRANDA, J. The influence of olive oil on human health: not a questiono $f$ fat alone. Mol. Nutr. Food Res., v. 51, n. 10, p. 1199-208, 2007.

PIETINEN, P.; ASCHERIO, A.; KORHONEN, P.; HARTMAN, A. M.; WILLETT, W. C.; ALBANES, D.; VIRTAMO, J. Intake of fatty acids and risk of coronary heart disease in a cohort of Finnish men. The Alpha-Tocopherol, Beta-Carotene Cancer Prevention Study. Am. J. Epidemiol., v. 145, n. 10, p. 876-87, 1997.

POLLOCK, D. M. How does endothelin induce vascular oxidative stress in mineralocorticoid hypertension? Clin. Sci. (Lond.), v. 110, n. 2, p. 205-6, 2006.

PRICE, P. T.; NELSON, C. M.; CLARKE, S. D. Omega-3 polyunsaturated fatty acid regulation of gene expression. Curr. Opin. Lipidol., v. 11, p. 3-7, 2000.

RACHEK, L. I.; THORNLEY, N. P.; GRISHKO, V. I.; LEDOUX, S. P.; WILSON, G. L. Protection of INS-1 cells from free fatty acid-induced apoptosis by targeting hOGG1 to mitochondria. Diabetes, v. 55, p. 1022-28, 2006.

RICHARD, D.; KEFI, K.; BARBE, U.; BAUSERO, P.; VISIOLI, F. Polyunsaturated fatty acids as antioxidants. Pharmacol. Res., v. 57, n. 6, p. 451-5, 2008. 
RIOUX, V.; LEGRAND, P. Saturated fatty acids: simple molecular structures with complex cellular functions. Curr. Opin. Clin. Nutr. Metab. Care, v. 10, n. 6, p. 752-8, 2007.

SABATIER, F.; CAMOIN-JAU, L.; ANFOSSO, F.; SAMPOL, J.; DIGNAT-GEORGE, F. Circulating endothelial cells, microparticles and progenitors: key players towards the definition of vascular competence. J. Cell Mol. Med., v. 13, n. 3, p. 454-71, 2009.

SAMPATH, H.; NTAMBI, J. M. The fate and intermediary metabolism os stearic acid. Lipids, v. 40, p. 1187-91, 2005.

SANDOW, L. S.; TARE, M. C-type natriuretic peptide: a new endothelium-derived hyperpolarizing factor? Trends Pharmacol. Sci., v. 28, n. 2, p. 61-7, 2007.

SARASWATHI, V.; WU, G.; TOBOREK, M.; HENNIG, B. Linoleic acid-induced endothelial activation: role of calcium and peroxynitrite signaling. J. Lipid Res., v. 45, n. 5, p. 794-804, 2004.

SAUVAGET, C.; NAGANO, J.; HAYASHI, M.; YAMADA, M. Animal protein, animal fat, and cholesterol intakes and risk of cerebral infarction mortality in the adult health study. Stroke, v. 35, n. 7, p. 1531-7, 2004.

SCHACHINGER, V.; ZEIHER, A. M. Atherosclerosis-associated endothelial dysfunction. Z. Kardiol., v. 89, n. 9, p. 70-4, 2000.

SCHMITZ, G.; ECKER, J. The opposing effects of n-3 and n-6 fatty acids. Prog. Lipid. Res., v. 47, n. 2, p. 147-55, 2008.

SCHONFELD, P.; REISER, G. Rotenone-like action of the branched-chain phytanic acid induces oxidative stress in mitochondria. J. Biol. Chem., v. 281, n. 11, p. 7136-42, 2006.

SCHONFELD, P.; WOITCZAK, L. Fatty acids decrease mitochondrial generation of reactive oxygen species at the reverse electron transport but increase it at the forward transport. Biochim. Biophys. Acta, v. 1767, n. 8, p. 1032-40, 2007.

SHAW, D. I.; HALL. W. L.; JEFFS, N. R.; WILLIAMS, C. M. Comparative effects of fatty acids on endothelial gene expression. Eur. J. Nutr., v. 46, p. 321-8, 2007.

SIMA, A .V.; STANCU, C. S.; SIMIONESCU, M. Vascular endothelium in atherosclerosis. Cell Tissue Res., v. 335, n. 1, p. 191-203, 2009. 
SIMIONESCU, M. Implications of early structural-functional changes in the endothelium for vascular disease. Arterioscler. Thromb. Vasc. Biol., v. 27, n. 2, p. 266-74, 2007.

SINGH, R. B.; DUBNOV, G.; NIAZ, M. A. Effect of an Indo-Mediterranean diet on progression of coronary artery disease in high risk patients (Indo-Mediterranean Diet Heart Study): a randomised single-blind trial. Lancet, v. 360, p. 1455-61, 2002.

SONG, G. Y.; GAO, Y.; DI, Y. W.; PAN, L. L.; ZHOU, Y.; YE, J. M. High-fat feeding reduces endothelium-dependent vasodilation in rats: differential mechanisms for saturated and unsaturated fatty acids? Clin. Exp. Pharmacol. Physiol., v. 33, n. 8, p. 708-13, 2006.

SPECTOR, A. A.; KADUCE, T. L.; HOAK, J. C.; FRY, G. L. Utilization of arachidonic and linoleic acids by cultured human endotheloial cells. J. Clin. Invest., v. 68, n. 4, p. 1003-11, 1981.

SPOLARICS, Z. Endotoxin stimulates gene expression of ROS-eliminating pathways in rat hepatic endothelial and Kupffer cells. Am. J. Physiol., v. 270, n. 4, p. 660-6, 1996.

SPRECHER, H.; LUTHRIA, D. L.; MOHAMMED, B. S.; BAYKOUSHEVA, S. P. Reevaluation of the pathways for the biosynthesis of polyunsaturated fatty acids. J. Lipid Res., v. 36, p. 2471-7, 1995.

SRIVASTAVA, R. C.; HUSAIN, M. M.; HASAN, S. K.; ATHAR, M. Green tea polyphenols and tannic acid act as potent inhibitors of phorbol ester-induced nitric oxide generation in rat hepatocytes independent of their antioxidant properties. Cancer Lett., v. 153, p. 1-5, 2000.

SUPHIOGLU, C.; DE MEL, D.; KUMAR, L.; SADLI, N.; FREESTONE, D.; MICHALCZYK, A.; SINCLAIR, A.; ACKLAND, M. L. The omega-3 fatty acid, DHA, decreases neuronal cell death in association with altered zinc transport. FEBS Lett., v. 584, p. 612-8, 2010.

TANIYAMA, Y.; GRIENDLING, K. K. Reactive oxygen species in the vasculatures: molecular and cellular mechanisms. Hypertension, v. 42, p. 1075-81, 2003.

TERÉS, S.; BARCELÓ-COBLIJN，G.; BENET, M.; ALVAREZ，R.; BRESSANI, R.; HALVER, J. E.; ESCRIBÁ, P. V. Oleic acid content is responsible for the reduction in blood pressure induced by olive oil. Proc. Natl. Acad. Sci. U. S. A., v. 105, n. 37, p. 13811-6, 2008. 
TOBOREK, M.; LEE, Y. W.; KAISER, S.; HENNIG, B. Measurement of inflammatory properties of fatty acids in human endothelial cells. Methods Enzymol., v. 352, p. 198-219, 2002.

THANOS, D.; MANIATIS, T. NF-kappa B: a lesson in family values. Cell, v. 80, n. 4, p. 529-32, 1995.

THIES, F.; GARRY, J. M.; YAGOOB, P.; RERKASEM, K.; WILLIAMS, J.; SHEARMAN, C. P.; GALlAGHER, P. J.; CALDER, P. C.; GRIMBLE, R. F. Association of n-3 polyunsaturated fatty acids with stability of atherosclerotic plaques: a randomized controlled trial. Lancet, v. 361, n. 9356, p. 477-85, 2003.

TRUJILLO, M.; FERRER-SUETA, G.; RADI, R. Peroxynitrite detoxification and its biologic implications. Antioxid. Redox Signal, v. 10, n. 9, 2008.

UESHIMA, H.; STAMLER, J.; ELLIOT, P.; CHAN, Q.; CARNETHON, M. R.; DAVIQLUS, M. L.; HE, K.; MOAQ-STAHLBERG, A.; RODRIGUEZ, B. L.; STEFFEN, L. M.; VAN HORN, L.; YARNELL, J.; ZHOU, B. Food omega-3 fatty acid intake of individuals (total, linoleic acid, long-chain) and their blood pressure: INTERMAP study. Hypertension, v. 50, n. 2, p. 313-9, 2007.

URBICH, C.; DIMMELER, S. Endothelial progenitor cells functional characterization. Trends Cardiovasc. Med., v. 14, n. 8, p. 318-22, 2004.

VALLANCE, P. Nitric oxide: therapeutic opportunities. Fundam. Clin. Pharmacol., v. 17, n. 1, p. 1-10, 2003.

VAN HINSBERG, W. M. Endothelial permeability for macromolecules. Mechanistic aspects of pathophysiological modulation. Arterioscler. Thromb. Vasc. Biol., v. 17, n. 6, p. 101823, 1997.

VANHOUTTE, P. M. How we learned to say NO. Arterioscler. Thromb. Vasc. Biol., v. 29, n. 8, p. 1156-60, 2009.

VANNINI, N.; PFEFFER, U.; LORUSSO, G.; NOONAN, D. M.; ALBINI, A. Endothelial cell aging and apoptosis in prevention and disease: E-selectin expression and modulation as a model. Curr. Pharm. Des., v. 14, n. 3, p. 221-5, 2008.

VISIOLI, F.; GALLI C.; GALLI, G.; CARUSO, D. Biological activities and metabolic fate of olive oil phenols. Eur. J. Lipid. Sci. Technol., v. 104, p. 677-84, 2002. 
VISIOLI, F.; GRANDE, S.; BOGANI, P.; GALLI, C. The role of antioxidants in the Mediterranean diets: focus on cancer. Eur. J. Cancer Prev., v. 13, p. 337-43, 2004.

VOETSCH, B.; JIN, R. C.; LOSCALZO, J. Nitric oxide insufficiency and atherothrombosis. Histochem. Cell Biol., v. 122, n. 4, p. 353-67, 2004.

WANG, F. Q.; WANG, E. T.; LIU, J.; CHEN, Q.; SUI, X. H.; CHEN, W. F.; CHEN, W. X. Mesorhizobium albiziae sp. nov., a novel bacterium that nodulates Albizia kalkora in a subtropical region of China. Int. J. Syst. Evol. Microbiol., v. 57, n. 6, p. 1192-9, 2007.

WHITELEY, W.; JACKSON, C.; LEWIS, S.; LOWE, G.; RUMLEY, A.; SANDERCOCK, P.; WARDLAW, J.; DENNIS, M.; SUDLOW, C. Inflammatory markers and poor outcome after stroke: a prospective cohort study and systematic review of interleukin-6. PLoS Med., v. 6, e1000145, 2009.

WEBER, C.; ERL, X.; PIETSCH, A.; DANESCH, U.; WEBER, P. C. Docosahexaenoic attenuates induction of vascular cell adhesion molecule-1 and subsequent monocytic cell adhesion to human endothelial cells stimulated by tumor necrosis factor alpha. Arterioscler. Thromb. Vasc. Biol., v. 15, n. 5, p. 622-8, 1995.

WU, K. K. Regulation of endothelial nitric oxide synthase activity and gene expression. Ann. N. Y. Acad. Sci., v. 962, p. 122-30, 2002.

WOOLLETT, L. A.; SPADY, D. K.; DIETSCHY, J. M. Saturated and unsaturated fatty acids independently regulate low density lipoprotein receptor activity and production rate. J. Lipid Res., v. 33, n. 1, p. 77-88, 1992.

YAM, D.; ELIRAZ, A.; BERRY, E. M. Diet and disease-the Israeli paradox: possible dangers of a high omega-6 polyunsaturated fatty acid diet. Isr. J. Med. Sci., v. 32, n. 11, p. 1134-43, 1996.

YUSUF, S.; VAZ, M.; PAIS, P. Tackling the challenge of cardiovascular disease burden in developing countries. Am. Heart J., v. 148, n. 1, p. 1-4, 2004.

XU, Q. Disturbed flow-enhanced endothelial turnover in atherosclerosis. Trends Cardiovasc. Med., v. 19, n. 6, p. 191-5, 2009. 
ANEXOS 


$$
\begin{array}{r}
\text { ANEXO A - } \\
\text { RESUMO } \\
\text { COMUNICAÇÃO } \\
\text { ORAL }
\end{array}
$$


Furthernoore, short hairpin RNA-mediated knockdown of the HIF-1a intibited elevation of VEGF wRNA and EC's migration induced by $\mathrm{NO}_{\mathrm{r}} \mathrm{PA}$ implying that the $\mathrm{NO}_{2}$ FA cflects migh be through the modulation of Hif-la sigialing pathway.

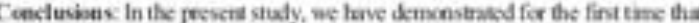

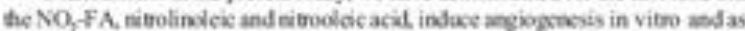

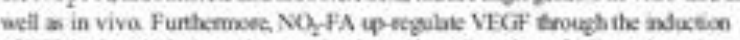

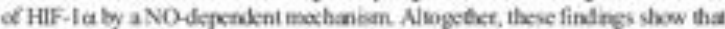

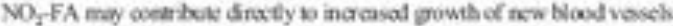


plapues.

\section{L013 Dosipidemia in HY/AIDS Patients in use of Antiretrevirat Therapy, Followed at the Hespital of Cliaies of LVIC AMP}

Sumi DD, Almeidr AC, Aabi FH, Corlho OR

Hoopial de Cinicas, Faculdade de Cibacias Modicas, Univcrsidade Fstadual de Canpinas - Unicamp, Campinas, SP. Bracil

Backeround: With the intoduction of new antirctroviral thespy (ART) for HIV/AIDS, this d wease, somerly knowe ber its fas develegenent, has now a chroeic poofle, leading wo the emergence of new comorbidties sech as dyslipideria secoedary to ART and possible cartiovascular evens, especially when using same elasses of drugs such as proteanes intabion (PI)

Objective: To evaluate the incidence of dyslipidemia and risk facengs (RF) for casdionascular disease in association with the ART afministrated

Methods Retrogpective cedor analysis of potients with HIViNIDS on ART, followed at the Hospital of C Enics of Unicanap-Brazil fouen lanuary/1997 to Dexcenber/2008, and evaluation of the lipid peofles and cardiovascular RF, in combination with antipctroviral therapies used

Resuks: We ax sesced, randoedly, 284 pabents, 174 (61.2\$) were men. mean age at initition of treafment was $33.9 \pm 9.1$ years (betapes 15 and 65)

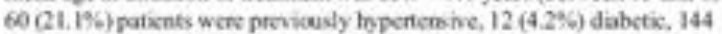
( $50.7 \%$ ) smokers and $89(31,4 \%)$ had family RF for candiovascular dseane The moan follow up was $80.9 ; 43$ months (between 3 and 204), and teatment of $68.75+41$ month. $118(41.5 \%$ ) patients dveloped dys of which $67.8 \%$ used PI $(p-0.028)$. The total time of Pl usc also favorod the development of dyslipidemia ( $48.8 \pm 46 \mathrm{vs} 25.1+34.6$ months, $p<0.001)$. Thene was a higher incidence of dysligidania in men $(68.6 \%, p=0.031)$ bet there wasn't a statutical sigificance uhen compared the onset of dysifpedemia with peior candionakular RF, The most prevalent dysl pidemia was by hpertrigyecridemia $(79.6 \%)$, and solated hypercholesterolemia and mixal dystipidemia were prescnt in $9.4 \%$ and $11 \%$ of cases, respectively. without stafistical coerelation with antirctroviral use. Hypol pulemic dng were used only in is canes of dys lpidemia $(12.7 \%$ ), ba showing significant molucton in the final variation of scrum triglycendes $(-19 \pm 73 \mathrm{v} 124=$ 143 mg/dl $p=0.024)$ compared with untreatod paicnts

Cenclesion: Doslipidemia is very cormmon in paticnts on ART, expecially with PI treatment rogimens, increasing the risk of earliovascelar everes and should be constantly evaluated. Hopolpidemic drugs have a posifive impact is the treatrent of dyslipidemia in these putents, justifyine its ereatcr use in elinical proctice.

\section{014 Contribution of Nitric Oxide to the Mtitochcedrat Onidathe Stros in Ihperdabsteroknic Mlice Senoxptible to Mllerenckerenh}

Leire ACR Gurcia R. Lino FI. Carnitho RF, Cassina A, Radi R. Vencesi AE, Oliveins $H C F$

Universidade Estudual de Campinas - Unicamp, Campinax, SP, Branl; Universidad de la Repeblica Moethideu, UY, Unuguai

Candiovascular discases are associated with elevated pooduction of ovitants derived from nitric ovide (NO) and superoxide radicals that lead io nitroxidative stress. We have recently showe that hypercholesterolemic L.DI. recerpoe knockout mice (LDL kjo) mitochondris release hiaker levels of reactive enyzen species (ROS). The aim of this work is to verify the effect of a nitric ovide synthase (NOS) inhibiler (L-NAMF) in the nitrovidative seress of L.DL $r$ ko liver milochondra. Mitochendrial pemembeliny wamsion. MPT (cyclosporine screstive swelling and calcium trampert) and ROS (H2DCF-DA and Amplex red) and NO (DAF-FM) poodaction rates were determind in control and LDL $\mathrm{k} / \mathrm{o}$ liver mikochondria before and aficr in vitro $(50 \mathrm{sM})$ and in vivo ( $\mathrm{mg} \mathrm{Kg}, 2$ wocks) treaiment with $\mathrm{L}$. NAME. LLr k/o misochondia presented higher levels of nitrotyrosine (Wesicm Bloth, which was absent in coetrol mischondria. L-NAME in vito probected LDL $x$ Ko millochondria against MPT. However, in control mitochondriz LNAME indused MPT. In vivo chronic L NAME treatmere

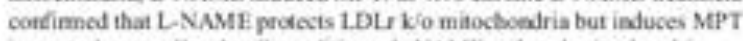
a control arganclies. Is all condtioen, L-NAME reduced mitoctendra ROS and NO production fates. Thex results veasest fhat IDL $r$ ko mitochondria corzais hiph conccatrations of NO which are nonmalized by L.NAME treatment thes correcting their higher sascepsibility to MPT. On the other tand, inhliting pitysiological MO froductioe is control miloshandna promotes MPT. Therefore, nitric aside synthase activity secnin bo be directly inuolved is the nitroxidative stress in LDU k/o mice

\section{O15 Effects of Fatty Acidh en Endethelial Cedl (ECV-304) Function}

Akas L.N, Silva EPP, Lima MM, Cirri R

Departamento de Fisiologia e Biofsica, Iathule de Cišcias Bionódicas, thiversidade de São Paulo, Sas Paula SP. Branl

Planme fatty acids (FA) are increased in obesity leasing a peripheral nselie renatance and increased rak for develoriag atbensicktoner. The frect effests of FA es endontelium function bowever gemais to be elocidaned. In this stady, the effects of saturated, $\omega-3$ and $00-6$ FA abd beir combination were investigated on function of endothelial cells (cell line FCV-304l. The parameters of inflanamatory response measured were: activation of transcription malcar factor XB (NFk.B). production of nitnc oxide (NO), relcased of neactive oxygrn species (ROS) and cell death. The sollowitg fany acids wete seuted: searie (SA) at 150 wM, lineleic (LA), pammatinolenic (CL) ricosapentacnoic (FPA) and docosahexacrois (DilA) at 50 and $100 \mathrm{pM}$. SA led 200 i of eclls to death after 24 bour treatment. increased by 2 - fold the relcase of RCS after treatmeat for 30 minutes and did not aler the production of NO and activation of NFXB as compared to controL. The combinatice of SA with 0 -3. EPA and DHA decreased the proportion of dead cells indoced by the first to 10 . affer 24 bour tecatment. The conbinastion with EPA decreased by 5 to $15 \%$, the prodaction of NO after treannent with SA for 2 hours. However, NFkB activation was increased by 3. Sold in the coenbisation of $\mathrm{SA}$ with DEA and the froduction of ROS raiked by $25 \%$ afker 30 minues of treatmat with EPA or DHA. The e-6 FA, L.A and LG, anoded the eell death induced by SA, reduced NO release by $15 \%$ and production of ROS by $10 \%$. There was

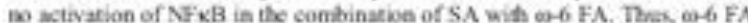
ean prevent, at leas partially, the effects of saburated FA (atherogenic) on endothelial cells. This fact may be associated with the cpidsmiokgical evidence that diets rich in $6-6$ polyunsaturated fatry acidb reduec the nisk of canfiovascular discases.

Finantial: CNPQ, FAPESP and CAPFS

\section{L016 Ponitive Cerredatien between Severity of Atberanckerais and Liver Mitechondrial Oxidative Stress}

\section{Drighello GGE, Paiw BA, hada NM, Vercesi AE, Obvina IKCF}

Uhivessidade Etadual de Campinas - Unicamp, Campinas, SP. Bravil

Objectives: We recenkiy demonsmied that LD. receptor knokout d DL

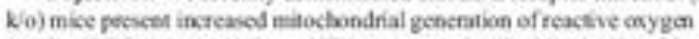
spoxics $($ ROS) in several tissues. Thes was asoocized with mitoxhoedra Giminishod content of NADPH litked substrates. Here, we investigated whether spentancoux atharosckerosi development and liver mikshondria oxidative stress uould be affected by kong krme treatment with NADFH linked whetrate istrate)


months of age with drinking solution containing citrate $(2.44 \mathrm{mM})$, provastane (jenva, 10 me kg), citnate + prava and plain water (control). Analyses included nombometry of acrtic root lipid stained lesioes, fluowenctry of ROS production (H2DCF.-DA oxidatoen) and NADFH oxidation in liver milochondria (mito) and splecen lymphocytes, plasma lipids, TBARS and hepatic enzymes.

Results: Similar extent of acrtic root lesions was found in citrate, prana and eortrol groum. However, the combination of earatetprava increased 4 Sold the lesion sine. The nates of liver mito ROS production and NADPH onidatioe did not differ among the groups. Fos production by spiest lymphocytes was sienificaesly increaned in the grava groep. Considening alt variables from all groups, multiple linear fegresion analysex $(C 2=0.999$, $p=0.01$ ) shownd that cholederoL, triglyserides and liver mito ROS


lipids confirmied mito $R O S$ as a independent factor $(p=0,009)$ 


\section{ANEXX B - ARTIGO EM SUBMISSÃO}




\title{
OMEGA-6 FATTY ACIDS PROTECT ECV-304 CELLS FROM DEATH INDUCED BY STEARIC ACID
}

\author{
MASI, Laureane Nunes ${ }^{\mathrm{a},{ }^{*}}$; PORTIOLI-SANCHES, Érica Paula ${ }^{\mathrm{a}}$; LIMA-SALGADO, Thaís \\ Martins ${ }^{\text {b; }}$ ROMANATTO, Talita ${ }^{a}$; CURI, Rui ${ }^{\mathrm{a}}$. \\ ${ }^{\mathrm{a}}$ Department of Physiology and Byiophisics, Institute of Biomedical Sciences, University of \\ São Paulo, Av. Prof. Lineu Prestes, 1524, 05508-900 São Paulo, Brazil. \\ ${ }^{\mathrm{b}}$ Department of Clinical Medicine, School of Medicine, University of São Paulo, Av. Dr. \\ Arnaldo, 455, 01246-903 São Paulo, Brazil.
}

\section{e-mail for address:}

corresponding author: laure_masi@hotmail.com

55-(11)-3091-7245

55-(11)-8187-8066

Av. Prof. Lineu Prestes, 1524, 05508-900 São Paulo, Brazil

ericaportisan@uol.com.br

thais@icb.usp.br

talitaromanatto@yahoo.com.br

ruicuri@icb.usp.br

\begin{abstract}
The effects of stearic acid (saturated fatty acid) and its combination with $\omega-3$ and $\omega-6$ polyunsaturated fatty acids (PUFA) on death of endothelial cells (ECV-304 cell line) were investigated. The parameters examined were: loss of plasma membrane integrity, DNA fragmentation, nitric oxide (NO) content and release of reactive oxygen species (ROS). The following fatty acids were studied: stearic (SA), linoleic (LA), gamma-linolenic $(\gamma \mathrm{A})$, eicosapentaenoic (EPA) and docosa-hexaenoic (DHA) acids. SA induced cell death, raised the release of ROS and did not alter the intracellular nitric oxide (NO) content. $\omega-3$ FA did not decreased the proportion of dead cells induced by stearic acid, but reduced the NO content and decreased the release of ROS. $\omega-6$ PUFA, LA and $\gamma$ A, abolished the cell death induced by SA and decreased the production of ROS. LA increased NO content. These results suggest that the $\omega-6$ PUFA protect against endothelial cell death induced by stearic acid.
\end{abstract}

Key Words: endothelial cell dysfunction, fatty acids, cell death, nitric oxide, reactive oxygen species. 


\section{Introduction}

The endothelium responds to physical and chemical stimuli releasing various organic and inorganic messenger molecules that influence surrounding tissue function. The endothelium produces and releases vasodilator factors, such as NO, endothelium-derived hyperpolarizing factor (EDHF), prostacyclin $\left(\mathrm{PGI}_{2}\right)$ and vasoconstrictor factors like endothelin 1 (ET1) (Aird, 2007). Vascular homeostasis is maintained by the balanced release of these factors (Murakami and Simons, 2009).

Pathological conditions (such as diabetes and obesity) and high fat diets promote increased plasma concentrations of free fatty acids (FFA) leading to vascular endothelial dysfunction (Mattern and Hardin, 2007). The fatty acids have specific modulating effects on release of endothelium-derived factors involved in the onset of the atherosclerotic process. Saturated fatty acids have pro-inflammatory actions (Basu et al., 2006) and increase the risk of cardiovascular diseases (CVD) ( Singh et al., 2002; Oh et al., 2005). $\omega$-3 Polyunsaturated fatty acids present anti-inflammatory effects and decrease the release of pro-atherosclerotic factors (He et al., 2009). The role of $\omega-6$ PUFA in the prevention of CVD however still remains controversial (Hamazaki et al., 2003; Harris, 2008). High concentrations of FFA cause apoptosis and necrosis in lymphocytes, macrophages (Felippe et al., 1997; CuryBoaventura et al., 2006a) and neutrophils (Cury-Boaventura et al., 2006b; Hatanaka et al., 2006). In spite of this information, however, the effect of fatty acids (FA) on endothelial cell death was poorly investigated. The death of endothelial cells (EC) plays a key role to trigger atherogenesis and acute coronary diseases (Tedgui and Mallat, 2003). The sites where plaques develop are associated with increased EC turnover rate, as indicated by the occurrence of cell (Xu, 2009). Regenerated endothelial cells do not function accordingly (Vanhoutte, 2009). Therefore, if the endothelial monolayer has to be repaired due to damage, the dysfunctional cells will be unable to provide sufficient atheroprotective activity (e.g. synthesis of NO). An additional contributory factor in the initiation of atherogenesis as well as plaque rupture is an alteration in the procoagulant state of apoptotic EC. Apoptosis of vascular cells is the basis for the generation of microparticles within the circulation, which act as potent procoagulant substrates both locally and systemically (Leroyer et al., 2008; George, 2008). These particles are increased in patients with unstable coronary disease, and account for pro-coagulant activity of the plaque (Tan et al., 2005). This information led us to investigate the effect of fatty acids on endothelial cell death. We examined if $\omega-3$ and $\omega-6$ polyunsaturated fatty acids (PUFA) can protect endothelial cells from death induced by stearic acid, a saturated FA. The involvement of $\mathrm{NO}$ and ROS in the effects of the FA was also investigated. 


\section{Materials and methods}

\subsection{Culture conditions}

An endothelial cell line derived from human umbilical vein (ECV-304) was maintained in RPMI-1640 culture medium containing 10\% fetal bovine serum (FBS). This medium was supplemented with glutamine (2 mM), HEPES (20 mM), streptomycin (10000 $\mathrm{g} / \mathrm{mL})$ and sodium bicarbonate $(24 \mathrm{mM})$. Under these conditions, the FBS is an insignificant contributor to fatty acid concentration ( $30 \mu \mathrm{g} / \mathrm{mL}$ of all fatty acids). Cells were maintained at $37{ }^{\circ} \mathrm{C}$ in a humidified atmosphere with $5 \% \mathrm{CO}_{2}$. Endothelial cells were cultured with $80-90 \%$ confluence. The cells were treated with stearic acid (SA; 18:0) combined with linoleic acid (LA; 18:2), $\gamma$-linolenic acid ( $\gamma \mathrm{A} ; 18: 3$ ), eicosapentaenoic acid (EPA; 20:5) or docosahexaenoic acid (DHA; 22:6) dissolved in ethanol. A control group with ethanol was included in all experiments. The concentrations used were based on preliminary studies of cytotoxicity carried out in our laboratory in the same cell line. We used a toxic concentration of stearic acid $(150 \mu \mathrm{M})$ and non-toxic concentrations of $\omega-3$ and $\omega-6$ polyunsaturated fatty acids (50 and $100 \mu \mathrm{M})$.

\subsection{Cytotoxicity}

Cell viability was tested in a time course study carried out for 2, 6 or 24 hours after treatment with the FA. After incubation, the proportion of cells with loss of membrane integrity and fragmented DNA was determined by flow cytometry using a FACSCalibur equipment (Becton and Dickinson System, San Juan, California, USA).

\subsection{Cell viability}

ECV-304 cells, grown in monolayer, were rinsed in phosphate buffered saline (PBS) and trypsinized for removal from the wells. At the end of the culture period, $0.5 \mathrm{~mL}$ medium containing cells was removed to determine the proportion of cells with intact plasma membrane. Both adherent and non-adherent cells were combined for analysis. In the cell viability assay, $50 \mu \mathrm{L}$ propidium iodide (PI) solution $(100 \mu \mathrm{g} / \mathrm{mL}$ in saline buffer) were added to the cells. PI is highly water-soluble fluorescent compound that cannot pass through intact membranes and is generally excluded from viable cells. It binds to DNA by intercalating between the bases with little or no sequence preference. After 5 min of incubation at room 
temperature, cells were evaluated by flow cytometry using the Cell Quest software. Fluorescence was measured using the FL2 channel (orange/red fluorescence at 585/42 nm).

\subsection{DNA fragmentation}

DNA fragmentation was analysed by flow cytometry after DNA staining with PI. Cells were resuspended in a solution containing detergents that permeabilize the cells for prompt incorporation of dye into DNA. Briefly, $0.5 \mathrm{~mL}$ medium containing cells was centrifuged at $1,000 \times \mathrm{g}$ for $10 \mathrm{~min}$ at $4{ }^{\circ} \mathrm{C}$. The pellet was gently resuspended in $300 \mu \mathrm{L}$ hypotonic solution containing $50 \mu \mathrm{g} / \mathrm{mL}$ PI, $0.1 \%$ sodium citrate and $0.1 \%$ Triton $\mathrm{X}-100$. The cells were then incubated in the dark at room temperature for $30 \mathrm{~min}$. Fluorescence was measured and analysed by flow cytometry as described above.

\subsection{Intracellular nitric oxide content}

Intracellular NO content was determined using the fluorescent dye 4-amino-5methylamino-2 ', 7'-difluorofluorescein diacetate (DAF-FM/DA) (Molecular Probes, Invitrogen, Carlsbad, CA, USA). Cells ( 1 x $10^{5}$ cells per well) were cultured in 24 -well plates containing coverslips on the botton of the dish. On the day of the experiment, the cells were maintained in RPMI-1640 culture medium and treated with FA for 1 hour and with DAF-DA $(10 \mu \mathrm{M})$ for 30 minutes at $37^{\circ} \mathrm{C}$. This period of treatment was based on a preliminary time course experiment. For negative control, a non-selective inhibitor of nitric oxide sinthase (NOS), L-Nitro-Arginine-Methyl Ester (L-NAME), was used at $300 \mu \mathrm{M}$ for 30 minutes. The cells were visualized using a fluorescence microscope (Carl Zeiss Vision, MunchenHallbergmoos, Germany), in the $520 / 450 \mathrm{~nm}$ filter, and analyzed by measuring the fluorescence intensity using the KS 300 software (Herestraat, Leuven, Belgium).

\subsection{Production of reactive oxygen species (ROS)}

Production of reactive oxygen species was determined by immunofluorescence using hydroethydine. This compound crosses plasma membrane and is cleaved by ROS inside the cells, forming ethidium, which merges the nitrogenous bases of DNA molecule. Cells were treated for 30 minutes with the fatty acids. This period of treatment was based on a preliminary time course experiment. After treatment, the cells were incubated with hydroethydine $(1 \mu \mathrm{M})$ for 30 minutes at room temperature in the dark. The cells were visualized in a fluorescence microscope (Carl Zeiss Vision, Munchen-Hallbergmoos, 
Germany), using the 590/46 nm filter and analyzed by fluorescence intensity using the KS 300 software (Herestraat, Leuven, Belgium).

\subsection{Statistical analysis}

Results are presented as means \pm S.E.M. of 6-9 determinations from 2-3 experiments. Statistical analysis was performed by using one-way ANOVA and Tukey's test (Graph Pad Prism 5; Graph Pad software) as indicated. The level of significance was set at $\mathrm{p}<0.05$.

\section{Results}

Treatment with SA at $150 \mu \mathrm{M}$ for 24 hours decreased the proportion of viable cells by $17.8 \%$ compared to vehicle (ethanol). SA plus docosa-hexaenoic (DHA) at $100 \mu \mathrm{M}$ decreased by $18.6 \%$ compared to SA. The association of SA with EPA at 50 and $100 \mu \mathrm{M}$ increased cell viability by $12.3 \%$ and $8.9 \%$, respectively, compared to SA. $\omega-6$ Fatty acids (LA and $\gamma \mathrm{A}$, at 50 and $100 \mu \mathrm{M}$ ) increased the proportion of viable cells in the presence of SA by $18.8 \%$ as compared to SA (Figure 1). Treatment with SA and the association of SA with PUFA ( $\omega-3$ and $\omega-6)$ for 6 hours did not alter the viability of ECV-304 cells compared to vehicle (ethanol) (data not shown).

The proportion of cells with DNA fragmentation was increased by 9 times due to treatment with SA at $150 \mu \mathrm{M}$ for 24 hours compared to vehicle (ethanol). $\omega-3$ PUFA (DHA and EPA) did not alter the SA effect. However, $\omega-6$ PUFA (LA and $\gamma$ A) markedly reduced the proportion of cells with DNA fragmentation caused by the SA treatment. The reduction in the proportion of cells with DNA fragmentation induced by $\omega-6$ PUFA was as follows: by $35.7 \%$ and $79 \%$ for LA at 50 and $100 \mu \mathrm{M}$, respectively, and by $35 \%$ and $46.5 \%$ for $\gamma \mathrm{A}$ at 50 and $100 \mu \mathrm{M}$, respectively (Figure 2). Treatment with SA and the association of SA with PUFA ( $\omega-$ 3 and $\omega-6$ ) for 6 hours did not alter the percentage of ECV-304 cells with DNA fragmentation compared to vehicle (ethanol) (data not shown).

SA did not alter the nitric oxide content in 1 hour treatment compared to vehicle. The combination with DHA at $50 \mu \mathrm{M}$ decreased by $58 \%$ and with EPA at 50 and $100 \mu \mathrm{M}$ decreased by $78.4 \%$ and $50 \%$, respectively, the NO content as compared to SA. SA at $150 \mu$ M plus $\omega-6$ LA at $50 \mu \mathrm{M}$ decreased by $27 \%$ and with $\gamma \mathrm{A}$ at 50 and $100 \mu \mathrm{M}$ decreased by $25.5 \%$ and $60.5 \%$, respectively, the NO content as compared to SA. Only the combination of SA with LA at 100 $\mu \mathrm{M}$ led to an increase of $32.5 \%$ compared to SA (Figure 3). The non-selective nitric oxide synthase inhibitor (NOS), L-Nitro-Arginine-Methyl Ester (L-NAME), was used as negative 
control and no fluorescence was obtained, confirming the specificity of the NO measurement (data not shown).

The values of the content of ROS in the treatments with fatty acids shown in the Figure 5B were subtracted of the values obtained with ethanol used as vehicle. Production of reactive oxygen species was increased by $99.2 \%$ due to SA treatment compared to ethanol (data not shown). SA associated with DHA, EPA and $\gamma$-linolenic acid $(\gamma \mathrm{A})$ at $50 \mu \mathrm{M}$ did not alter the production of ROS compared to SA. However, combinations of SA with DHA, EPA and $\gamma \mathrm{A}$ at $100 \mu \mathrm{M}$ decreased approximately by $20 \%$ the production of ROS compared to SA. SA plus LA at 50 and $100 \mu \mathrm{M}$ decreased by $50 \%$ and $67 \%$, respectively, the production of ROS compared to SA (Figure 4).

\section{Discussion}

Endothelial dysfunction, atherosclerosis and cardiovascular diseases are mediated by factors including angiotensin II, proinflammatory cytokines and free fatty acids. Fatty acids have different and sometimes opposite effects on vascular endothelium function. In the present study, stearic acid increased the death of ECV-304 endothelial cells, and raised ROS production with no change in intracellular NO content. $\omega-3$ PUFA (DHA and EPA) did not protect endothelial cells from death induced by stearic acid, decreased the production of ROS and the content of NO. In contrast, $\omega-6$ PUFA (LA and $\gamma \mathrm{A}$ ) reduced cell death induced by stearic acid, decreased ROS production and linoleic acid increased the intracellular content of NO.

Stearic acid-induced cell death confirms the results obtained in previous studies (Artwohl et al., 2004; Rioux and Legrand, 2007). Artwohl et al. (2008) showed that stearic acid causes apoptosis of various endothelial cell lines (HUVECs, HAECs, and EPCs HRECs). Endothelial cell apoptosis may directly affect blood thrombogenicity through the release of apoptotic microparticles into the bloodstream (Blann et al., 2009). High occurrence of apoptotic endothelial cells (ECs) is observed in patients with myocardial infarction and angina (Chironi et al., 2009). So, the death of endothelial cells induced by fatty acids is an important process for the endothelium dysfunction takes place. Several studies have shown the antiinflammatory and anti-apoptotic properties of the $\omega$-3 PUFA (DHA and EPA) (Massaro et al., 2008; Suphioglu et al., 2010). Artwohl et al. (2008) evaluated the effects of a broad spectrum of nutritional FA on endothelial cell apoptosis in target tissues of diabetic vascular complications and showed that EPA at low concentration inhibits stearic acid-induced 
apoptosis in HUVEC, HAEC, EPC and HREC, and also reduces stearic acid-induced membrane rigidity in HUVEC cells. In our study, there was no reduction of SA-induced ECV-304 endothelial cell death by treatment with EPA and DHA. $\omega-6$ PUFA have been reported to favour atherogenic and diabetogenic processes (Schmitz and Ecker, 2008). No significant association between LA (or $\omega-6$ PUFA) intake (or tissues levels) and CHD risk (Esrey et al., 1996; Pietinen et al., 1997) and no consistent relations between stroke and LA intakes (He et al., 2003; Iso et al., 2003; Sauvaget et al., 2004) have been found. In others studies however $\omega-6$ PUFA have been shown to reduce the risk of coronary heart disease (CHD) (Harris et al., 2007). We observed herein that $\omega-6$ PUFA protect endothelial cells from death induced by stearic acid.

NO is a potent vasodilator and inhibits the synthesis of pro-inflammatory cytokines, chemokines and expression of leukocyte adhesion molecules, reduces activation and aggregation of platelets, and proliferation of vascular smooth muscle cells (Whiteley et al., 2009). Wu (2002) and Milkowski et al. (2010) extensively reviewed the regulation of nitric oxide production by the diet. Dietary factors are either beneficial to health or contribute to the pathogenesis of chronic diseases, partially by modulation of nitric oxide production through iNOS or eNOS (Wu, 2002). Abnormalities in vascular nitric oxide production and transport result in endothelial dysfunction that leads to cardiovascular disorders such as hypertension and atherosclerosis (Chen et al., 2008). Protection against a decrease in constitutive nitric oxide production in the vasculature may prevent the development of vascular diseases. Insults to ECs reduce or abolish the NO functions (Simionescu, 2007). Some FA (oleic, linoleic and gamma-linoleic acid) decrease NO production by pulmonary artery endothelial cells (PAEC) in a dose $(100 \mu \mathrm{M} / \mathrm{L})$ and time-dependent (30 minutes) manner (Karman et al., 1997). Herein, the treatment with SA at $150 \mu \mathrm{M}$ did not alter intracellular NO content in ECV-304 endothelial cells in relation to vehicle. These results are according to those of Song et al. (2006). These authors showed that stearic acid at $600 \mu \mathrm{M}$ does not alter NO production by endothelial cells from human umbilical vein (HUVECs) in 24 hours. Kuroda et al. (2001) also observed that treatment with palmitic acid at $100 \mu \mathrm{M}$ for 1 hour, another saturated fatty acid present in the blood at high concentration, does not affect NO release by endothelial cells from bovine aorta. $\omega-3$ PUFA cause endothelial relaxation and promote arterial compliance (Theobald et al., 2007; Ayer et al., 2009), which might be related to increased nitric oxide production (Matsumoto et al., 2009). There is a general consense that NO produced by endothelial NO-synthase (eNOS) is beneficial for the vasculature (Gewaltig and Kojda, 2002). 
We observed that $\omega-3$ PUFA, DHA and EPA, at $50 \mu \mathrm{M}$, in the presence of SA reduced intracellular NO content. This observation may be associated with the highest endothelial cell death observed under these conditions. However, we showed that $\omega-6$ PUFA plus SA led to an increase of intracellular NO content as compared to SA only. This increase in NO content may be associated with the observation that linoleic acid protected endothelial cells from death induced by stearic acid. These results corroborate with those of Saraswathi et al. (2004). These authors found linoleic acid at $90 \mu \mathrm{M}$ for 3 hours increases NO production by porcine pulmonary artery endothelial cells.

Several vascular diseases are associated with oxidative stress and inactivation of NO (Li and Forstermann, 2009). Exacerbated production of ROS leading to NO inactivation is a more effective way to decrease NO content and to promote endothelial dysfunction (Higashi et al., 2009). The supplementation with enzymatic or chemical antioxidants protects NO against exogenous and endogenous superoxide attack and restores endothelial function (Laursen et al., 1997; Chu et al., 2003). Stimulation of ROS production by FA has been demonstrated in many cell types such as vascular smooth muscle cell (Lu et al., 1998), skeletal muscle cell (Rachek et al., 2006; Lambertucci et al., 2008), cardiomyocytes (Fauconnier et al., 2007), proximal tubular cells (Ishola et al., 2006), rat hepatocytes (Srivastava et al., 2000), neutrophils (Levada-Pires et al., 2010), lymphocytes (CuryBoaventura et al., 2005) and adipocytes (Guo et al., 2006). Stearic acid led to an increase in superoxide anion production after treatment of ECV-304 cells for 30 minutes.

The combination of SA with DHA or EPA led to a reduction of ROS production indicating a dose-dependent protective effect on endothelial cells. This effect was not able to protect the cells from death and to maintain the content of intracellular NO due to treatment with stearic acid. Our findings corroborate with those observed by Richard et al. (2008). These authors showed low production of ROS by human aorta endothelial cells treated with $\omega-3$ FA compared with saturated, monounsaturated and $\omega-6$ PUFA, all at $10 \mu \mathrm{M}$.

Under physiological circumstances, ROS produced in a controlled manner contribute to maintain vascular homeostasis. ROS modulate downstream signaling molecules such as protein kinases and ion channels, expression of pro-inflammatory mediators, cell migration and apoptosis. Maziere et al. (1998) compared the effects of $\omega-3$ and $\omega-6$ PUFA on endothelial cells. These authors observed that $\omega-3$ PUFA decrease the content of TBARS, production of superoxide anion when compared with $\omega-6$ PUFA. In our study, the $\omega-6$ PUFA, linoleic and $\gamma$-linolenic acid at $100 \mu \mathrm{M}$, led to a decrease in SA-induced production of ROS. 
These findings contradict studies by others indicating that $\omega-6$ PUFA have more potent effect on production of superoxide than the saturated fatty acids (Schonfeld and Reiser, 2006; Schonfeld and Reiser, 2007).

Taking as a whole, $\omega-3$ PUFA decreased intracellular NO content, decreased ROS production and did not protect against ECV-304 cell death induced by stearic acid. On the other hand, $\omega-6$ PUFA inhibited stearic acid-induced cell death, increased intracellular NO content and decreased production of ROS. These findings suggest that $\omega-6$ FA have a greater protective effect than $\omega-3$ PUFA on the deleterious effects caused by saturated stearic acid on ECV-304 endothelial cells.

\section{Acknowledgements}

We acknowledge the financial support of FAPESP, CAPES and CNPq. 




Figure 1. Viability of ECV-304 endothelial cells incubated with stearic acid combined with $\omega-6$ or $\omega-3$ fatty acids for 24 hours. ECV-304 endothelial cells were incubated with fatty acids for 24 hours and analyzed by flow cytometry. The fluorescence was measured in FL2 channel (585/42 nm). Values are presented as mean \pm SEM $(n=9) . * p<0.05$ compared to ethanol as indicated by ANOVA, $\# \mathrm{p}<0.05$ compared to stearic acid as indicated by ANOVA. EtOH $=$ ethanol; SA = stearic acid always at $150 \mu \mathrm{M}$; DHA = docosa-hexaenoic acid; EPA = eicosapentaenoic acid; LA = linoleic acid; $\gamma \mathrm{A}=\gamma$ linolenic acid; all at 50 or $100 \mu \mathrm{M}$ as indicated.

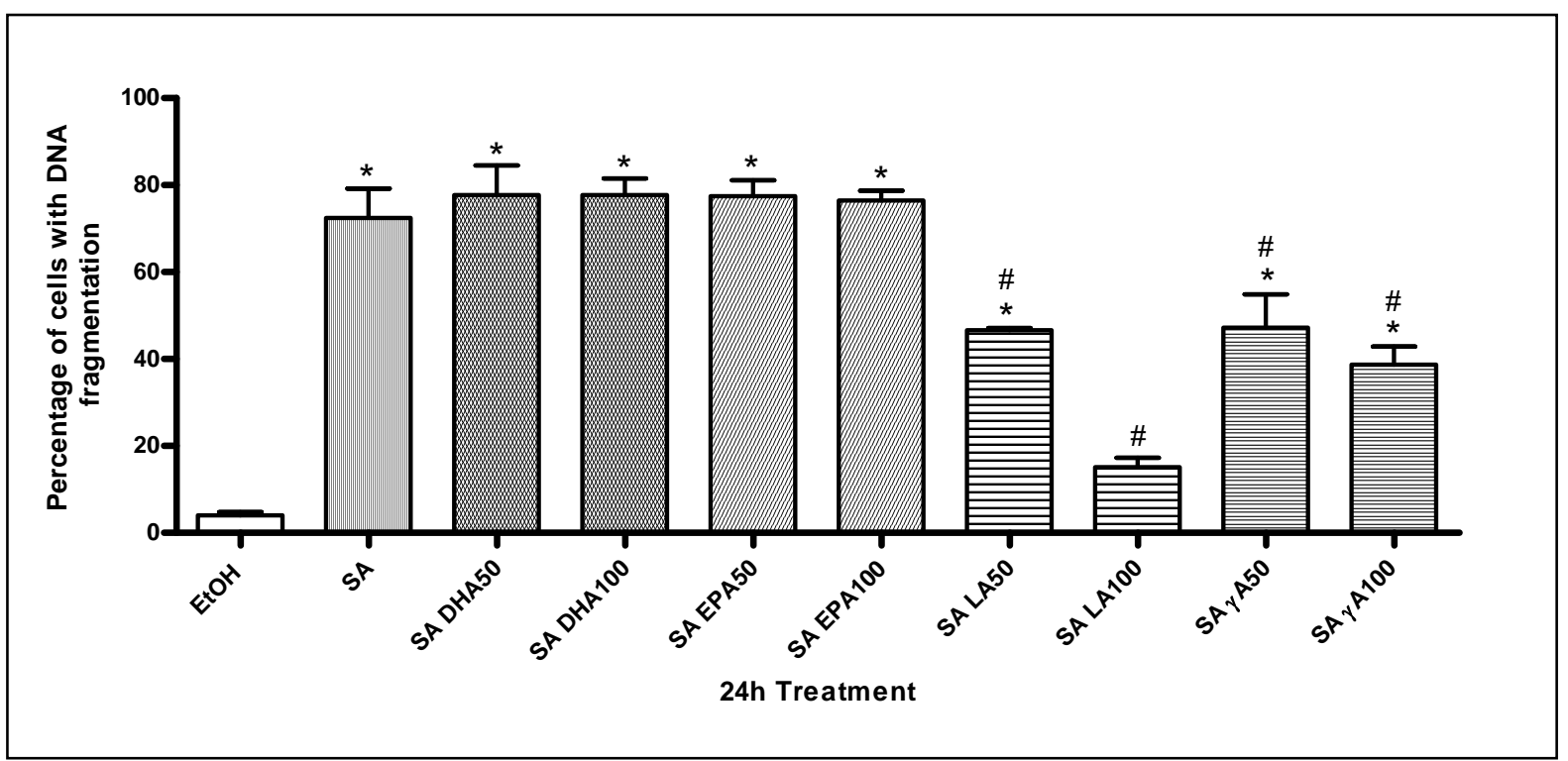

Figure 2. DNA fragmentation in ECV-304 endothelial cells incubated with stearic acid combined with $\omega-6$ or $\omega$-3 fatty acids for 24 hours. ECV-304 endothelial cells were incubated with fatty acids for 24 hours and analyzed by flow cytometry. The fluorescence was measured in FL2 channel (5\& $\mathrm{nm})$. Values are presented as mean $\pm \operatorname{SEM}(\mathrm{n}=9) . * \mathrm{p}<0.05$ compared to ethanol as indicate ANOVA, \# p <0.05 compared to stearic acid as indicated by ANOVA. EtOH $=$ ethanol; SA = st acid always at $150 \mu \mathrm{M}$; DHA = docosa-hexaenoic acid; EPA = eicosapentaenoic acid; LA = linveur acid; $\gamma \mathrm{A}=\gamma$-linolenic acid; all at 50 or $100 \mu \mathrm{M}$ as indicated. 

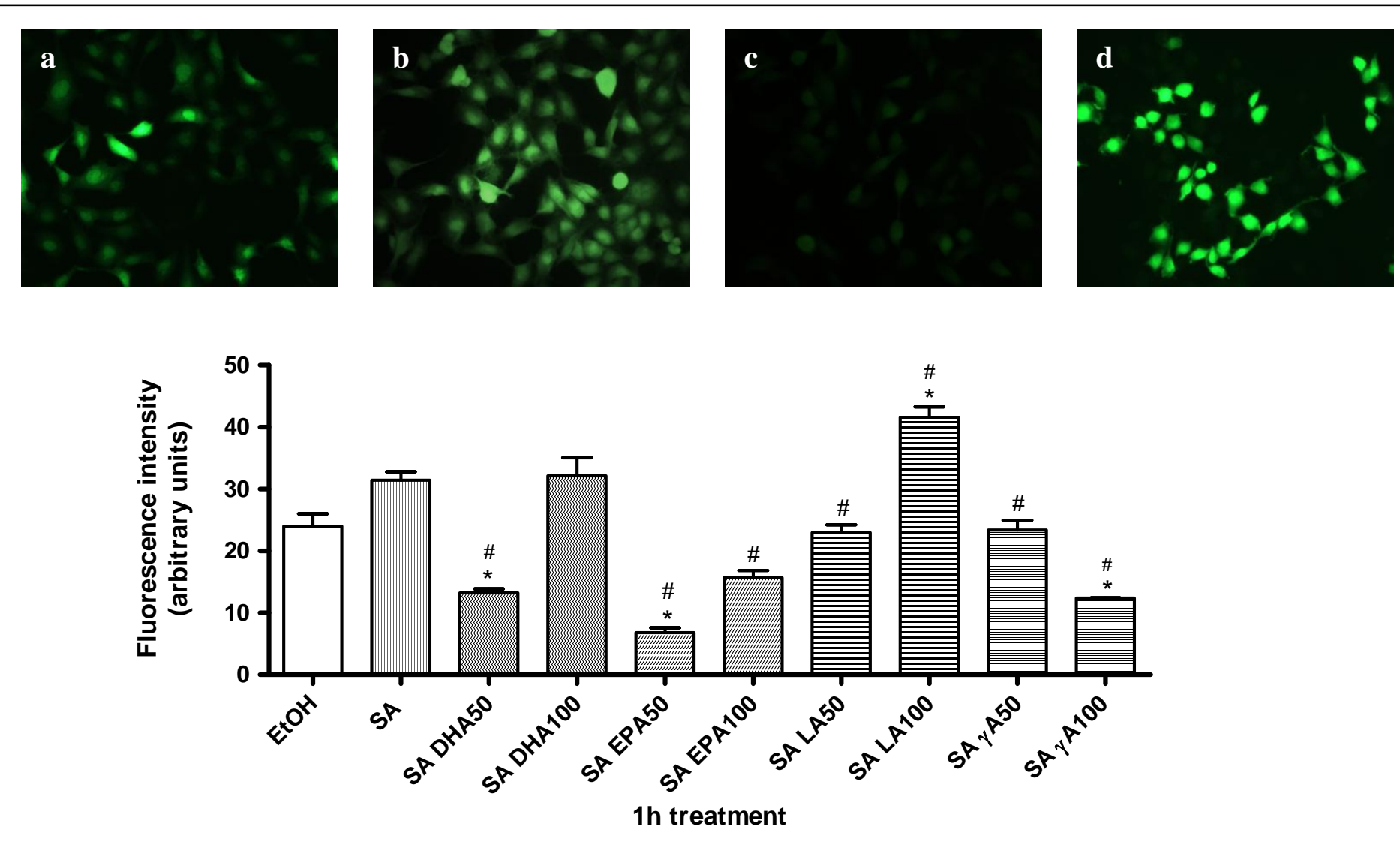

Figure 3. Fluorescence intensity of intracellular nitric oxide content in ECV-304 endothelial cells treated with stearic acid combined with $\omega-\mathbf{6}$ and $\boldsymbol{\omega} \mathbf{- 3}$ fatty acids for $\mathbf{1}$ hour. ECV-304 endothelial cells were incubated with a fluorescent probe (DAF-FM/DA) for 30 minutes and then incubated with fatty acids for 1 hour. Intracellular NO content was determined by fluorescence microscopy using the $520 / 450 \mathrm{~nm}$ filter. (A) The photos illustrate the most significant results; a. Ethanol; b. stearic acid $150 \mu \mathrm{M}$; c. stearic acid $150 \mu \mathrm{M}$ plus eicosapentaenoic acid $50 \mu \mathrm{M}$; d. stearic acid 150 $\mu \mathrm{M}$ plus linoleic acid $100 \mu \mathrm{M}$. (B) The graphs show the results expressed as mean \pm SEM of three experiments performed in duplicate; $* \mathrm{p}<0.05$ compared to ethanol as indicated by ANOVA, \# $\mathrm{p}<0.05$ compared to stearic acid as indicated by ANOVA. EtOH = ethanol; SA = stearic acid always at $150 \mu \mathrm{M}$; DHA = docosa-hexaenoic acid; EPA = eicosapentaenoic acid; $\mathrm{LA}=$ linoleic acid; $\gamma \mathrm{A}=\gamma$-linolenic acid; all at 50 or $100 \mu \mathrm{M}$ as indicated. 

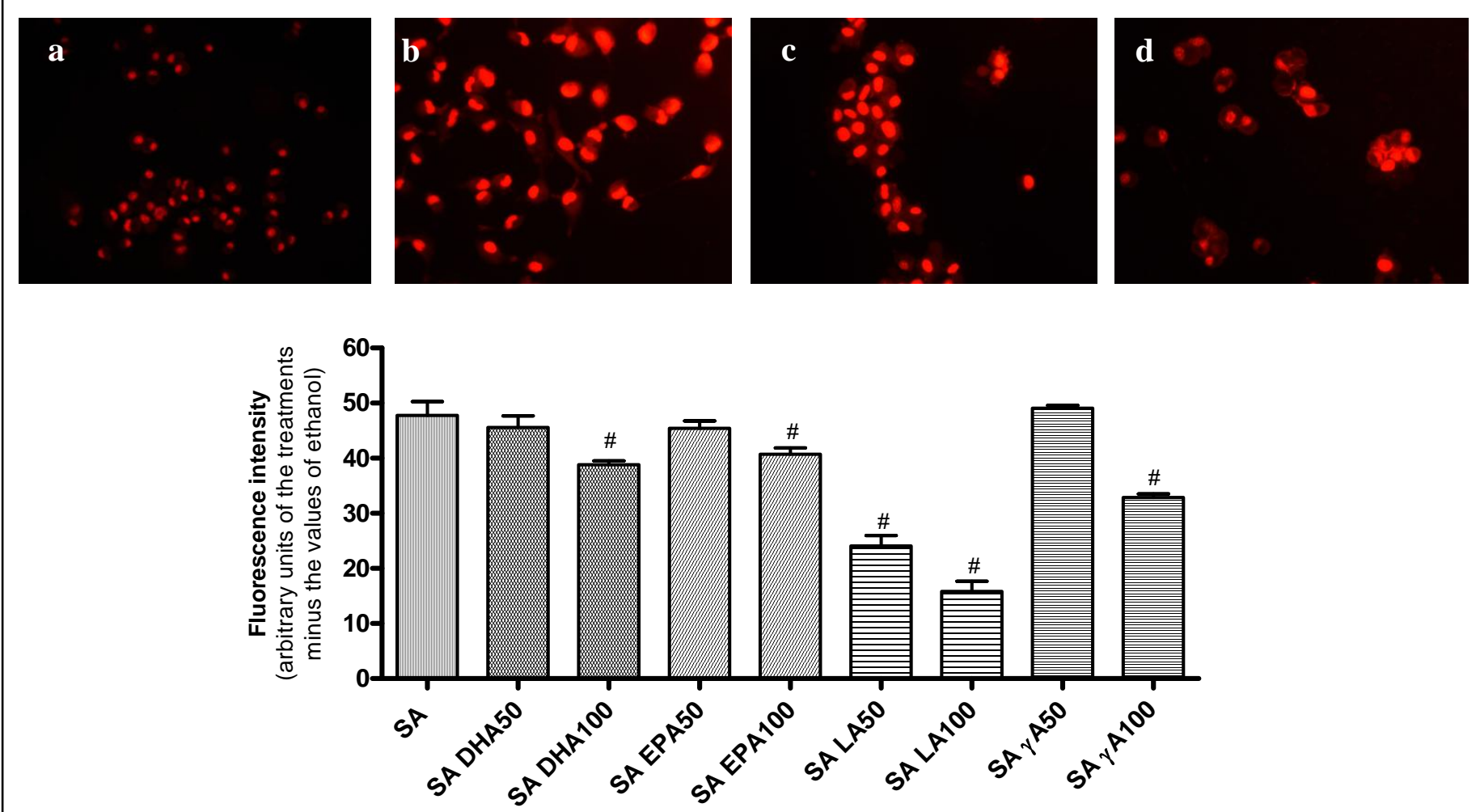

1h treatment

Figure 4. Fluorescence intensity relative to the content of reactive oxygen species produced in ECV-304 endothelial cells incubated for $\mathbf{3 0}$ minutes with stearic acid combined with $\boldsymbol{\omega}-\mathbf{6}$ and $\boldsymbol{\omega} \mathbf{- 3}$ fatty acids. ECV-304 endothelial cells were incubated with fatty acids for 30 minutes and then with hydroethydine for 30 minutes. Subsequently, the cells were analyzed to determine the production of superoxide anion in a fluorescence microscope using 590/46 nm filter. The graph shows the values of production of ROS induced by fatty acid treatment subtracted of the values obtained with ethanol. (A) The photos illustrate the most significant results; a. ethanol; b. stearic acid 150 $\mu \mathrm{M}$; c. stearic acid $150 \mu \mathrm{M}$ plus eicosapentaenoic acid $100 \mu \mathrm{M}$; d. stearic acid $150 \mu \mathrm{M}$ plus linoleic acid $100 \mu \mathrm{M} ;(\mathbf{B})$ The graphs show the results of fluorescence intensity of the treatments minus the values obtained with ethanol, expressed as mean \pm SEM of three experiments performed in duplicate; $* p<0.05$ compared to ethanol as indicated by ANOVA; \# $\mathrm{p}<0.05$ compared to stearic acid as indicated by ANOVA. SA $=$ stearic acid always at $150 \mu \mathrm{M}$; DHA $=$ docosa-hexaenoic acid; EPA $=$ eicosapentaenoic acid; LA = linoleic acid; $\gamma \mathrm{A}=\gamma$-linolenic acid; all at 50 or $100 \mu \mathrm{M}$ as indicated. 


\section{References}

Artwohl, M., Lindenmair, A., Sexl, V., Maier, C., Rainer, G., Freudenthaler, A., Huttary, N., Wolzt, M., Nowotny, P., Luger, A., Baumgartner-Parzer, S.M., 2008. Different mechanisms of saturated versus polyunsaturated FFA-induced apoptosis in human endothelial cells. J Lipid Res 49, 2627-2640.

Artwohl, M., Roden, M., Waldhausl, W., Freudenthaler, A., Baumgartner-Parzer, S.M., 2004. Free fatty acids trigger apoptosis and inhibit cell cycle progression in human vascular endothelial cells. Faseb J 18, 146-148.

Basu, A., Devaraj, S., Jialal, I., 2006. Dietary factors that promote or retard inflammation. Arterioscler Thromb Vasc Biol 26, 995-1001.

Beckman, J.S., Koppenol, W.H., 1996. Nitric oxide, superoxide, and peroxynitrite: the good, the bad, and ugly. Am J Physiol 271, C1424-1437.

Buchner, R.R., Vogen, S.M., Fischer, W., Thoman, M.L., Sanderson, S.D., Morgan, E.L., 1997. Anti-human kappa opioid receptor antibodies: characterization of site-directed neutralizing antibodies specific for a peptide kappa $\mathrm{R}(33-52)$ derived from the predicted amino terminal region of the human kappa receptor. J Immunol 158, 1670-1680.

Calder, P.C., 2008. The relationship between the fatty acid composition of immune cells and their function. Prostaglandins Leukot Essent Fatty Acids 79, 101-108.

Chen, C., Chai, H., Wang, X., Jiang, J., Jamaluddin, M.S., Liao, D., Zhang, Y., Wang, H., Bharadwaj, U., Zhang, S., Li, M., Lin, P., Yao, Q., 2008. Soluble CD40 ligand induces endothelial dysfunction in human and porcine coronary artery endothelial cells. Blood 112, 3205-3216.

Christon, R.A., 2003. Mechanisms of action of dietary fatty acids in regulating the activation of vascular endothelial cells during atherogenesis. Nutr Rev 61, 272-279.

Chu, Y., Iida, S., Lund, D.D., Weiss, R.M., DiBona, G.F., Watanabe, Y., Faraci, F.M., Heistad, D.D., 2003. Gene transfer of extracellular superoxide dismutase reduces arterial pressure in spontaneously hypertensive rats: role of heparin-binding domain. Circ Res 92, 461-468.

Costa Rosa, L.F., Safi, D.A., Guimaraes, A.R., 1996. The effect of N-3 PUFA rich diet upon macrophage and lymphocyte metabolism and function. Biochem Mol Biol Int 40, 833-842.

Cury-Boaventura, M.F., Gorjao, R., de Lima, T.M., Newsholme, P., Curi, R., 2006a. Comparative toxicity of oleic and linoleic acid on human lymphocytes. Life Sci 78, 14481456.

Cury-Boaventura, M.F., Gorjao, R., de Lima, T.M., Piva, T.M., Peres, C.M., Soriano, F.G., Curi, R., 2006b. Toxicity of a soybean oil emulsion on human lymphocytes and neutrophils. JPEN J Parenter Enteral Nutr 30, 115-123. 
Cury-Boaventura, M.F., Pompeia, C., Curi, R., 2005. Comparative toxicity of oleic acid and linoleic acid on Raji cells. Nutrition 21, 395-405.

De Caterina, R., Bernini, W., Carluccio, M.A., Liao, J.K., Libby, P., 1998. Structural requirements for inhibition of cytokine-induced endothelial activation by unsaturated fatty acids. J Lipid Res 39, 1062-1070.

Fauconnier, J., Andersson, D.C., Zhang, S.J., Lanner, J.T., Wibom, R., Katz, A., Bruton, J.D., Westerblad, H., 2007. Effects of palmitate on $\mathrm{Ca}(2+)$ handling in adult control and ob/ob cardiomyocytes: impact of mitochondrial reactive oxygen species. Diabetes 56, 1136-1142.

Felippe, C.R., Calder, P.C., Vecchia, M.G., Campos, M.R., Mancini-Filho, J., Newsholme, E.A., Curi, R., 1997. Fatty acid composition of lymphocytes and macrophages from rats fed fiber-rich diets: a comparison between oat bran- and wheat bran-enriched diets. Lipids 32, 587-591.

Gewaltig, M.T., Kojda, G., 2002. Vasoprotection by nitric oxide: mechanisms and therapeutic potential. Cardiovasc Res 55, 250-260.

Guo, W., Xie, W., Han, J., 2006. Modulation of adipocyte lipogenesis by octanoate: involvement of reactive oxygen species. Nutr Metab (Lond) 3, 30.

Hatanaka, E., Levada-Pires, A.C., Pithon-Curi, T.C., Curi, R., 2006. Systematic study on ROS production induced by oleic, linoleic, and gamma-linolenic acids in human and rat neutrophils. Free Radic Biol Med 41, 1124-1132.

He, K., Liu, K., Daviglus, M.L., Jenny, N.S., Mayer-Davis, E., Jiang, R., Steffen, L., Siscovick, D., Tsai, M., Herrington, D., 2009. Associations of dietary long-chain n-3 polyunsaturated fatty acids and fish with biomarkers of inflammation and endothelial activation (from the Multi-Ethnic Study of Atherosclerosis [MESA]). Am J Cardiol 103, $1238-1243$.

Higashi, Y., Noma, K., Yoshizumi, M., Kihara, Y., 2009. Endothelial function and oxidative stress in cardiovascular diseases. Circ J 73, 411-418.

Ishola, D.A., Jr., Post, J.A., van Timmeren, M.M., Bakker, S.J., Goldschmeding, R., Koomans, H.A., Braam, B., Joles, J.A., 2006. Albumin-bound fatty acids induce mitochondrial oxidant stress and impair antioxidant responses in proximal tubular cells. Kidney Int 70, 724-731.

Karman, R.J., Gupta, M.P., Garcia, J.G., Hart, C.M., 1997. Exogenous fatty acids modulate the functional and cytotoxic responses of cultured pulmonary artery endothelial cells to oxidant stress. J Lab Clin Med 129, 548-556.

Kuroda, R., Hirata, K., Kawashima, S., Yokoyama, M., 2001. Unsaturated free fatty acids inhibit Ca2+ mobilization and NO release in endothelial cells. Kobe J Med Sci 47, 211-219.

Lambertucci, R.H., Hirabara, S.M., Silveira Ldos, R., Levada-Pires, A.C., Curi, R., PithonCuri, T.C., 2008. Palmitate increases superoxide production through mitochondrial electron 
transport chain and NADPH oxidase activity in skeletal muscle cells. J Cell Physiol 216, 796804.

Laursen, J.B., Rajagopalan, S., Galis, Z., Tarpey, M., Freeman, B.A., Harrison, D.G., 1997. Role of superoxide in angiotensin II-induced but not catecholamine-induced hypertension. Circulation 95, 588-593.

Levada-Pires, A.C., Fonseca, C.E., Hatanaka, E., Alba-Loureiro, T., A, D.A., Velhote, F.B., Curi, R., Pithon-Curi, T.C., 2010. The effect of an adventure race on lymphocyte and neutrophil death. Eur J Appl Physiol.

Li, P., Kim, S.W., Li, X., Datta, S., Pond, W.G., Wu, G., 2009. Dietary supplementation with cholesterol and docosahexaenoic acid affects concentrations of amino acids in tissues of young pigs. Amino Acids 37, 709-716.

Lu, G., Greene, E.L., Nagai, T., Egan, B.M., 1998. Reactive oxygen species are critical in the oleic acid-mediated mitogenic signaling pathway in vascular smooth muscle cells. Hypertension 32, 1003-1010.

Massaro, M., Carluccio, M.A., De Caterina, R., 1999. Direct vascular antiatherogenic effects of oleic acid: a clue to the cardioprotective effects of the Mediterranean diet. Cardiologia 44, 507-513.

Massaro, M., Scoditti, E., Carluccio, M.A., Montinari, M.R., De Caterina, R., 2008. Omega-3 fatty acids, inflammation and angiogenesis: nutrigenomic effects as an explanation for antiatherogenic and anti-inflammatory effects of fish and fish oils. J Nutrigenet Nutrigenomics 1 , 4-23.

Mattern, H.M., Hardin, C.D., 2007. Vascular metabolic dysfunction and lipotoxicity. Physiol Res 56, 149-158.

Maziere, C., Dantin, F., Conte, M.A., Degonville, J., Ali, D., Dubois, F., Maziere, J.C., 1998. Polyunsaturated fatty acid enrichment enhances endothelial cell-induced low-densitylipoprotein peroxidation. Biochem J 336 ( Pt 1), 57-62.

Milkowski, A., Garg, H.K., Coughlin, J.R., Bryan, N.S., 2010. Nutritional epidemiology in the context of nitric oxide biology: a risk-benefit evaluation for dietary nitrite and nitrate. Nitric Oxide 22, 110-119.

Mutin, M., Canavy, I., Blann, A., Bory, M., Sampol, J., Dignat-George, F., 1999. Direct evidence of endothelial injury in acute myocardial infarction and unstable angina by demonstration of circulating endothelial cells. Blood 93, 2951-2958.

Oh, K., Hu, F.B., Manson, J.E., Stampfer, M.J., Willett, W.C., 2005. Dietary fat intake and risk of coronary heart disease in women: 20 years of follow-up of the nurses' health study. Am J Epidemiol 161, 672-679.

Ohashi, Y., Kawashima, S., Hirata, K., Yamashita, T., Ishida, T., Inoue, N., Sakoda, T., Kurihara, H., Yazaki, Y., Yokoyama, M., 1998. Hypotension and reduced nitric oxide-elicited 
vasorelaxation in transgenic mice overexpressing endothelial nitric oxide synthase. J Clin Invest 102, 2061-2071.

Ozaki, M., Kawashima, S., Hirase, T., Yamashita, T., Namiki, M., Inoue, N., Hirata Ki, K., Yokoyama, M., 2002. Overexpression of endothelial nitric oxide synthase in endothelial cells is protective against ischemia-reperfusion injury in mouse skeletal muscle. Am J Pathol 160, $1335-1344$

Price, P.T., Nelson, C.M., Clarke, S.D., 2000. Omega-3 polyunsaturated fatty acid regulation of gene expression. Curr Opin Lipidol 11, 3-7.

Rachek, L.I., Thornley, N.P., Grishko, V.I., LeDoux, S.P., Wilson, G.L., 2006. Protection of INS-1 cells from free fatty acid-induced apoptosis by targeting hOGG1 to mitochondria. Diabetes 55, 1022-1028.

Richard, D., Kefi, K., Barbe, U., Bausero, P., Visioli, F., 2008. Polyunsaturated fatty acids as antioxidants. Pharmacol Res 57, 451-455.

Rioux, V., Legrand, P., 2007. Saturated fatty acids: simple molecular structures with complex cellular functions. Curr Opin Clin Nutr Metab Care 10, 752-758.

Saraswathi, V., Wu, G., Toborek, M., Hennig, B., 2004. Linoleic acid-induced endothelial activation: role of calcium and peroxynitrite signaling. J Lipid Res 45, 794-804.

Schonfeld, P., Reiser, G., 2006. Rotenone-like action of the branched-chain phytanic acid induces oxidative stress in mitochondria. J Biol Chem 281, 7136-7142.

Schonfeld, P., Reiser, G., 2007. Ca2+ storage capacity of rat brain mitochondria declines during the postnatal development without change in ROS production capacity. Antioxid Redox Signal 9, 191-199.

Singh, R.B., Dubnov, G., Niaz, M.A., Ghosh, S., Singh, R., Rastogi, S.S., Manor, O., Pella, D., Berry, E.M., 2002. Effect of an Indo-Mediterranean diet on progression of coronary artery disease in high risk patients (Indo-Mediterranean Diet Heart Study): a randomised singleblind trial. Lancet 360, 1455-1461.

Song, G.Y., Gao, Y., Di, Y.W., Pan, L.L., Zhou, Y., Ye, J.M., 2006. High-fat feeding reduces endothelium-dependent vasodilation in rats: differential mechanisms for saturated and unsaturated fatty acids? Clin Exp Pharmacol Physiol 33, 708-713.

Srivastava, R.C., Husain, M.M., Hasan, S.K., Athar, M., 2000. Green tea polyphenols and tannic acid act as potent inhibitors of phorbol ester-induced nitric oxide generation in rat hepatocytes independent of their antioxidant properties. Cancer Lett 153, 1-5.

Suphioglu, C., De Mel, D., Kumar, L., Sadli, N., Freestone, D., Michalczyk, A., Sinclair, A., Ackland, M.L., 2010. The omega-3 fatty acid, DHA, decreases neuronal cell death in association with altered zinc transport. FEBS Lett 584, 612-618. 
Szmitko, P.E., Wang, C.H., Weisel, R.D., Jeffries, G.A., Anderson, T.J., Verma, S., 2003. Biomarkers of vascular disease linking inflammation to endothelial activation: Part II. Circulation 108, 2041-2048.

Tedgui, A., Mallat, Z., 2001. Apoptosis as a determinant of atherothrombosis. Thromb Haemost 86, 420-426.

Tedgui, A., Mallat, Z., 2003. [Acute coronary thrombosis]. Rev Prat 53, 602-606.

Toborek, M., Hennig, B., 1998. The role of linoleic acid in endothelial cell gene expression. Relationship to atherosclerosis. Subcell Biochem 30, 415-436.

Tripathy, D., Aljada, A., Dandona, P., 2003. Free fatty acids (FFA) and endothelial dysfunction; role of increased oxidative stress and inflammation. --to: Steinberg et al. (2002) Vascular function, insulin resistance and fatty acids. Diabetologia 46, 300-301.

Wheatcroft, S.B., Williams, I.L., Shah, A.M., Kearney, M.T., 2003. Pathophysiological implications of insulin resistance on vascular endothelial function. Diabet Med 20, 255-268.

Whiteley, W., Jackson, C., Lewis, S., Lowe, G., Rumley, A., Sandercock, P., Wardlaw, J., Dennis, M., Sudlow, C., 2009. Inflammatory markers and poor outcome after stroke: a prospective cohort study and systematic review of interleukin-6. PLoS Med 6, e1000145.

Wu, K.K., 2002. Regulation of endothelial nitric oxide synthase activity and gene expression. Ann N Y Acad Sci 962, 122-130.

Yam, D., Eliraz, A., Berry, E.M., 1996. Diet and disease--the Israeli paradox: possible dangers of a high omega-6 polyunsaturated fatty acid diet. Isr J Med Sci 32, 1134-1143. 